\title{
Five new species of Caliscelidae (Insecta, Hemiptera) from Mexico and Panama, with additional redescriptions of little-known species
}

\author{
Abner S. de FREITAS ${ }^{1, *}$, Christopher H. DIETRICH ${ }^{2}$ \& Daniela M. TAKIYA ${ }^{3}$ \\ ${ }^{1,3}$ Laboratório de Entomologia, Departamento de Zoologia, Instituto de Biologia, \\ Universidade Federal do Rio de Janeiro, Rio de Janeiro, RJ, Brazil. \\ ${ }^{1}$ Programa de Pós-graduação em Biodiversidade e Biologia Evolutiva, \\ Universidade Federal do Rio de Janeiro, Rio de Janeiro, RJ, Brazil. \\ ${ }^{2}$ Illinois Natural History Survey Prairie Research Institute, University of Illinois, \\ Champaign, IL, USA. \\ *Corresponding author: defreitasabner@gmail.com \\ ${ }^{2}$ Email: chdietri@illinois.edu \\ ${ }^{3}$ Email: takiya@gmail.com

\footnotetext{
${ }^{1}$ urn:1sid:zoobank.org:author:F5BAAFAC-ACDB-49D9-B074-CC190645AED1

${ }^{2}$ urn:lsid:zoobank.org:author:82FCB86C-54B4-456A-AE5E-D7847D271CB9

${ }^{3}$ urn:1sid:zoobank.org:author:7E88BC1C-8D6A-411D-B97B-52E64EF5BA70
}

\begin{abstract}
Five new species of Peltonotellini (Caliscelinae) are described and illustrated: Bruchomorpha pseudodorsata sp. nov., Fitchiella brachyrhina sp. nov., Protrocha nigrilutea sp. nov. and P. punctatosa sp. nov. from Mexico, and Fitchiella zahniseri sp. nov. from Panama. Additionally, five previously described species are redescribed based on newly collected specimens: Aphelonema brevata Caldwell, 1945 (proposed original combination), Bruchomorpha decorata Metcalf, 1923, Bruchomorpha mormo Kirkaldy, 1907, Nenema virgata (Doering, 1941) and Protrocha nesolitaria (Caldwell, 1945). Bruchomorpha decorata is recorded from Panama for the first time. Redescriptions provide new information on the distribution of sensory pits and the first detailed descriptions of male and female terminalia for these species.
\end{abstract}

Keywords. Caliscelinae, new combination, new record, new species, morphology, Neotropics, Peltonotellini, sensory pits, taxonomy.

Freitas A.S. de, Dietrich C.H. \& Takiya D.M. 2020. Five new species of Caliscelidae (Insecta, Hemiptera) from Mexico and Panama, with additional redescriptions of little-known species. European Journal of Taxonomy 717: 27-69. https://doi.org/10.5852/ejt.2020.717.1097

\section{Introduction}

Caliscelidae Amyot \& Serville, 1843 is a small fulgoroid family distributed worldwide (Gnezdilov 2013) with 235 species described in 76 genera (Bourgoin 2019). Caliscelids are usually brachypterous (O'Brien 
2002), except for representatives of the tribe Augilini Baker, 1915, which are always macropterous, and Adenissini Dlabola, 1980, which are usually macropterous. They are also small, generally measuring from 1 to $5 \mathrm{~mm}$, but can reach up to $16 \mathrm{~mm}$. They are often confused with nymphs and are, therefore, seldom collected. In the past, they had been treated as a family by Melichar (1906), then considered as a subfamily of Issidae Spinola, 1839 by Fennah (1954). Later, Emeljanov (1999) reestablished Caliscelidae as a family based on specific features of the ovipositor (Gnezdilov 2013). Other studies corroborate this classification with analyses of bioacoustic data (Tishechkin 1998, 2003) and molecular phylogenetic data (Yeh et al. 1998, 2005; Urban \& Cryan 2007; Song \& Liang 2013; Wang et al. 2016).

Caliscelidae as presently defined cannot be characterized by unique autapomorphies, but can be recognized by a combination of the following features (Gnezdilov 2003, 2008a; Gnezdilov \& Wilson 2006): (1) prevalence of strongly brachypterous form; (2) coryphe (= vertex) with apical callus transformed into a large areolet fused with coryphe and recognizable by a weak suture, often the median keel of coryphe bifurcates anteriorly and its arms diverge at an obtuse angle; (3) anterior connective lamina of gonapophyses VIII narrow, without comb, bearing 1-9 large teeth; and (4) gonoplacs flat, rounded, or nearly triangular without teeth.

The family has been taxonomically well studied in the Oriental and African regions (e.g., Gnezdilov 2003, 2008b, 2011, 2014, 2015a, 2015b, 2015c, 2017, 2019; Gnezdilov \& Wilson 2006, 2011; Emeljanov 2013, 2015; Meng et al. 2015) and the Nearctic diversity of Caliscelidae was fairly well studied in the past (Lawson 1933; Doering 1939, 1941), with 54 species described in six genera north of Mexico (Bartlett et al. 2014). All New World Caliscelidae belong to the tribe Peltonotellini Emeljanov, 2008 and they are characterized by the presence of sensory pits on head, thorax and abdomen of adults (Gnezdilov 2013). However, the Neotropical diversity was historically poorly studied, with only 17 previously described species placed in 11 genera (Metcalf 1958; Bourgoin 2019), most of them monotypic.

Concerning the fauna of Caliscelidae north of Mexico, Fitchiella Van Duzee, 1917 was first reviewed by Paul B. Lawson (1933). Kathleen C. Doering subsequently included caliscelids in her review of the Issidae (Doering 1939, 1941) and consequently reviewed three genera: Aphelonema Uhler, 1876, Bruchomorpha Newman, 1838 and Fitchiella. Doering's broad definition of Aphelonema comprised species currently placed in other genera, including some previously treated as subgenera of Aphelonema (Emeljanov 1996) such as Acromega Emeljanov, 1996, Ceragra Emeljanov, 1996, Nenema Emeljanov, 1996, Peltonotellus Puton, 1886 and Protrocha Emeljanov, 1996, which were later elevated to genus level by Gnezdilov (2013).

Seven species of the most diverse New World genus, Bruchomorpha, have been described or previously reported from Mexico, as well as some species of Aphelonema (3), Nenema (1) and Protrocha (3) (Doering 1939, 1941; Caldwell 1945; Metcalf 1958; Bourgoin 2019). Additionally, according to Bartlett et al. (2014), undescribed species of Fitchiella also occur in Mexico. No species of Caliscelidae were described or recorded from Panama until now.

In the present study, five caliscelids from Mexico and Panama are redescribed based on newly collected material. In these redescriptions, the distribution of sensory pits is emphasized and the first detailed descriptions of the male and female terminalia of these species are given. In addition, five new species are described, including four from Mexico and one from Panama.

\section{Material and methods}

We studied 45 specimens collected in Mexico and Panama, and photographs of additional two type specimens. Specimens were collected mainly using a vacuum sampler or by sweeping. Specimens were studied and compared to published works of Lawson $(1933)$, Doering $(1939,1941)$ and Caldwell $(1945)$ 
to identify them. The key to subgenera of Aphelonema by Emeljanov (1996) was used to correctly allocate the species previously identified as belonging to Aphelonema. Identified subgenera were treated as genera following the classification by Gnezdilov (2013).

The external habitus morphology of these species was photographed and described. At least one male and one female of each species were dissected to examine and describe the terminalia. Abdomens were removed and treated with a warm $10 \% \mathrm{KOH}$ solution and, after washing with water, dissected and immersed in glycerin for study using a stereo microscope. Photographs were taken using a Leica DFC450 digital camera coupled to a Leica M205C stereo microscope. Illustrations of male genitalia were made using a ZEISS Stemi SV8 stereo microscope coupled with a camera lucida. The terminology of the external morphology follows O'Brien \& Wilson (1985) and of the male and female terminalia follows Bourgoin (1993), Gnezdilov (2003) and Gnezdilov \& Bourgoin (2009).

Studied specimens are deposited in the following repositories:

DZRJ = Coleção Entomológica Prof. José Alfredo Pinheiro Dutra, Departamento de Zoologia, Instituto de Biologia, Universidade Federal do Rio de Janeiro, Rio de Janeiro, Brazil

INHS $=$ Insect Collection, Illinois Natural History Survey, Champaign, USA

$\mathrm{NMNH}=$ Entomology collection, National Museum of Natural History, Smithsonian Institution, Washington, DC, USA

\title{
Results
}

\author{
Class Insecta Linnaeus, 1758 \\ Order Hemiptera Linnaeus, 1758 \\ Family Caliscelidae Amyot \& Audinet-Serville, 1843 \\ Subfamily Caliscelinae Amyot \& Audinet-Serville, 1843 \\ Tribe Peltonotellini Emeljanov, 2008 \\ Genus Aphelonema Uhler, 1876
}

Aphelonema brevata Caldwell, 1945

Figs 1-2, 26A

Aphelonema brevata Caldwell, 1945: 94, pl. I: fig. 6.

Aphelonema (Protrocha) brevata - Emeljanov 1996: 835 (proposed new subgenus for Aphelonema). Protrocha brevata - Gnezdilov 2013: 212.

\section{Diagnosis}

Body mainly light brown with some regions dark brown (Fig. 1); central plate dark brown with pair of swirl-shaped light brown maculae (Fig. 1A); sides of frons with two rows of sensory pits on each side (Fig. 1C); clypeus not swollen (Fig. 1A, C), with median carina (Fig. 1A); lateral lobe of pronotum with approximately three sensory pits arranged in group (Fig. 1C); abdominal tergites (Fig. 1C, 26A) with row of sensory pits followed by single isolated ventral sensory pit (tergite IV) or by isolated pair of diagonally aligned ventral sensory pits (tergites V to VII).

\section{Material examined}

Holotype

MEXICO • ^`; Toluca Rd.; 24 Nov. 1938; J.S. Caldwell leg.; NMNH USNMENT 01513543 (based on photographs). 
Other material

MEXICO • 1 đ̊; "MICH" [Michoacán], E Morelia, route 15, Km 18; $19.68392^{\circ} \mathrm{N}, 101.00981^{\circ} \mathrm{W}$; 2050 m a.s.1.; Oct. 2005; R. Rakitov leg.; sweep; DNA voucher ENT4920; INHS.

\section{Description}

Body LENGTH. Male $=2.4 \mathrm{~mm}$.

Coloration. Body mainly light brown with some regions dark brown (Fig. 1A-C). Vertex (Fig. 1B) with pair of dark brown maculae. Central plate (Fig. 1A) dark brown with pair of swirl-shaped light brown maculae; median carina dark brown. Gena and lateral lobe of pronotum (Fig. 1C) dark brown. Clypeus dark brown with pair of light brown triangular maculae (Fig. 1A). Pronotum (Fig. 1B) dark brown with three median light brown stripes connected to stripes on mesonotum. Mesonotum (Fig. 1B) with additional pair of lateral light brown stripes. Forewing (Fig. 1B) brown. Legs (Fig. 1A, C) light brown with several dark brown maculae. Abdomen (Fig. 1B-C) dark brown with three median light brown interrupted stripes in dorsal view.

HeAD AND thORAX. Vertex (Fig. 1B) hexagonal, shorter than half its width, almost as long as pronotum; posterior margin slightly elevated. Frons (Fig. 1A) with median carina and pair of sublateral carinae; sublateral carinae convergent and almost fused to each other ventrally (Fig. 1A); central plate (Fig. 1A) as long as wide at widest portion, not visible in dorsal view (Fig. 1B), not extending anteriorly beyond sublateral carinae in lateral view (Fig. 1C); sides of frons partially visible in frontal view (Fig. 1A) and almost fused above clypeus, with two rows of sensory pits on each side in lateral view (Fig. 1C): anterior row with eight sensory pits, ventral pair slightly displaced; posterior row with four sensory pits, most ventral one slightly isolated. Clypeus (Fig. 1C) not swollen, with median carina. Ocelli absent. Eye oblong. Antenna short, with several small circular structures visible on pedicel. Pronotum (Fig. 1B) semicircular, shorter than half its width, with median carina; median portion of disc without sensory pits; lateral portion of disc with 14 to 15 sensory pits; lateral lobe of pronotum (Fig. 1C) with three sensory pits arranged in group. Mesonotum (Fig. 1B) with median carina and pair of lateral carinae; region between lateral carinae depressed and without sensory pits; region laterad of lateral carinae with nine to 11 sensory pits. Brachypterous, with reduced venation. Legs simple, with carinae, setose; tibia III with single median spine.
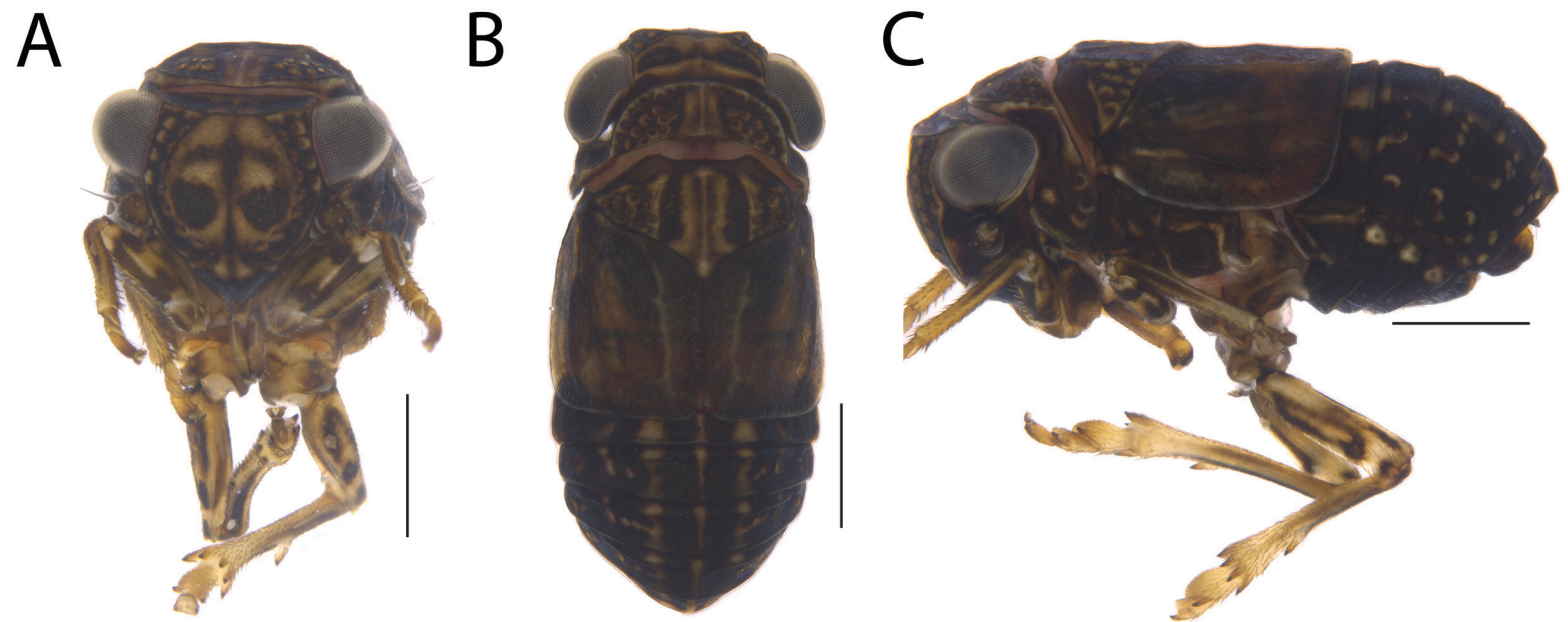

Fig. 1. Habitus of Aphelonema brevata Caldwell, 1945, $\widehat{o}$ (INHS). A. Frontal view. B. Dorsal view. C. Lateral view. Scale bars $=0.5 \mathrm{~mm}$. 
AbDomen. Terga with longitudinal carina. Tergite III (Figs 1C, 26A) without sensory pits. Tergite IV (Figs 1C, 26A) with row of two sensory pits followed by single isolated ventral one. Tergites V and VI (Figs 1C, 26A) with row of four sensory pits followed by isolated ventral pair aligned diagonally. Tergite VII (Figs 1C, 26A) with row of three sensory pits followed by isolated ventral pair aligned diagonally. Tergite VIII with one sensory pit (Fig. 26A).

Male terminalia. Pygofer (Fig. 2A) with anterior margin deeply concave; posterior margin with dorsal third rounded, middle third concave, ventral third wide and rounded. Connective (Fig. 2B) inverted Y-shaped, with support bridge with dorsal flap. Style (Fig. 2C-D) hook-like; anterior portion pointed; dorsal margin with slight protuberance on median third (Fig. 2D); caudal portion strongly curved anterodorsally in lateral view (Fig. 2D) and mesad in dorsal view (Fig. 2C); ventral margin (Fig. 2D) truncate between anterior and middle portion, irregularly rounded posteriorly; middle portion longer than high, setose; apex serrated (Fig. 2D). Phallobase (Fig. 2E-H) sclerotized, symmetrical, with two defined

\section{A}

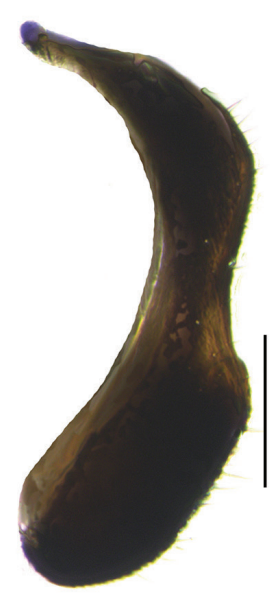

E
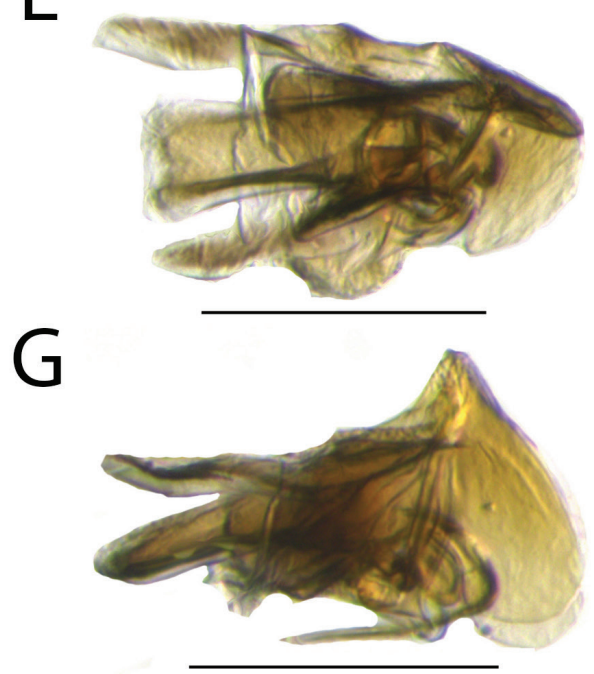
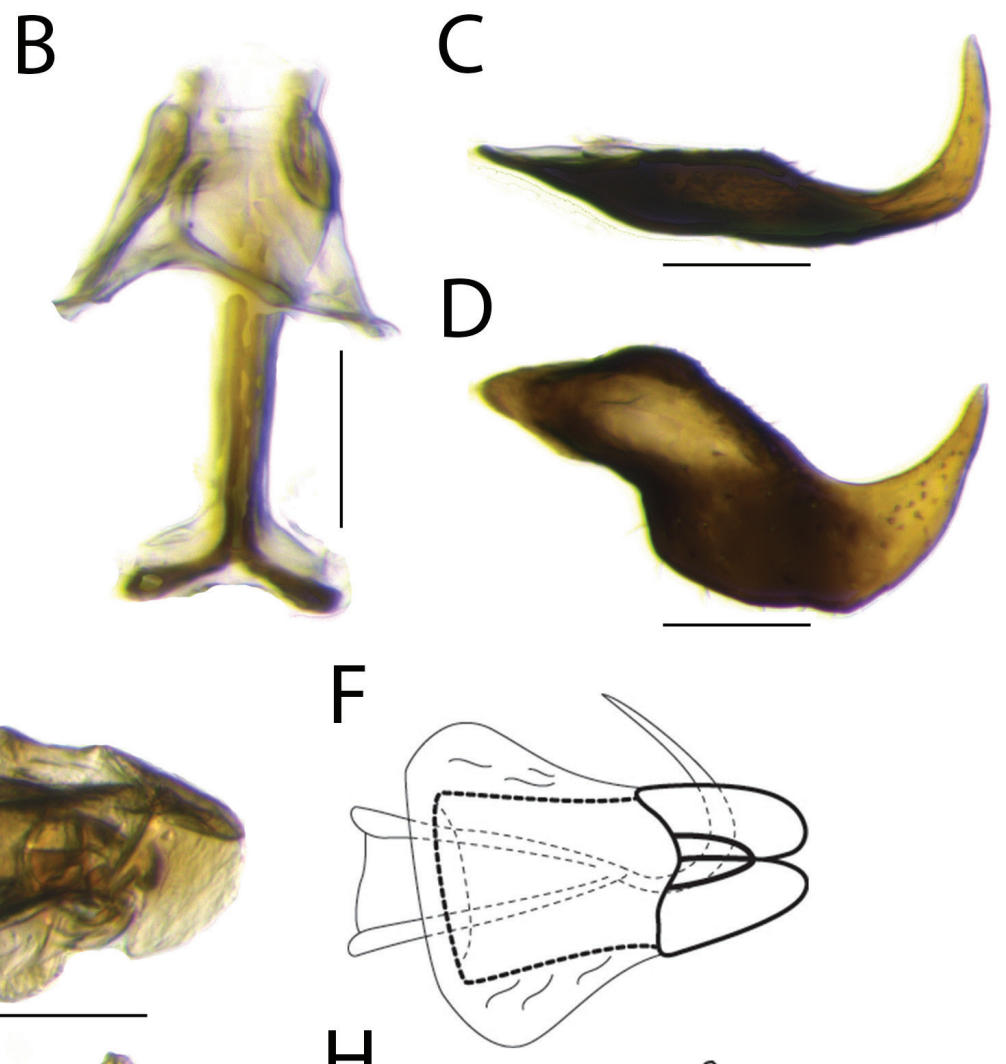

$\mathrm{H}$

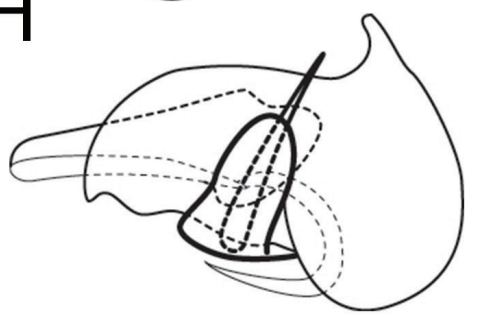

Fig. 2. Male terminalia of Aphelonema brevata Caldwell, 1945 (INHS). A. Pygofer, lateral view. B. Connective, anterior view. C-D. Style. C. Dorsal view. D. Lateral view. E-H. Phallus. E-F. Dorsal view. $\mathbf{G}-\mathbf{H}$. Lateral view. Scale bars $=0.1 \mathrm{~mm}$. 
lobes; apex with pair of lobes fused in dorsal view (Fig. 2E-F) and rounded in lateral view (Fig. 2G-H); sides expanded and rounded at half-length of aedeagus in dorsal view (Fig. 2E-F); with dorsal process near to apex in lateral view (Fig. 2G-H), surrounding almost all aedeagus length. Aedeagus (Fig. 2E-F) apex narrow and open dorsally, with pair of aedeagal hooks, one curved to side of aedeagus and visible in dorsal view (Fig. 2E-F), another visible in lateral view (Fig. 2G-H) and curved ventrally to other side of aedeagus. Suspensorium V-shaped.

\section{Remarks}

This species was originally placed in Aphelonema but later transferred to Protrocha by Emeljanov (1996). However, the species treated herein shares more characteristics of Aphelonema, according to the diagnostic features given by Emeljanov (1996, see Discussion), such as (1) lateral lobe of pronotum with no fewer than two, but usually with three or more sensory pits (Fig. 1C); (2) sides of frons in upper half with two parallel rows of sensory pits (Fig. 1C); and (3) abdomen with sensory pits aligned in one row and with an isolated pair of ventral sensory pits (Fig. 26A). Based on this combination of characters we propose that this species returns to its original combination. Its original description is short, includes only a superficial illustration of the male terminalia, and does not include information about abdominal sensory pits or female terminalia. The single male specimen at hand was identified based on the original description, illustrations of male terminalia made by Caldwell (1945), and photographs of the head, thorax and male terminalia of the holotype. However, the abdomen of the holotype was lost so redescription of the distribution of sensory pits on this structure was based on the specimen at hand. Unfortunately, the anal tube of the studied specimen was damaged during dissection.

Genus Bruchomorpha Newman, 1838

Bruchomorpha decorata Metcalf, 1923

Figs 3-5, 26B

Bruchomorpha decorata Metcalf, 1923: 186, figs 57, 223.

Bruchomorpha decorata - Ball 1935: 198 (key, notes). - Doering 1939: 126, pl. XX: fig. 14, pl. XXI: fig. 2, pl. XXII: figs 12, 12a, 12b (redescription, illustration). — Caldwell 1945: 92, pl. I: fig. 9 (redescription, illustration).

\section{Diagnosis}

Body mainly dark brown to black with several pale maculae (Fig. 3); vertex hexagonal (Fig. 3B, E); frons with strong median carina and central plate with pale heart-shaped macula (Fig. 3A, D); clypeus extending anteriorly, produced into slight snout (Fig. 3C, F); lateral lobe of pronotum with three to four sensory pits arranged in a row (Fig. 3C, F); abdominal tergites (Fig. 3C, F, 26B) with row of sensory pits followed by single isolated ventral sensory pit (tergite IV) or by isolated pair of diagonally aligned ventral sensory pits (tergites V to VII).

\section{Material examined}

\section{Type material}

USA 1 Oे, holotype of Bruchomorpha decorata Metcalf, 1923; "Brownsville, Tex[as]"; 21 Nov. 1911; palm jungle sweepings; INHS • 1 \%, allotype of Bruchomorpha decorata Metcalf, 1923; same collection data as for preceding; INHS.

MEXICO • 1 , holotype of Bruchomorpha decorata var. nihldecorata Caldwell, 1947; Sonora, Hacienda Naynari, M.B. 209; 19 Mar. 1927; NMNH (based on photographs). 


\section{Other material}

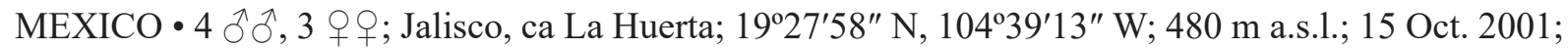
J.N. Zahniser leg.; vacuum sample; INHS • 1 \%; same collection data as for preceding; $19^{\circ} 27^{\prime} 58^{\prime \prime} \mathrm{N}$,

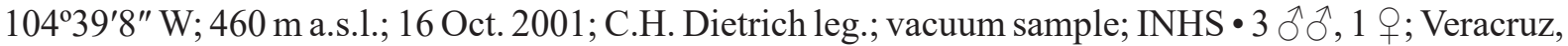
rt. 180, Km 31, 17 km NW of Alvarado; $18^{\circ} 50^{\prime}$ N, 95 $5^{\circ} 7^{\prime}$ W; 0 m a.s.1.; 28 Oct. 2001; C.H. Dietrich leg.; sweep/vacuum sample; INHS • 1 o $^{\top}$; Durango, rt. 45, Km 121 ca Fco. Primo Verdad; $24.89762^{\circ}$ N, 104.46098 W; 1590 m a.s.1.; 27 Oct. 2005; C.H. Dietrich leg.; vacuum sample; INHS.

PANAMA • 1 q; Verugas, Pan-Am Highway, $40 \mathrm{~km} \mathrm{~W}$ of Santiago; 8.20298 N, 81.18768 $\mathrm{W} ; 166 \mathrm{~m}$ a.s.1.; Aug. 2005; J.N. Zahniser leg.; sweep; DNA voucher ENT4205; NMNH.

\section{Description}

Body LeNGTH. Male (holotype of Bruchomorpha decorata Metcalf, 1923) $=2.6 \mathrm{~mm}$; females $=3.4$ to $4.0 \mathrm{~mm}$.

Coloration. Body mainly black with several pale maculae in males (Fig. 3A-C); females (Fig. 3D-F) having lighter, dark brown coloration overall with pale maculae larger than in males. Central plate of
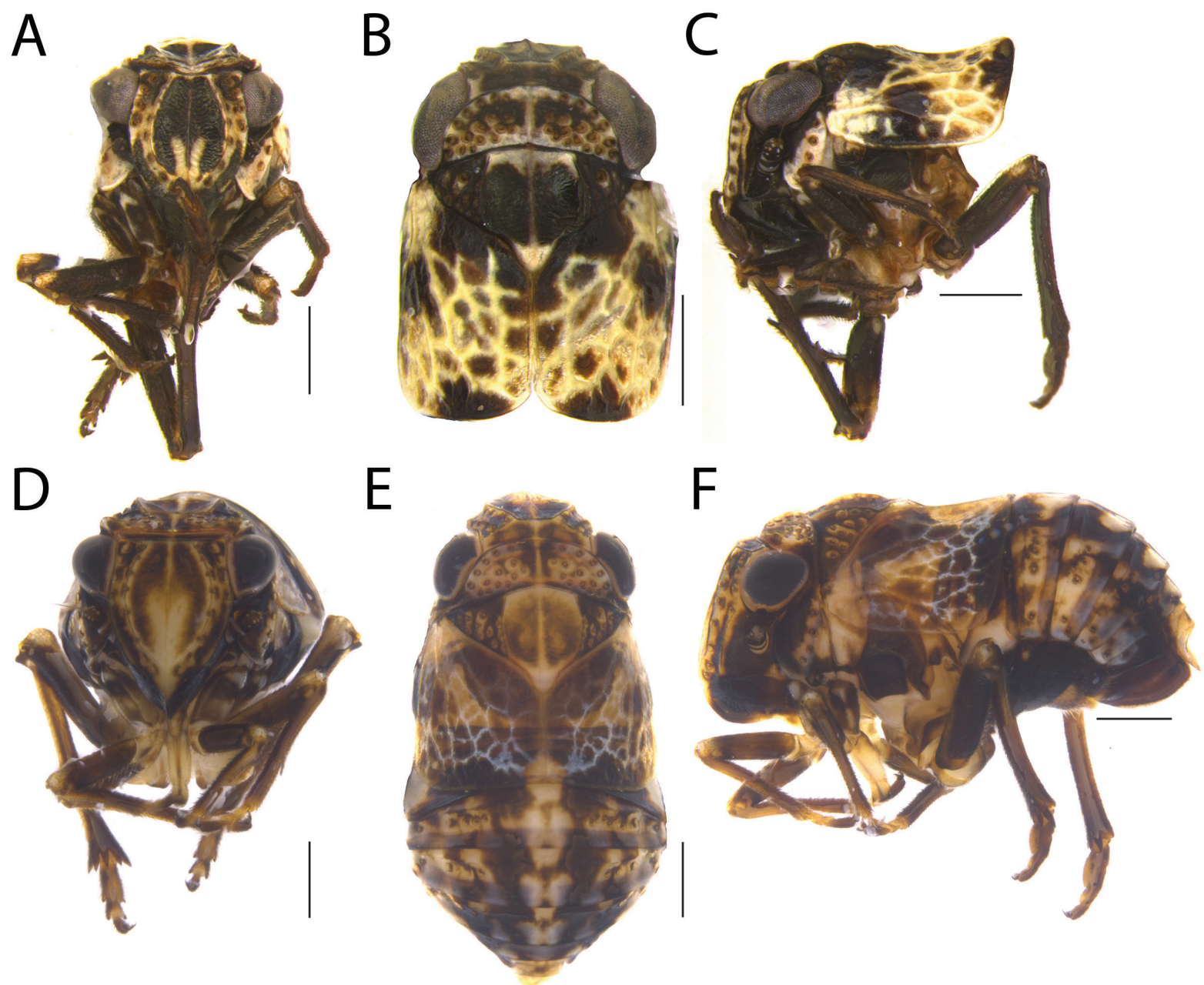

Fig. 3. Habitus of Bruchomorpha decorata Metcalf, 1923. A-C. § (INHS). A. Frontal view. B. Dorsal view. C. Lateral view. D-F. o (NMNH). D. Frontal view. E. Dorsal view. F. Lateral view. Scale bars = $0.5 \mathrm{~mm}$. 
frons (Fig. 3A, D) with pale heart-shaped macula divided by median carina; side of frons (Fig. 3C, F) pale. Pronotum (Fig. 3B, E) mostly pale; lateral lobe of pronotum (Fig. 3C, F) with posterior half pale. Mesonotum (Fig. 3B, E) with anterior and posterior portions of middle region distinctly pale. Forewings black in males (Fig. 3B-C) and hyaline in females (Fig. 3E-F), both with white veins.

HeAD AND THORAX. Vertex (Fig. 3B, E) hexagonal, shorter than half its width, shorter than pronotum length; posterior margin slightly elevated. Frons (Fig. 3A, D) with strong median carina and pair of sublateral carinae; sublateral carinae convergent and fused to each other ventrally; central plate (Fig. 3A, D) longer than wide at widest portion, visible in dorsal view (Fig. 3B, E), not extending anteriorly beyond sublateral carinae in lateral view (Fig. 3C, F); sides of frons partially visible in frontal view (Fig. 3A, D) and fused above clypeus, with two rows of sensory pits on each side in lateral view (Fig. 3C, F): anterior row with eight sensory pits, five dorsal ones grouped together, followed by sixth isolated one aligned with antenna, and pair of ventral ones isolated next to clypeus; posterior row with four sensory pits, most ventral one slightly isolated. Clypeus (Fig. 3C, F) swollen, extending anteriorly in lateral view, consequently pushing frons anteriorly and producing very lightly produced snout; longer than high in

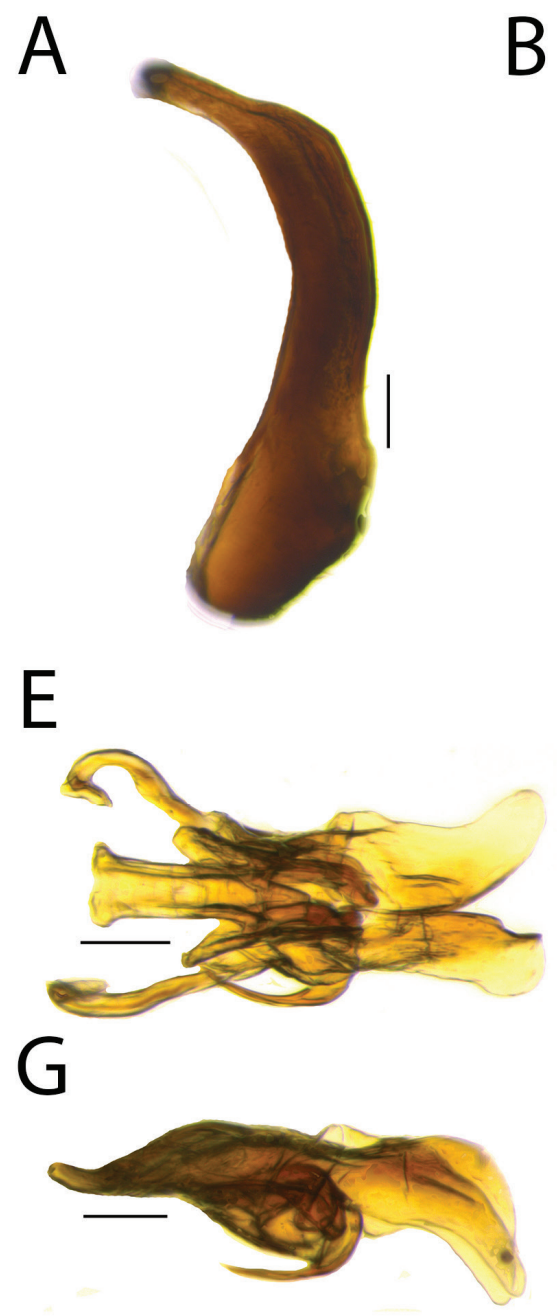

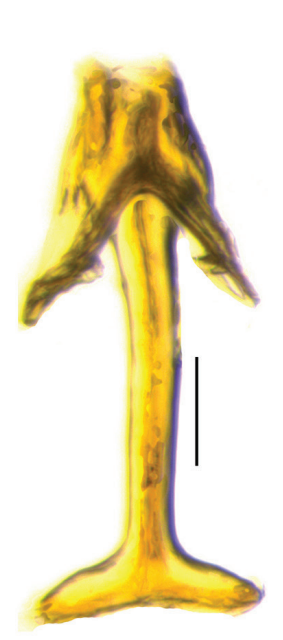

$\mathrm{F}$
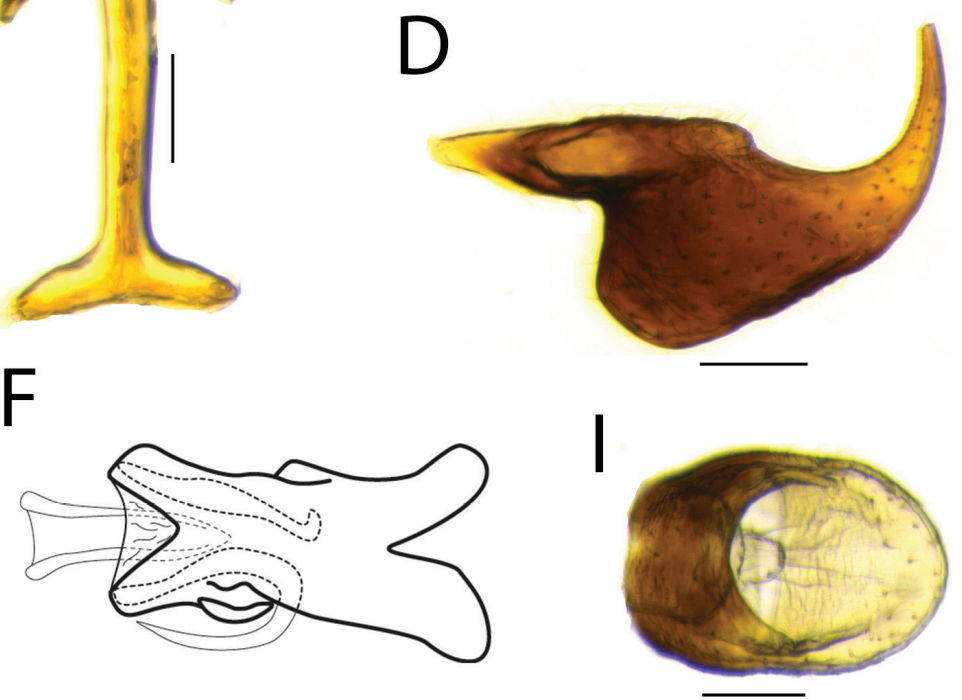

$\mathrm{H}$

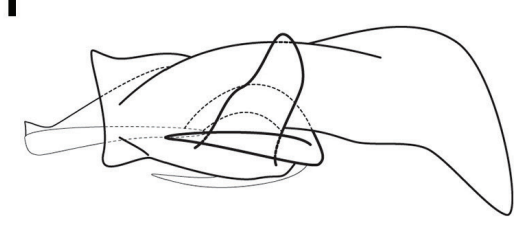

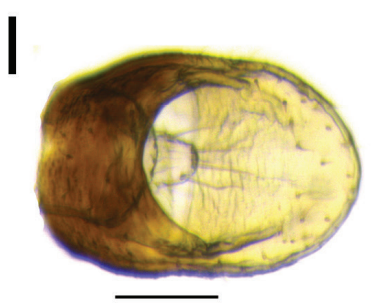

$\mathrm{J}$

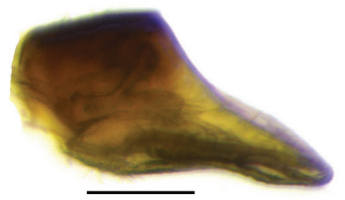

Fig. 4. Male terminalia of Bruchomorpha decorata Metcalf, 1923 (INHS). A. Pygofer, lateral view. B. Connective, anterior view. C-D. Style. C. Dorsal view. D. Lateral view. E-H. Phallus. E-F. Dorsal view. G-H. Lateral view. I-J. Anal tube. I. Dorsal view. J. Lateral view. Scale bars $=0.1 \mathrm{~mm}$. 
lateral view, with complete and elevated median carina. Ocelli absent. Eye oblong. Antenna short, with several small circular structures visible on pedicel. Pronotum (Fig. 3B, E) semicircular, shorter than half its width, with distinct median carina; median portion of disc without sensory pits; lateral portion of disc with 15 to 19 (holotype and allotype with 18 to 19) sensory pits; lateral lobe (Fig. 3C, F) with three (holotype) to four sensory pits arranged in row. Mesonotum (Fig. 3B, E) with distinct median carina and pair of lateral carinae; region between lateral carinae depressed, without sensory pits; region outerad of lateral carina with 10 to 13 (holotype with 11) sensory pits. Brachypterous, with reticulated venation. Legs simple; with carinae and setae; tibia III with single median spine.

Abdomen. Terga without longitudinal carinae. Tergite III (Figs 3F, 26B) without sensory pits. Tergite IV (Figs 3F, 26B) with one row of three to five sensory pits followed by single isolated ventral one. Tergites V to VII (Figs 3F, 26B) with one row of three to four (holotype and allotype with three to four) sensory pits followed by isolated ventral pair aligned diagonally (Fig. 26B). Tergite VIII (Fig. 26B) with one sensory pit.

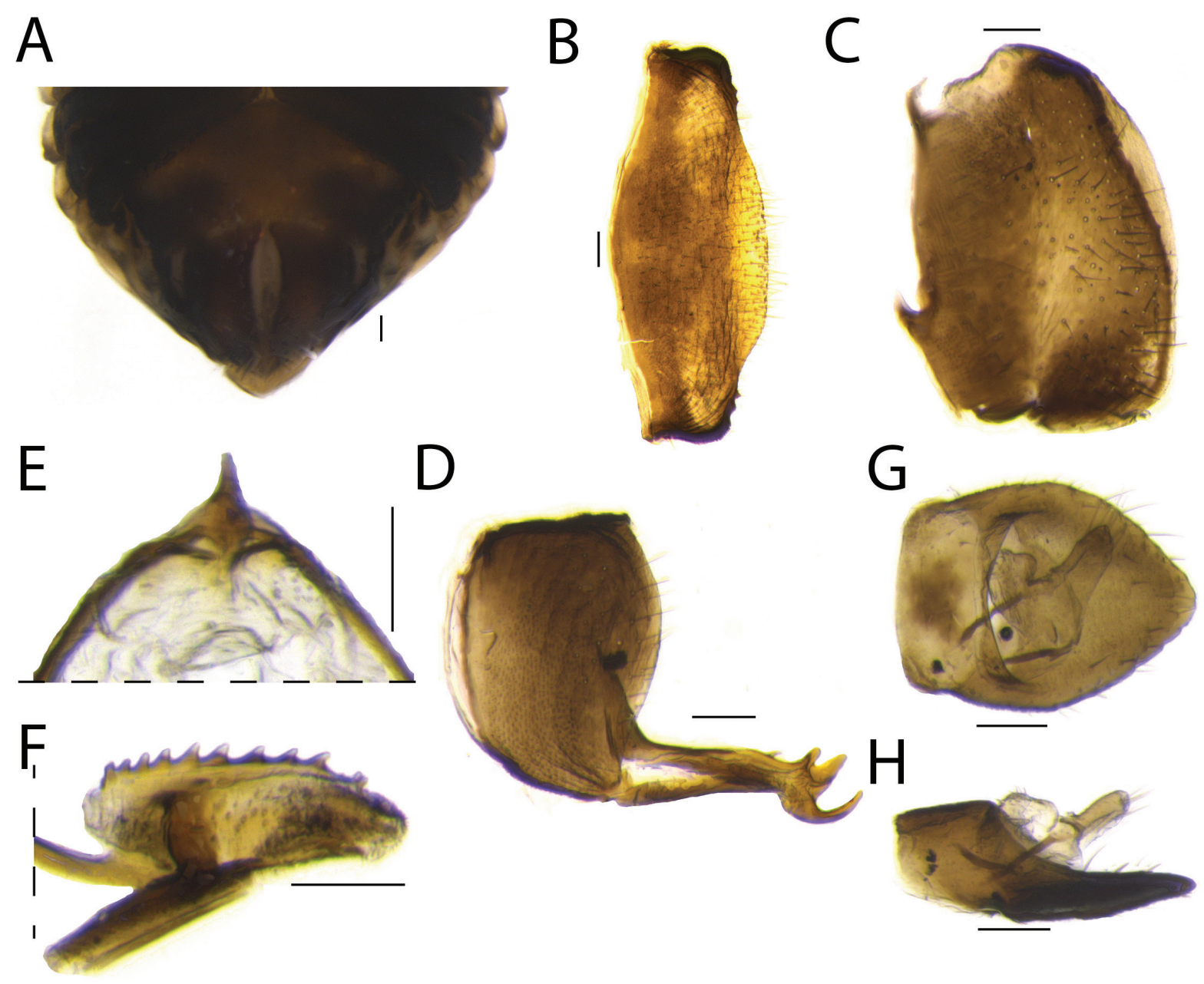

Fig. 5. Female terminalia of Bruchomorpha decorata Metcalf, 1923, $q$ (NMNH). A. External female terminalia, ventral view. B. Sternite VII, ventral view. C. Gonoplac, lateral view. D. Anterior connective lamina of gonapophysis VIII, ventral view. E-F. Posterior connective lamina of gonapophysis IX. E. Connective part in dorsal view. F. Distal part in lateral view. G-H. Anal tube. G. Dorsal view. H. Lateral view. Scale bars $=0.1 \mathrm{~mm}$. 
Male terminalia. Pygofer (Fig. 4A) narrow, with anterior margin deeply concave; posterior margin almost straight. Connective (Fig. 4B) inverted Y-shaped, with support bridge with dorsal flap. Style (Fig. 4C-D) hook-like; anterior portion pointed; posterior portion strongly curved anterodorsally (Fig. 4D), converging towards the other in dorsal view (Fig. 4C); dorsal margin (Fig. 4D) with slight protuberance on median third; ventral margin (Fig. 4D) with concavity on anterior third, remainder rounded; middle portion (Fig. 4D) almost as long as high, setose; apex serrated (Fig. 4D). Phallobase (Fig. 4E-H) sclerotized, symmetrical, with two defined lobes; apex with pair of lobes curved ventrally in lateral view (Fig. 4G-H); apices of lobes truncate in dorsal view (Fig. 4E-F), surrounding aedeagus from middle third. Aedeagus (Fig. 4E-F) apex narrow and open dorsally, with pair of hooks, both curved ventrad and anterolaterally, but one positioned more dorsally than other. Suspensorium V-shaped. Segment $\mathrm{X}$ of anal tube (Fig. 4I-J) as long as wide; posterior margin (Fig. 4I) rounded; setose.

Female terminalia. Posterior margin of sternite VII (Fig. 5B) with median portion slightly produced, setose. Gonoplac (Fig. 5C) sclerotized, sub-rectangular with apex truncate, setose. Anterior connective lamina of gonapophysis VIII (Fig. 5D) with three apical teeth: innermost larger than outer ones, narrow and long, middle one widest, outer one short and apically rounded; middle and outer ones closer to each other than to inner one. Posterior connective lamina of gonapophysis IX (Fig. 5E-F) distal part with longitudinal row of ten to twelve short and triangular spines in lateral view (Fig. 5F); middle portion with several pits (Fig. 5F); apex setose (Fig. 5F). Segment X of anal tube (Fig. 5G-H) longer than wide at widest portion; posterior margin (Fig. $5 \mathrm{G}$ ) pointed with apex rounded; setose.

\section{Remarks}

This species was identified based on comparisons with the type series (holotype and allotype) from Texas (USA) and the original description by Metcalf (1923) plus the redescription by Doering (1939), which do not include the arrangement of abdominal sensory pits or female terminalia. Previously published illustrations of the dorsal view of the body and lateral view of the head allow comparison of the sensory pits of the sides of the frons and the lateral lobe of pronotum to those of other species. The male terminalia were previously illustrated superficially, but the overall shape could also be compared. Two recently collected available specimens have four sensory pits on each lateral lobe of pronotum (Fig. 3C, F), which is different from the three sensory pits illustrated by Metcalf (1923) and Doering (1939). Both specimens of the type series have three pits on the right side, but the female allotype has four pits on the left side. A series of several additional specimens from Mexico (see Material examined above) includes one additional male and female with three pits on one pronotal lobe and four on the other; the remaining specimens have three pits on both lobes, as in the holotype, and their genitalia match those of other studied specimens of this species. The holotype of Bruchomorpha decorata var. nihldecorata Caldwell, 1945 also has four pits.

Finally, this species is firstly recorded from Panama.

Bruchomorpha mormo Kirkaldy, 1907

Figs 6-8, 26C

Bruchomorpha mormo Kirkaldy, 1907: 64.

Bruchomorpha mormo - Dozier 1928: 14 (key), 96 (redescription). — Doering 1939: 127, pl. XX: fig. 2, pl. XXI: fig. 17, pl. XXII: figs 7, 7a, 7b (redescription, illustration), 103 (key), 121, 128, 135 (comparative notes). - Caldwell 1945: 92 (comparative notes).

\section{Diagnosis}

Body mainly black, with coppery sheen (Fig. 6); vertex semicircular (Fig. 6B, E); frons with median carina (Fig. 6A, D), central plate visible in dorsal view (Fig. 6B, E); clypeus swollen, but not forming snout (Fig. 6C, F); lateral lobe of pronotum with three sensory pits arranged in a row (Fig. 6C, F); 
abdominal tergites (Figs 6C, F, 26C) with row of sensory pits followed by single isolated ventral sensory pit (tergite IV) or isolated pair of diagonally aligned ventral sensory pits (tergites V to VII).

\section{Material examined}

\section{Other material}

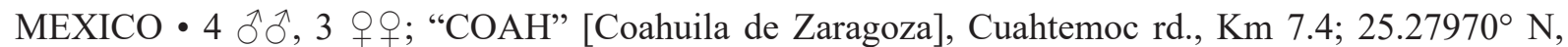
$100.98747^{\circ}$ W; 2120 m a.s.l.; Oct. 2005; C. Dietrich leg.; vacuum sample; INHS • 1 \%; same collection data as for preceding; DZRJ $\bullet 1 \hat{\delta}$; same collection data as for preceding; DNA voucher ENT4915; DZRJ.

\section{Description}

Body LENGTH. Males $=1.7$ to $2 \mathrm{~mm}$; females $=2.4$ to $3 \mathrm{~mm}$.

ColORATION. Body mainly black, with coppery sheen (Fig. 6A-F). Forewings (Fig. 6B, E) black. Males with legs mostly yellow, except femur III black basally (Fig. 6A, C). Females with legs light brown with black maculae (Fig. 6D, F).
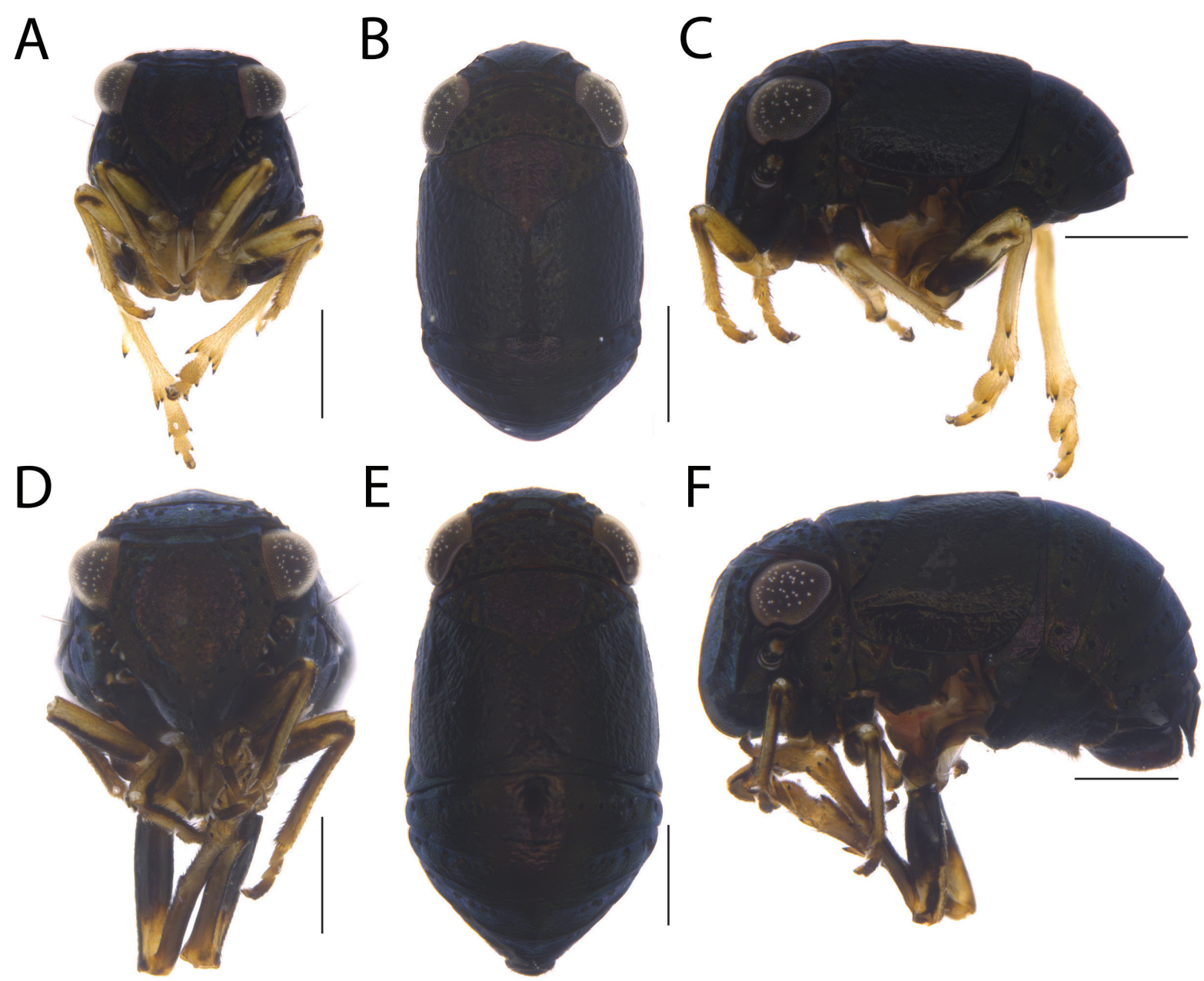

Fig. 6. Habitus of Bruchomorpha mormo Kirkaldy, 1907. A-C. OA (DZRJ). A. Frontal view. B. Dorsal view. C. Lateral view. D-F. o (DZRJ). D. Frontal view. E. Dorsal view. F. Lateral view. Scale bars = $0.5 \mathrm{~mm}$. 
HEAD AND THORAX. Vertex (Fig. 6B, E) semicircular, shorter than half its width, shorter than half of pronotum length; posterior margin slightly elevated. Frons (Fig. 6A, D) with median carina and pair of sublateral carinae; sublateral carinae converge and fuse to each other ventrally; central plate (Fig. 6A, D) as long as wide at widest portion, visible in dorsal view (Fig. 6B, E), extending slightly anteriorly beyond sublateral carinae in lateral view (Fig. 6C, F); sides of frons partially visible in frontal view (Fig. 6A, D) and fused above clypeus, with two rows of sensory pits on each side in lateral view (Fig. 6C, F): anterior row with eight sensory pits; posterior row with four sensory pits. Clypeus (Fig. 6C, F) swollen, extending anteriorly but not producing snout in lateral view; with complete median carina. Ocelli absent. Eye oblong. Antenna short, with several small circular structures visible on pedicel. Pronotum (Fig. 6B, E) semicircular, shorter than half its width, with median carina; median portion of disc without sensory pits; lateral portion of disc with 12 to 14 sensory pits on each side; lateral lobe of pronotum (Fig. 6C, F) with three sensory pits arranged in row. Mesonotum (Fig. 6B, E) with median carina and pair of lateral carinae; region between lateral carinae without sensory pits; regions outerad of lateral carinae with 10 to

A

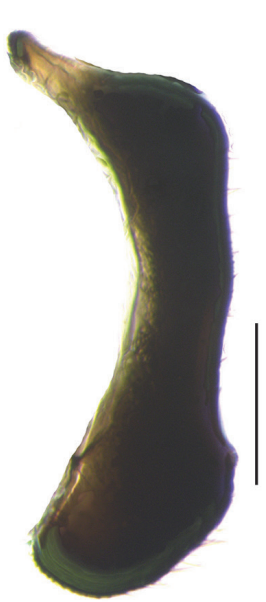

$\mathrm{E}$

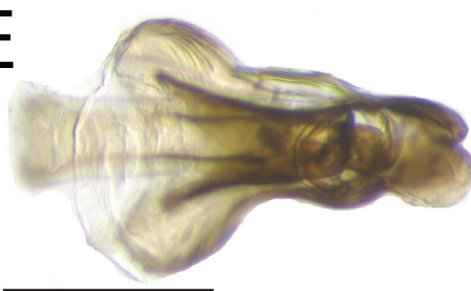

G

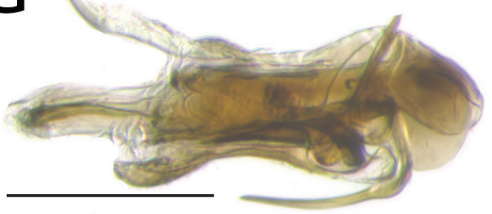

B
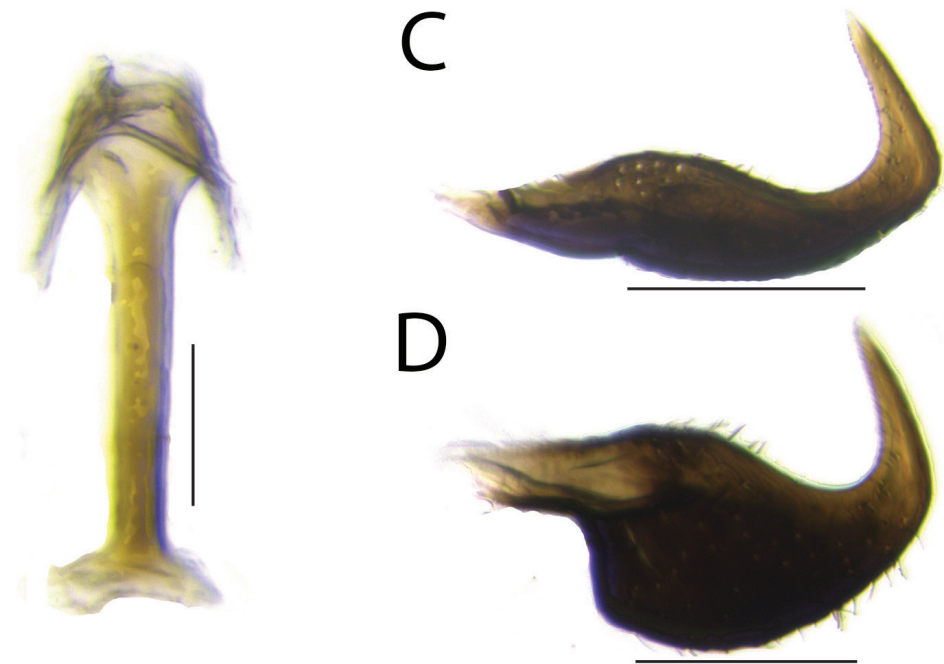

$\mathrm{F}$

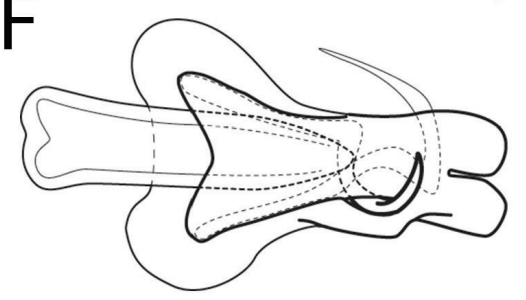

$\mathrm{H}$

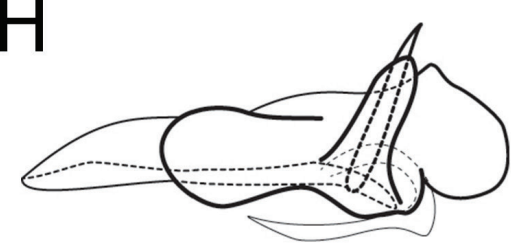

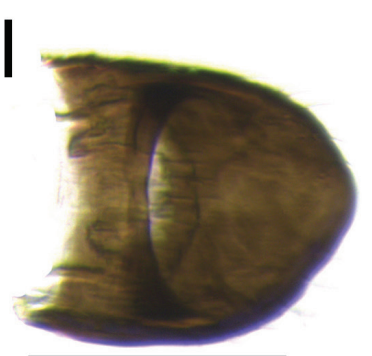

J

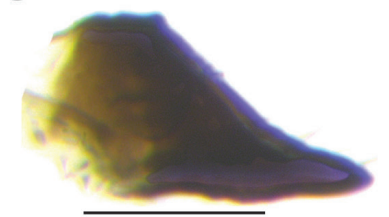

Fig. 7. Male terminalia of Bruchomorpha mormo Kirkaldy, 1907 (DZRJ). A. Pygofer, lateral view. B. Connective, anterior view. C-D. Style. C. Dorsal view. D. Lateral view. E-H. Phallus. E-F. Dorsal view. G-H. Lateral view. I-J. Anal tube. I. Dorsal view. J. Lateral view. Scale bars $=0.1 \mathrm{~mm}$. 
11 sensory pits on each side. Brachypterous, with reduced venation. Legs simple, with carinae and setae; tibia III with single median spine.

Abdomen. Terga without longitudinal carinae. Tergite III (Figs 6C, F, 26C) without sensory pits. Tergite IV (Figs 6C, F, 26C) with one row of three to five sensory pits, with penultimate pit slightly displaced from row, followed by single isolated ventral one. Tergites V to VII (Figs 6C, F, 26C) with one row of three to five sensory pits followed by isolated ventral pair aligned diagonally. Tergite VIII (Fig. 26C) with one sensory pit.

Male terminalia. Pygofer (Fig. 7A) narrow, with anterior margin concave; posterior margin almost straight. Connective (Fig. 7B) inverted Y-shaped, with support bridge with dorsal flap. Style (Fig. 7C-D) hook-like; anterior portion pointed; caudal portion strongly curved anterodorsally (Fig. 7D) and curved mesad in dorsal view (Fig. 7C); dorsal margin (Fig. 7D) sinuous; ventral margin (Fig. 7D) with straight angle concavity on anterior fourth, remainder rounded; middle third (Fig. 7D) as long as high, setose; apex serrated (Fig. 7D). Phallobase (Fig. 7E-H) sclerotized, symmetrical, with two defined lobes; apex

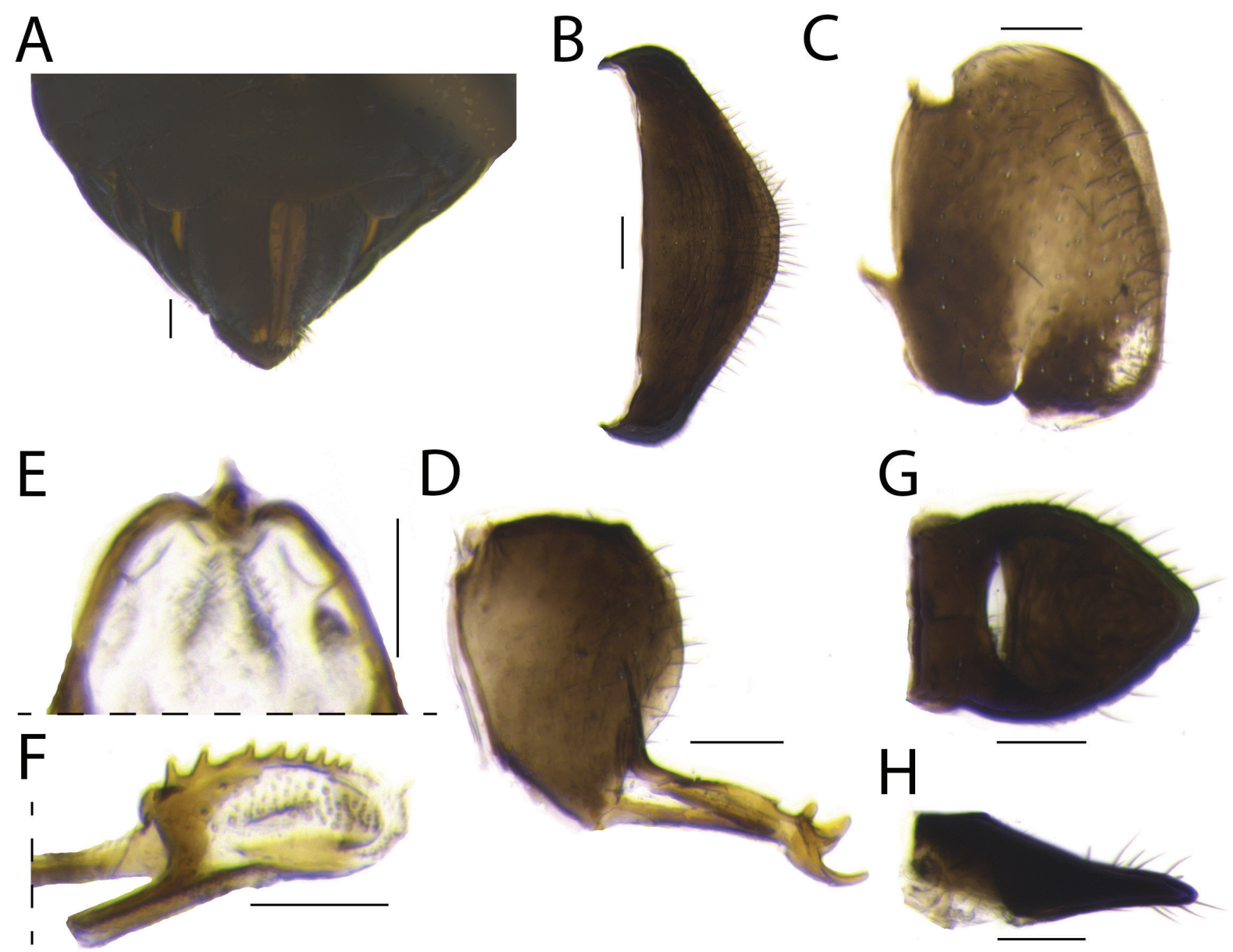

Fig. 8. Female terminalia of Bruchomorpha mormo Kirkaldy, 1907 (DZRJ). A. External female terminalia, ventral view. B. Sternite VII, ventral view. C. Gonoplac, lateral view. D. Anterior connective lamina of gonapophysis VIII, ventral view. E-F. Posterior connective lamina of gonapophysis IX. E. Connective part in dorsal view. F. Distal part in lateral view. G-H. Anal tube. G. Dorsal view. H. Lateral view. Scale bars $=0.1 \mathrm{~mm}$. 
with pair of lobes with apices truncate in dorsal view (Fig. 7E-F) and rounded in lateral view (Fig. 7G$\mathrm{H}$ ); sides expanded and rounded at half-length of aedeagus in dorsal view (Fig. 7E-F); with dorsal process near apex in lateral view (Fig. 7G-H), surrounding apical half of aedeagus; with a flap covering aedeagal hook in lateral view (Fig. 7G-H). Aedeagus (Fig. 7E-F) apex narrow and open dorsally; with pair of hooks, one curved dorsally (Fig. 7E-F), other curved anteroventrally (Fig. 7G-H). Suspensorium V-shaped. Segment X of anal tube (Fig. 7I-J) as long as wide, posterior margin (Fig. 7I) pointed; setose.

Female terminalia. Posterior margin of sternite VII (Fig. 8B) with median portion produced, setose. Gonoplac (Fig. 8C) sclerotized, sub-rectangular with apex truncate, setose. Anterior connective lamina of gonapophysis VIII (Fig. 8D) with three apical teeth: innermost bigger than outer ones, narrow and long, middle one widest, outer one short and apically rounded. Posterior connective lamina of gonapophysis IX (Fig. 8E-F) distal part with longitudinal row of eight short and wide spines in lateral view (Fig. 8F); middle portion with several pits (Fig. 8F); apex setose (Fig. 8F); region between distal parts with two patches of small setae (Fig. 8E). Segment X of anal tube (Fig. 8G-H) longer than wide at widest portion, posterior margin (Fig. $8 \mathrm{G}$ ) pointed with apex rounded; setose.

\section{Remarks}

Specimens at hand were identified based on the redescription and illustration of the dorsal view of the body, lateral view of the head, and male terminalia by Doering (1939). This species resembles several other species of Bruchomorpha, including Bruchomorpha oculata Newman, 1838, Bruchomorpha minima Metcalf, 1923, Bruchomorpha pallidipes Stål, 1862 and Bruchomorpha tristis Stål, 1862, in its mostly black, metallic shiny appearance. According to Doering (1939), B. mormo can be easily distinguished from other black-colored species by: (1) lack of a lighter colored dorsal stripe (Fig. 6B, E) and shorter snout (Fig. 6C, F), which distinguish it from B. oculata; (2) small size, which distinguishes it from B. tristis; (3) shorter snout and yellow legs (Fig. 6C, F), which distinguish it from B. minima; and (4) circular central plate of frons (Fig. 6A, D), which is much less elongated than in B. pallidipes.

Bruchomorpha pseudodorsata sp. nov. urn:1sid:zoobank.org:act:DA853D0B-3BF0-4D22-BFBD-D897F8CEA14B

Figs 9-10, 26D

\section{Diagnosis}

Body mainly brown, with several randomly distributed irregular pale maculae, and with continuous broad median longitudinal pale-yellow stripe crossing frons, vertex, thorax and abdomen (Fig. 9); vertex hexagonal (Fig. 9B); frons with ventrally elevated median carina (Fig. 9A) and central plate visible in dorsal view (Fig. 9B); clypeus extending anteriorly, produced into slight snout (Fig. 9A, C); lateral lobe of pronotum with five sensory pits, one pit isolated anteriorly and one posterior vertical row with four pits (Fig. 9C); abdominal tergites (Figs 9C, 26D) with group of sensory pits followed by an isolated pair of diagonally aligned ventral sensory pits.

\section{Etymology}

The specific name 'pseudodorsata' ('pseudo-', Greek = 'false'.) refers to the superficial similarity to Bruchomorpha dorsata Fitch, 1856.

\section{Material examined}

Holotype

MEXICO • +; "COAH” [Coahuila de Zaragoza], Cuahtemoc rd., Km 7.4; $25.27970^{\circ}$ N, $100.98747^{\circ}$ W; 2120 m a.s.1.; Oct. 2005; C. Dietrich leg.; sweep; DNA voucher ENT4917; INHS. 


\section{Paratypes}

MEXICO • 1 \%; same collection data as for holotype; INHS • 1 \%; same collection data as for holotype; DZRJ.

\section{Description}

Body LENGTH. Females $=3.6$ to $4.0 \mathrm{~mm}$.

ColORATION. Body mainly brown, with several randomly distributed irregular pale maculae (Fig. 9AC). Frons, vertex, thorax and abdomen (Fig. 9B) with continuous broad median longitudinal pale-yellow stripe. Forewing hyaline, with longitudinal white stripe over commissural margins following body stripe, but not as well defined (Fig. 9B).

HeAd AND THORAX. Vertex (Fig. 9B) hexagonal, shorter than wide, shorter than pronotum length; posterior margin slightly elevated. Frons (Fig. 9A) with median carina and pair of sublateral carinae; median carina elevated ventrally; sublateral carinae converge and fuse to each other ventrally (Fig. 9A); central plate (Fig. 9A) longer than wide at widest portion, visible in dorsal view (Fig. 9B), not extending anteriorly beyond sublateral carinae in lateral view (Fig. 9C); sides of frons partially visible in frontal view (Fig. 9A) and fused above clypeus (Fig. 9A), with two rows of sensory pits on each side in lateral view (Fig. 9C): anterior row with eight sensory pits, five dorsal ones grouped together, followed by three isolated ones after the concavity at anterior margin of frons; posterior row with four sensory pits. Clypeus (Fig. 9C) swollen, extending anteroventrally in lateral view, forming slightly produced snout, longer than high in lateral view, composing most of snout anteriorly; snout shortly produced, nearly truncate in lateral view (Fig. 9C), rounded in frontal view (Fig. 9A), with complete and elevated median carina. Ocelli absent. Eye oblong. Antenna short, with several small circular structures visible on pedicel. Pronotum (Fig. 9B) sub-rectangular, shorter than half its width; median portion of disc without sensory pits; lateral portion of disc with 20 to 22 sensory pits; with median carina; lateral lobe of pronotum (Fig. 9C) with five sensory pits, one pit isolated anteriorly and one posterior vertical row with four pits. Mesonotum (Fig. 9B) with median carina and pair of lateral carinae; region between lateral carinae depressed, without sensory pits; region laterad of lateral carina with 19 to 22 sensory pits. Brachypterous, with reduced venation. Legs simple, with carinae, setose; tibia III with single median spine.
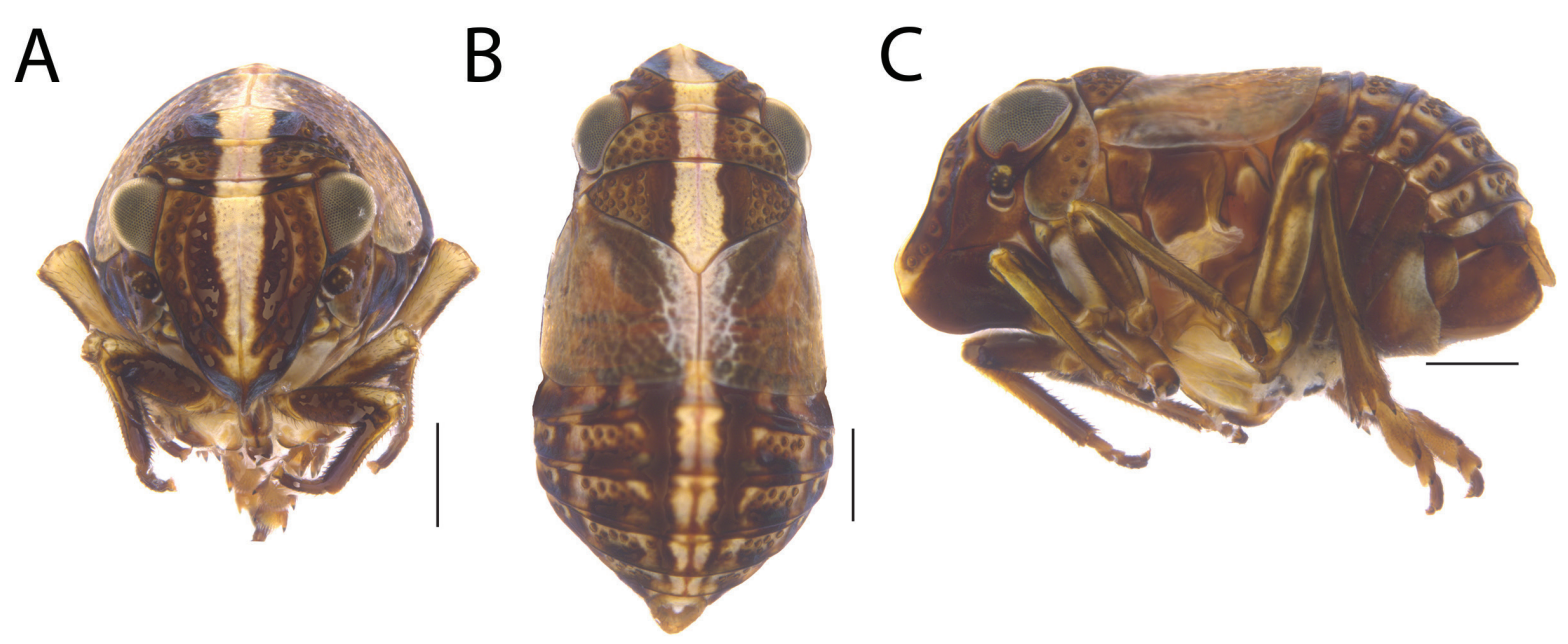

Fig. 9. Habitus of Bruchomorpha pseudodorsata sp. nov.,, , holotype (INHS). A. Frontal view. B. Dorsal view. C. Lateral view. Scale bars $=0.5 \mathrm{~mm}$. 
AbDomen. Terga with longitudinal carina. Tergite III without sensory pits (Figs 9C, 26D). Tergites IV to VII (Figs 9C, 26D) with group of seven to nine sensory pits followed by isolated ventral pair aligned diagonally (Fig. 26D). Tergite VIII (Fig. 26D) with one sensory pit.

Female terminalia. Posterior margin of sternite VII (Fig. 10B) with median portion straight, setose. Gonoplac (Fig. 10C) sclerotized, sub-rectangular with apex truncate, setose. Anterior connective lamina of gonapophysis VIII (Fig. 10D) with three apical teeth: innermost larger than outer ones, narrow and long, middle one widest of all, outer one short and apically rounded. Posterior connective lamina of gonapophysis IX (Fig. 10E-F) distal part with longitudinal row of 10 short spines in lateral view (Fig. 10F); middle portion with several pits (Fig. 10F); apex setose (Fig. 10F). Segment X of anal tube (Fig. 10G-H) longer than wide at widest portion; caudal margin (Fig. 10G) with apex rounded; setose.

\section{Remarks}

This new species superficially resembles Bruchomorpha dorsata in coloration and overall external morphology, but differs from it mainly in: (1) the shape of the vertex and pronotum, which are both

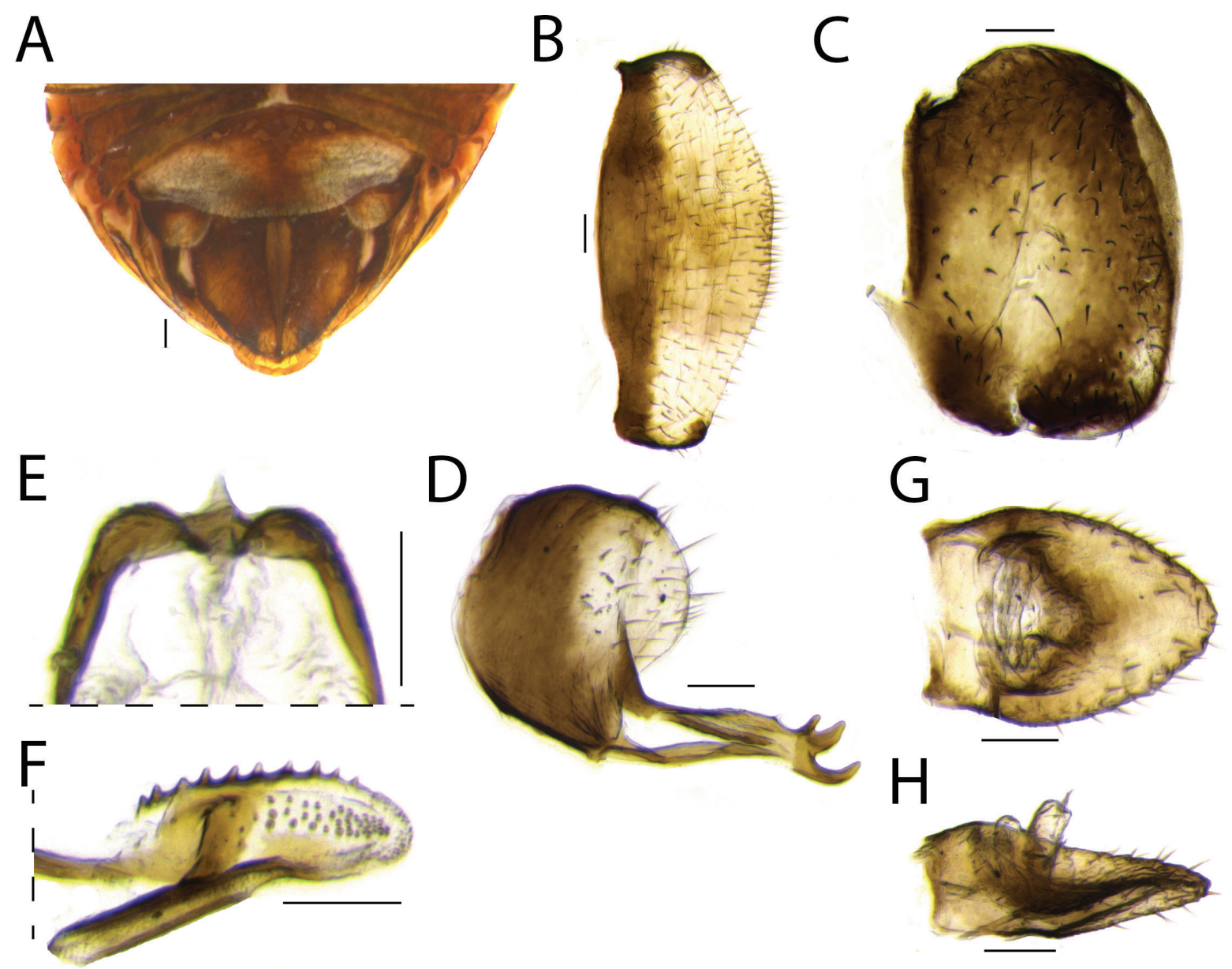

Fig. 10. Female terminalia of Bruchomorpha pseudodorsata sp. nov., holotype (INHS). A. External female terminalia, ventral view. B. Sternite VII, ventral view. C. Gonoplac, lateral view. D. Anterior connective lamina of gonapophysis VIII, ventral view. E-F. Posterior connective lamina of gonapophysis IX. E. Connective part in dorsal view. F. Distal part in lateral view. G-H. Anal tube. G. Dorsal view. H. Lateral view. Scale bars $=0.1 \mathrm{~mm}$. 
almost semicircular in B. dorsata but hexagonal and subrectangular in B. pseudodorsata sp. nov. (Fig. 9B); (2) the coloration of the forewing, which is as brown as the body and with a well-defined white stripe following the body stripe in B. dorsata but blurred in B. pseudodorsata sp. nov. (Fig. 9B); and (3) the pattern of distribution of sensory pits on the abdomen, with one defined row on all segments followed by an isolated ventral pair in $B$. dorsata and one group of several sensory pits followed by an isolated ventral pair in B. pseudodorsata sp. nov. (Figs 9C, 26D). Although the new species is here placed in Bruchomorpha, the pattern of distribution of abdominal sensory pits is different from all the other species of this genus studied herein (Fig. 26B-C).

Genus Fitchiella Van Duzee, 1917

Fitchiella brachyrhina sp. nov. urn:1sid:zoobank.org:act:BCE22551-8002-459E-9C6D-93D144BF08E1

Figs 11-12, 26E

\section{Diagnosis}

Body mainly off white with several black maculae and sensory pits bordered by black (Fig. 11); snout as long as half of interocular distance (measured from base to tip) with apex rounded in frontal and lateral view (Fig. 11A, C); lateral lobe of pronotum with three sensory pits arranged in a row (Fig. 11C); forewings with reticulated venation (Fig. 11B-C); abdominal tergites (Figs 11C, 26E) with row of sensory pits followed by single isolated ventral sensory pit (tergite IV and V) or an isolated pair of diagonally aligned ventral sensory pits (tergites VI to VII).

\section{Etymology}

The specific name 'brachyrhina' ('brachy-', Greek = 'short'; 'rhina', Greek = 'nose') refers to the short snout of this species if compared to other species of the genus.

\section{Material examined}

Holotype

MEXICO • ${ }^{\top}$; “ZAC" [Zacatecas], 10.4 km NW Vasco de Quiroga; $23.39637^{\circ} \mathrm{N}, 103.55023^{\circ} \mathrm{W} ; 2500$ m a.s.1.; Oct. 2005; C. Dietrich leg.; vacuum sample; DNA voucher ENT4913; INHS.

\section{Description}

Body LENGTH. Male $=2.4 \mathrm{~mm}$.

Coloration. Body mainly off-white with several black maculae and sensory pits bordered by black (Fig. 11A-C). Vertex (Fig. 11B) with pair of large black maculae. Frons (Fig. 11A) with pair of black stripes bordering sublateral carinae and very weak black line covering median carina; side of frons (Fig. 11C) black where sensory pits are lacking. Gena (Fig. 11A) black with border white. Clypeus in lateral view (Fig. 11C) with dorsal portion extended anteriorly black, median portion white with lateral black stripes, ventral portion black. Lateral lobe of pronotum (Fig. 11C) with anterior portion black. Mesonotum (Fig. 11B) region between lateral carinae white with pair of elongated black maculae near lateral carinae. Forewings (Fig. 11B-C) black with white veins; white stripes within cells. Legs (Fig. 11A, C) white with some elongated black maculae. Abdomen (Fig. 11B, C) with approximately 15 parallel longitudinal black maculae on each segment; black maculae forming continuous longitudinal line between row of sensory pits and isolated one.

HeAD AND thorax. Vertex (Fig. 11B) hexagonal, shorter than half its width, as long as half of pronotum length, with slight median carina; posterior margin slightly elevated. Frons (Fig. 11A) with median carina and pair of sublateral carinae; sublateral carinae converge and fuse to each other ventrally 
(Fig. 11A); central plate (Fig. 11A) longer than wide at widest portion, visible in dorsal view (Fig. 11B), not extending anteriorly beyond sublateral carinae in lateral view (Fig. 11C); sides of frons partially visible in frontal view (Fig. 11), fused above clypeus, with two rows of sensory pits on each side in lateral view (Fig. 11C): anterior row with eight sensory pits, four dorsal ones are grouped, followed by a fifth isolated one aligned between ventral margin of eye and antenna, and three isolated ones ventrally to concavity on anterior margin of frons; posterior row with four sensory pits. Clypeus (Fig. 11C) not swollen, with dorsal portion extended anteroventrally into slightly produced snout; snout in dorsal view (Fig. 11B) as long as half of interocular distance (measured from base to tip), apex rounded in frontal and lateral view and with slight median anterodorsal concavity in lateral view (Fig. 11A, C); with median carina. Ocelli absent. Eye oblong. Antenna short, with several small circular structures visible on pedicel. Pronotum (Fig. 11B) semicircular, shorter than half its width; posterior margin straight; with median carina; surface of disc almost completely covered by 15 to 17 sensory pits on each side; lateral lobe of pronotum (Fig. 11C) with three sensory pits arranged in a row. Mesonotum (Fig. 11B) with slight median carina and pair of lateral carinae; region between lateral carinae depressed, without sensory pits; region outerad of lateral carina with 11 sensory pits. Brachypterous, with reticulated venation, with large cells and lines within those cells. Legs simple, with carinae and setae; tibia III with single median spine.

AbDomen. Terga with longitudinal carina. Tergite III (Figs 11C, 26E) without sensory pits. Tergites IV and V (Figs 11C, 26E) with one row of four to five sensory pits, with penultimate one slightly displaced, followed by single isolated ventral one. Tergites VI and VII (Figs 11C, 26E) with one row of four sensory pits, penultimate one slightly displaced, followed by isolated ventral pair aligned diagonally (Figs 11C, 26E). Tergite VIII (Fig. 26E) with one sensory pit.

MALE TERMinAlia. Pygofer (Fig. 12A) narrow, with anterior margin deeply concave, posterior margin almost straight, except for slight concavity near ventral portion. Connective inverted Y-shaped, with support bridge with dorsal flap. Style (Fig. 12B-C) hook-like; anterior portion pointed; caudal portion strongly curved anterodorsally, curved medially in dorsal view (Fig. 12B); dorsal margin (Fig. 12C) with slight protuberance on median third; ventral margin (Fig. 12C) with straight angle between anterior and middle third, mostly rounded posteriorly; median portion (Fig. 12C) longer than high, setose. Phallobase (Fig. 12D-G) sclerotized symmetrical, with two defined lobes; apex with pair of lobes truncate in dorsal view (Fig. 12D-E) and rounded in lateral view (Fig. 12F-G); sides expanded and rounded at midlength of aedeagus in dorsal view (Fig. 12D-E); with dorsal process near apex in lateral view, surrounding
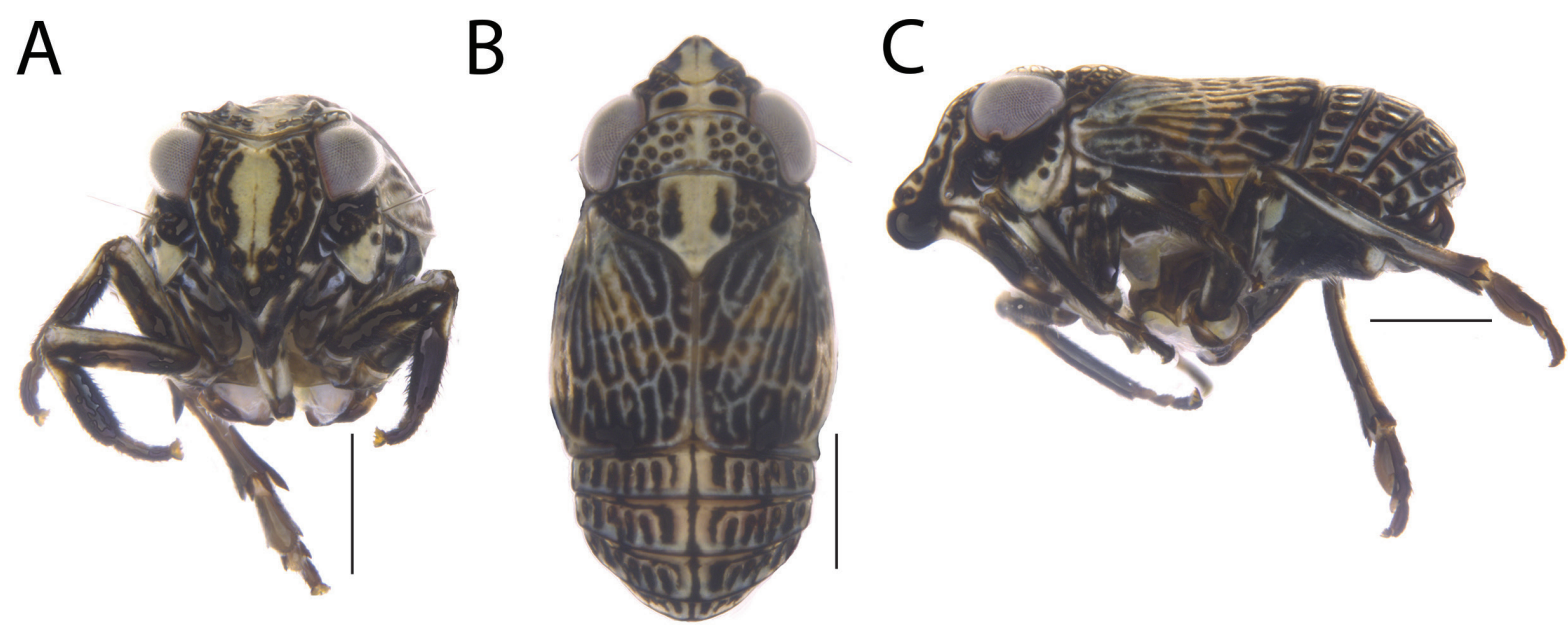

Fig. 11. Habitus of Fitchiella brachyrhina sp. nov., ふૈ, holotype (INHS). A. Frontal view. B. Dorsal view. C. Lateral view. Scale bars $=0.5 \mathrm{~mm}$. 
apical half of aedeagus; with flap covering aedeagal hook in lateral view (Fig. 12F-G). Aedeagus (Fig. 12D-E) with apex narrow and open dorsally; with pair of hooks, one curved anterodorsally, the other curved posterocaudally in lateral view (Fig. 12F-G). Suspensorium V-shaped. Segment X of anal tube (Fig. 12H-I) as long as wide; posterior margin (Fig. 12H) rounded; setose.

\section{Remarks}

The new species is apparently very similar to B. rugosa Metcalf, 1923 based on the descriptions and illustrations by Metcalf (1923) and Doering (1939), but can be distinguished from the latter by its darker coloration and slightly more produced snout. Both species are also similar to Fitchiella zahniseri sp. nov., but can be distinguished from the latter by their shorter snout. Unfortunately, the holotype of B. rugosa
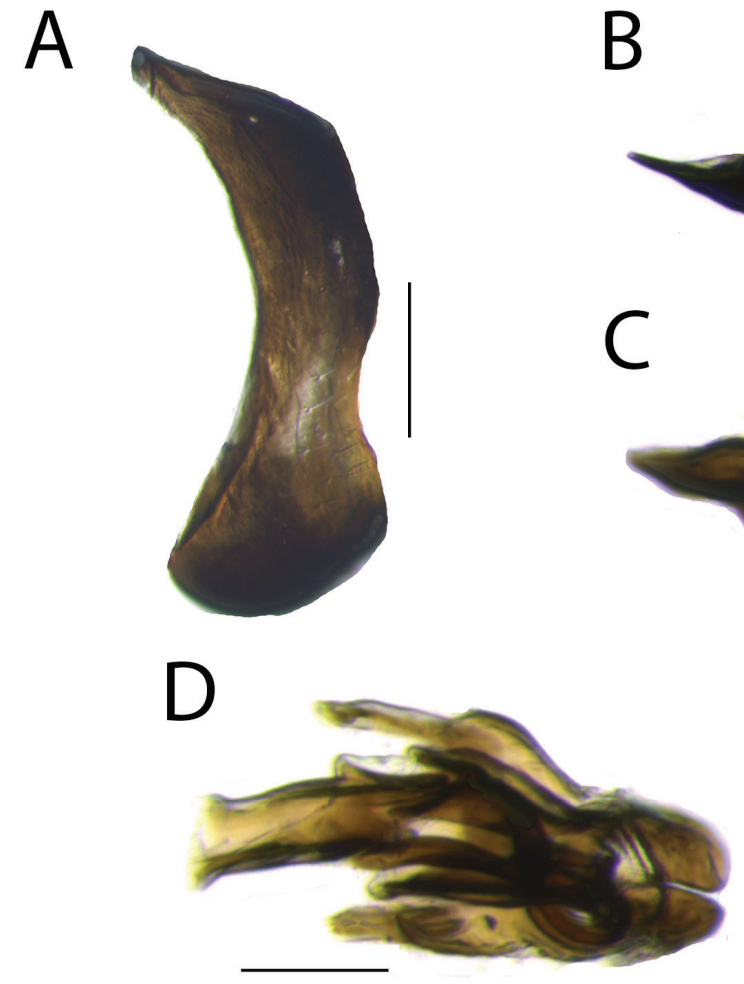

$\mathrm{F}$

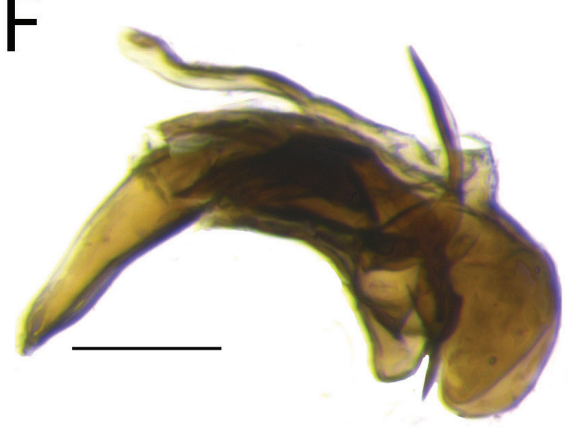

B

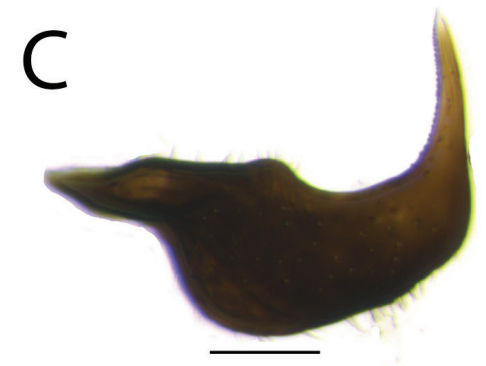

E
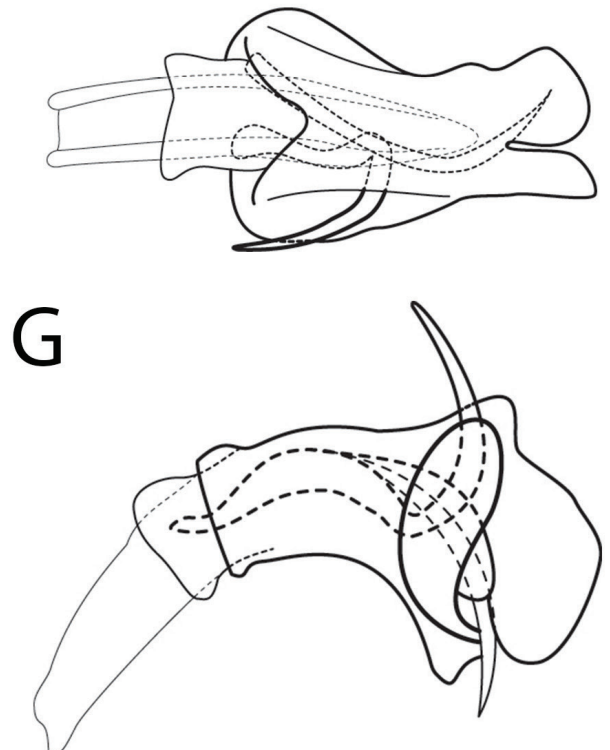

Fig. 12. Male terminalia of Fitchiella brachyrhina sp. nov., holotype (INHS). A. Pygofer, lateral view. B-C. Style. B. Dorsal view. C. Lateral view. D-G. Phallus. D-E. Dorsal view. F-G. Lateral view. H-I. Anal tube. H. Dorsal view. I. Lateral view. Scale bar: $\mathbf{A}-\mathbf{I}=0.1 \mathrm{~mm}$. 
was not studied herein (it was not found at the INHS collection), but a photograph of a specimen in the L.B. O'Brien collection identified by Doering is available online. Nevertheless, B. rugosa is most likely a species of Fitchiella, based mainly on the shape of the snout and coloration, however, a detailed study of the holotype of B. rugosa is necessary to better allocate this species.

The remarkable coloration of F. brachyrhina sp. nov., F. zahniseri sp. nov. and B. rugosa is also present in other species of Fitchiella, such as the type species, Fitchiella robertsoni (Fitch, 1856). These four species can be distinguished from other species of Fitchiella by their color pattern or by the lack of foliaceous legs. Furthermore, these species of Fitchiella can be easily distinguished from the others by the size of their snout.

Unfortunately, the connective of the studied specimen was damaged during dissection, but connective shape does not seem informative enough to distinguish genera or species of Peltonotellini.

Fitchiella zahniseri sp. nov. urn:1sid:zoobank.org:act:24D79AE7-EA07-4A0D-AF6D-FFBA6D5A9107

Figs $13-15,26 \mathrm{~F}$

\section{Diagnosis}

Body mainly stramineous with several dark brown maculae and sensory pits bordered by dark brown (Fig. 13); snout longer than interocular distance (measured from base to tip) with apex rounded in frontal and lateral view (Fig. 13A, C-D, F); lateral lobe of pronotum with four sensory pits arranged in a row (Fig. 13C); forewings with reticulated venation (Fig. 13B-C, E-F); abdominal tergites (Figs 13C, $\mathrm{F}, 26 \mathrm{~F}$ ) with row of sensory pits followed by single isolated ventral sensory pit (tergite IV and $\mathrm{V}$ ) or isolated pair of diagonally aligned ventral sensory pits (tergites VI to VII).

\section{Etymology}

The specific name 'zahniseri' is in honor of Dr James Zahniser (USDA = US Department of Agriculture) who collected the type series of this species in Panama and kindly sent us photographs of holotypes of Caliscelidae deposited at the NMNH.

\section{Material examined}

Holotype

PANAMA • \} \text { ; Verugas, Pan-Am Highway, } 4 0 \mathrm { km } \text { W of Santiago; } 0 8 . 2 0 2 9 8 ^ { \circ } \mathrm { N } , 0 8 1 . 1 8 7 6 8 ^ { \circ } \mathrm { W } ; 1 6 6 \mathrm { m } a.s.l.; Aug. 2005; J.N. Zahniser leg.; sweep; DNA voucher ENT4204; NMNH.

\section{Paratypes}

PANAMA $\bullet 1$; ; same collection data as for holotype; INHS • 1 ; ; same collection data as for holotype; DZRJ.

\section{Description}

Body LENGTH. Male $=2.7 \mathrm{~mm}$; females $=3.5 \mathrm{~mm}$.

COLORATION. Body mainly stramineous with several dark brown maculae and sensory pits bordered by dark brown; dark brown maculae darker and more extensive in males than females (Fig. 13A-C vs Fig. 13D-F). Vertex (Fig. 13B, E) with pair of large dark brown maculae. Frons (Fig. 13A, D) with pair of dark brown stripes bordering sublateral carinae and dark brown stripe covering median carina; side of frons (Fig. 13C, F) dark brown where sensory pits are lacking. Gena (Fig. 13C, F) with large dark brown macula. Clypeus in lateral view (Fig. 13C, F) with dorsal portion extended anteriorly dark brown, median portion stramineous, ventral portion dark brown. Lateral lobe of pronotum (Fig. 13C, F) with 
anterior portion dark brown. Mesonotum (Fig. 13B, E) region between lateral carinae stramineous with pair of elongated dark brown maculae near lateral carinae. Forewings (Fig. 13B-C, E-F) light brown with veins white; white stripes within cells. Legs stramineous with some elongated dark brown maculae. Abdomen (Fig. 13B-C, E-F) with several elongated dark brown maculae starting from sensory pits and extending posteriorly; dark brown maculae forming continuous longitudinal line between row of sensory pits and isolated one.

HEAD AND THORAX. Vertex (Fig. 13B, E) hexagonal, as long as half its width, as long as half of pronotum length, with slight median carina; posterior margin slightly elevated. Frons (Fig. 13A, D) with median carina and pair of sublateral carinae; sublateral carinae convergent and fused to each other ventrally (Fig. 13A, D); central plate (Fig. 13A, D) longer than wide at widest portion, visible in dorsal view (Fig. 13B, E), not extending anteriorly beyond sublateral carinae in lateral view (Fig. 13C, F); sides of frons partially visible in frontal view (Fig. 13A, D), fused above clypeus, with two rows of sensory pits in lateral view: anterior row with eight sensory pits, five dorsal ones grouped together, followed by three isolated ones ventrally to concavity on anterior margin of frons; posterior row with four sensory pits. Clypeus (Fig. 13C, F) not swollen, with dorsal portion extending anteriorly, consequently pushing frons and producing moderately produced snout; snout in dorsal view (Fig. 13B) longer than interocular

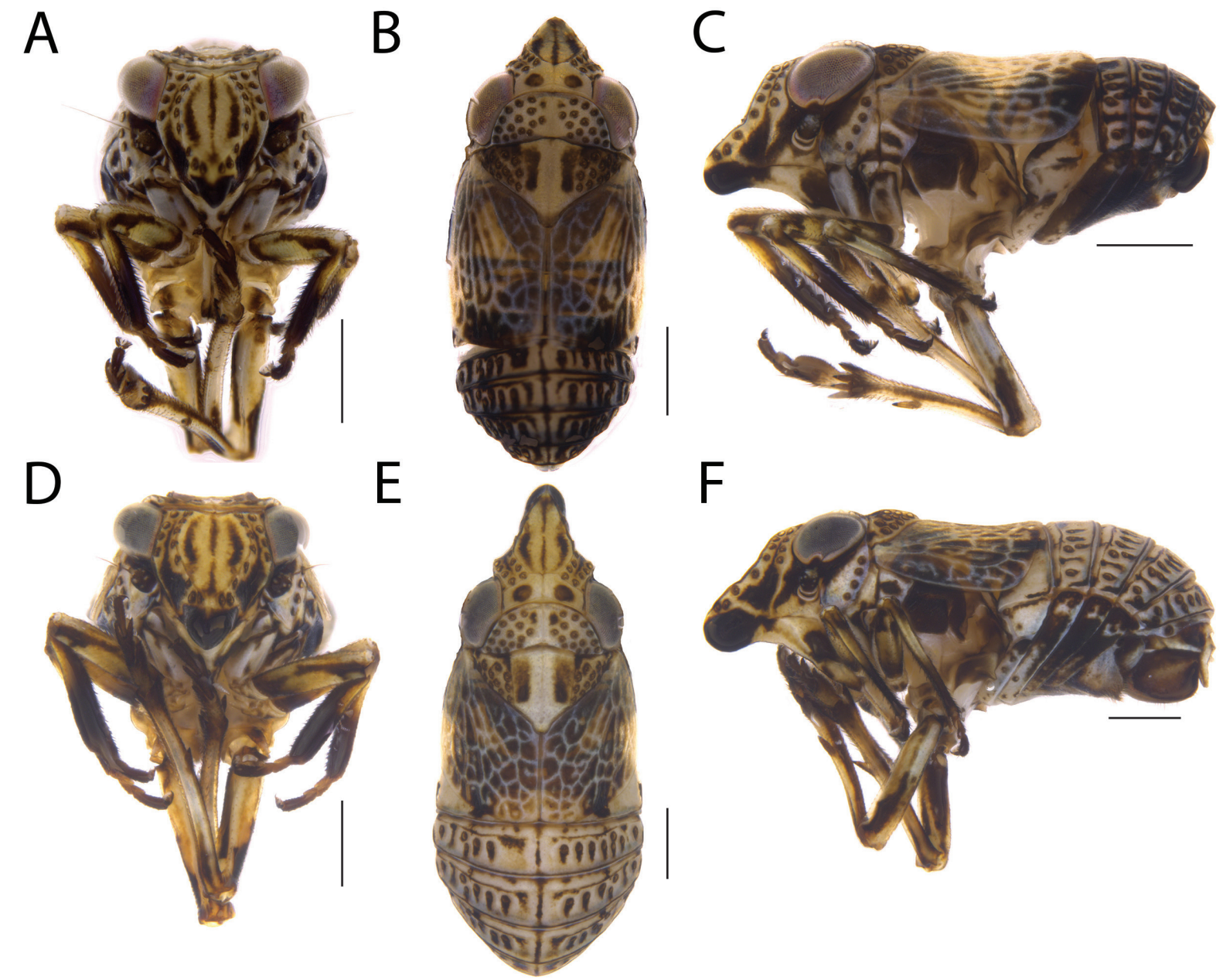

Fig. 13. Habitus of Fitchiella zahniseri sp. nov. A-C. Holotype, § (NMNH). A. Frontal view. B. Dorsal view. C. Lateral view. D-F. Paratype, + (INHS). D. Frontal view. E. Dorsal view. F. Lateral view. Scale bars $=0.5 \mathrm{~mm}$. 
distance (measured from base to tip), rounded in frontal and lateral view (Fig. 13C, F), with median carina. Ocelli absent. Eye oblong. Antenna short, with several small circular structures visible on pedicel. Pronotum (Fig. 13B, E) semicircular, shorter than half its width; posterior margin straight; with median carina; surface of disc almost completely covered by 15 sensory pits on each side; lateral lobe of pronotum (Fig. 13C, F) with four sensory pits arranged in a row. Mesonotum (Fig. 13B, E) with slight median carina and pair of lateral carinae; region between lateral carinae depressed, without sensory pits; region outerad of lateral carinae with 11 to 12 sensory pits on each side. Brachypterous, with reticulated venation. Legs simple, with carinae and setae; tibia III with single median spine.

Abdomen. Terga with longitudinal carina. Tergite III (Figs 13C, F, 26F) without sensory pits. Tergite IV (Figs 13C, F, 26F) with one row of four to seven (four in holotype) sensory pits, with penultimate one slightly displaced, followed by single isolated ventral one. Tergite V (Figs 13C, F, 26F) with one row of four to five (five in holotype) sensory pits, with penultimate one slightly displaced, followed by
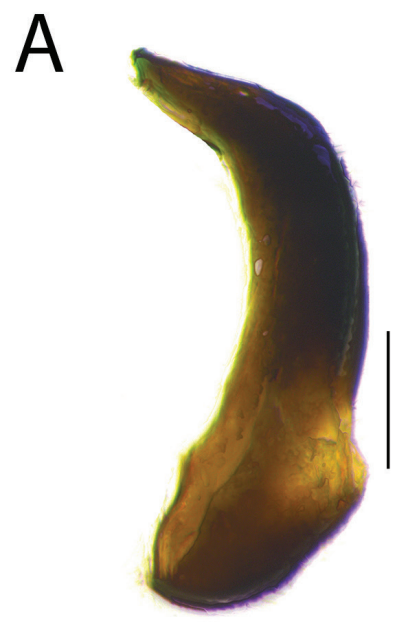

$\mathrm{E}$

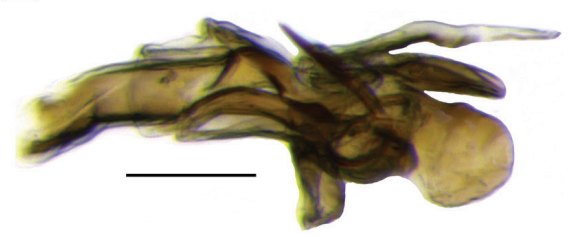

G

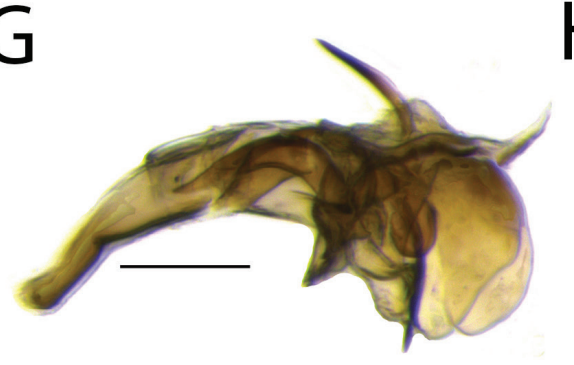

B
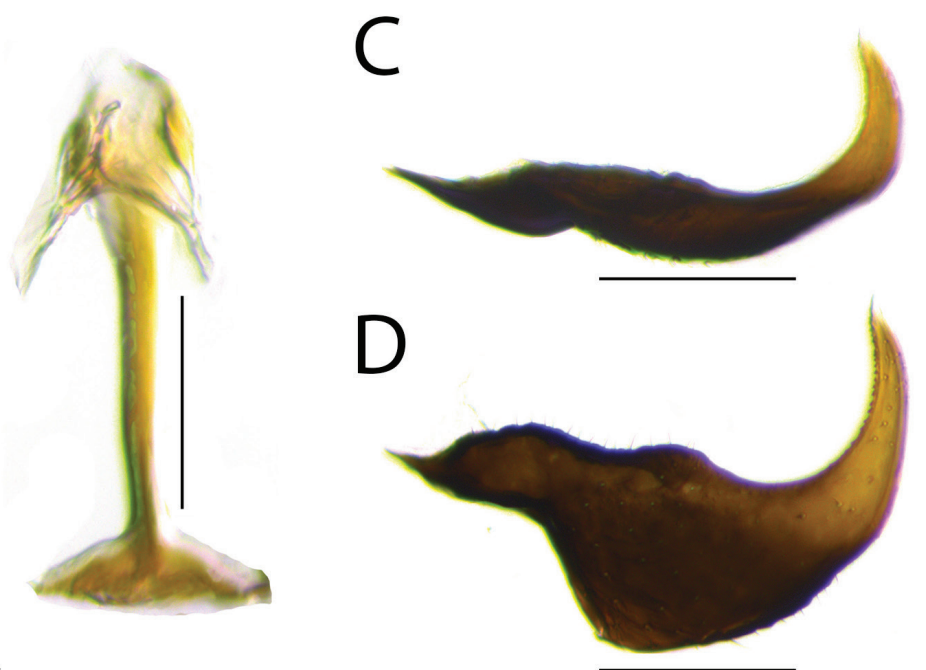

$\mathrm{F}$

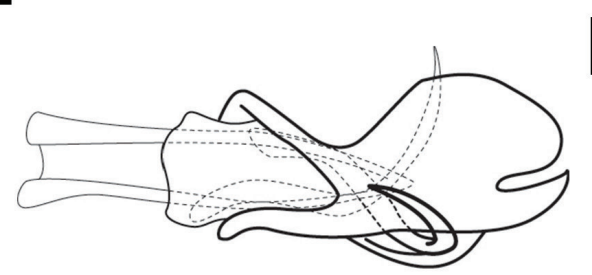

$\mathrm{H}$
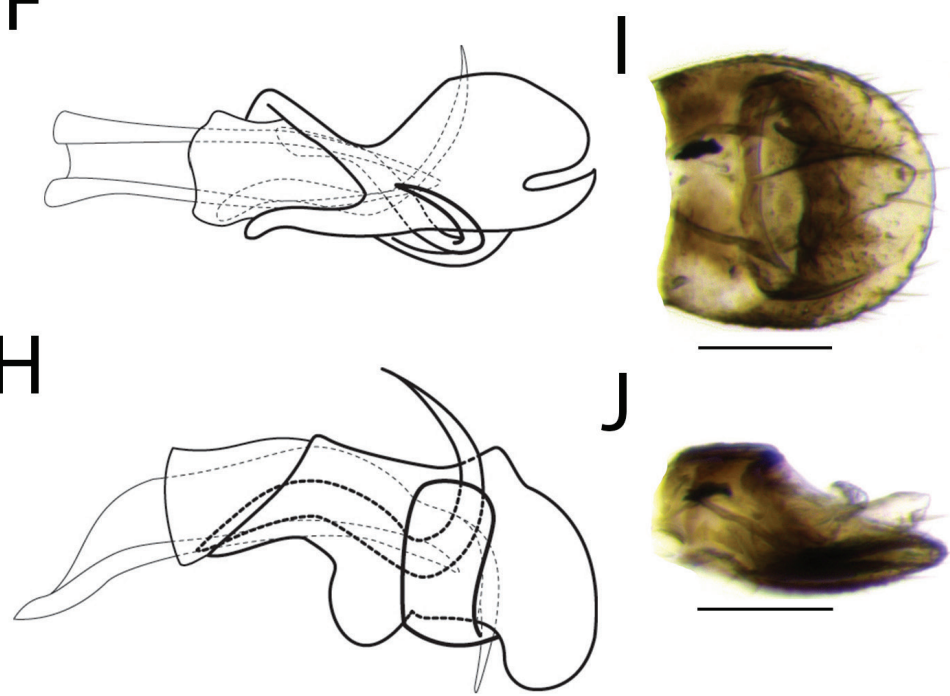

Fig. 14. Male terminalia of Fitchiella zahniseri sp. nov., holotype (NMNH). A. Pygofer, lateral view. B. Connective, anterior view. C-D. Style. C. Dorsal view. D. Lateral view. E-H. Phallus. E-F. Dorsal view. G-H. Lateral view. I-J. Anal tube. I. Dorsal view. J. Lateral view. Scale bars $=0.1 \mathrm{~mm}$. 
single isolated ventral one. Tergites VI and VII (Figs 13C, F, 26F) with one row of four to five (five in holotype) sensory pits, with penultimate one slightly displaced, followed by isolated ventral pair aligned diagonally. Tergite VIII (Fig. 26F) with one sensory pit.

Male terminalia. Pygofer (Fig. 14A) narrow, with anterior margin deeply concave; posterior margin almost straight, except for slight concavity near ventral portion. Connective (Fig. 14B) inverted Y-shaped, with support bridge with dorsal lap. Style (Fig. 14C-D) hook-like; anterior portion pointed; caudal portion strongly curved anterodorsally and converging towards the other in dorsal view (Fig. 14C); dorsal margin (Fig. 14D) with slight protuberance on median third; ventral margin (Fig. 14D) with straight angle between anterior and middle third, after that mostly rounded; median portion (Fig. 14D) longer than high, setose; apex serrated. Phallobase (Fig. 14E-H) sclerotized, symmetrical, with two defined lobes; apex with pair of lobes truncate in dorsal view (Fig. 14E-F), rounded in lateral view (Fig. 14G-H), with dorsal process near apex in lateral view (Fig. 14G-H) surrounding apical half of aedeagus; with flap covering aedeagal hook in lateral view (Fig. 14G-H). Aedeagus (Fig. 14E-F) apex

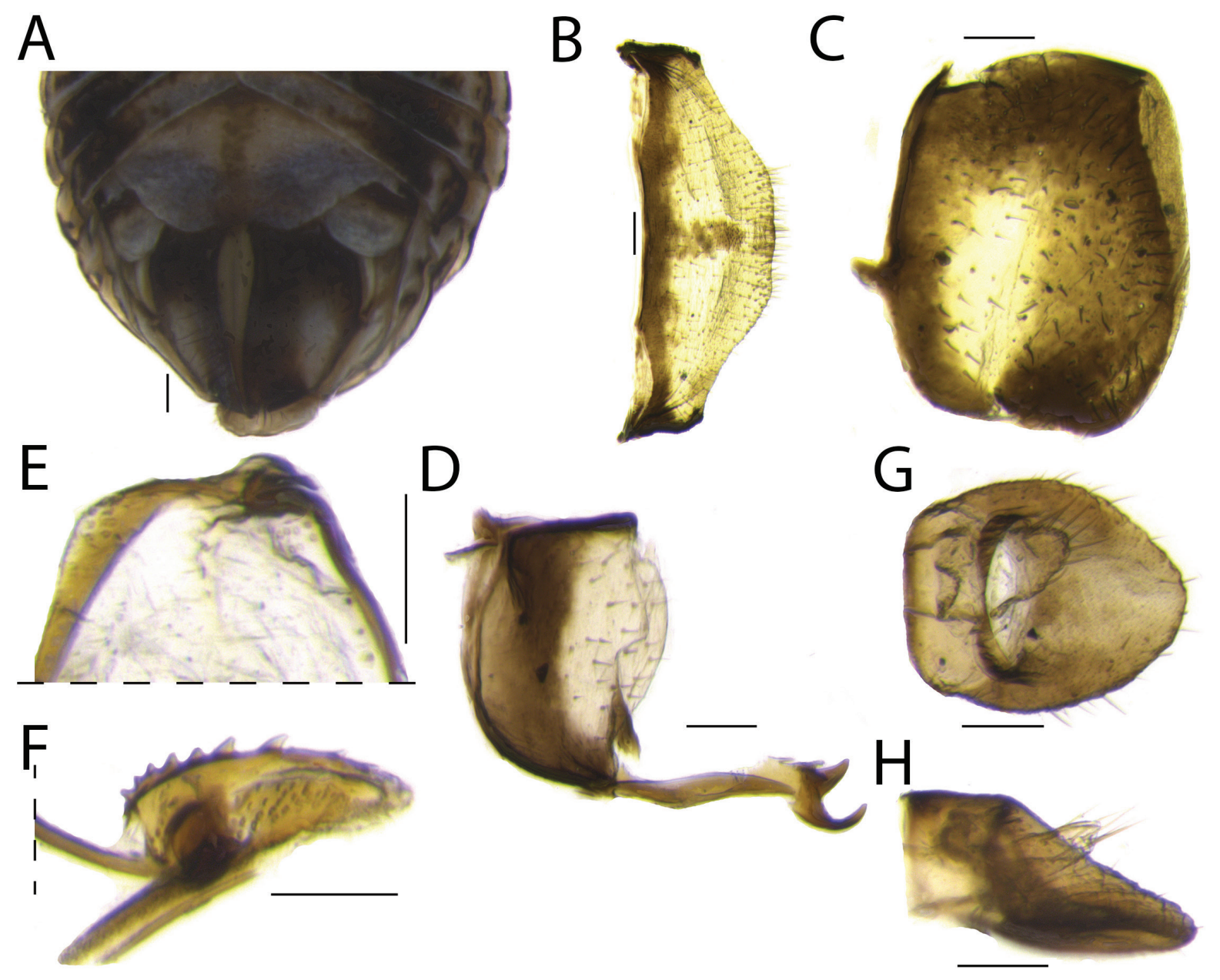

Fig. 15. Female terminalia of Fitchiella zahniseri sp. nov., paratype (INHS). A. External female terminalia, ventral view. B. Sternite VII, ventral view. C. Gonoplac, lateral view. D. Anterior connective lamina of gonapophysis VIII, ventral view. E-F. Posterior connective lamina of gonapophysis IX. E. Connective part in dorsal view. F. Distal part in lateral view. G-H. Anal tube. G. Dorsal view. H. Lateral view. Scale bars $=0.1 \mathrm{~mm}$. 
narrow and open dorsally; with pair of hooks, one curved anterodorsally, other curved posteroventrally in lateral view (Fig. 14G-H). Suspensorium V-shaped. Segment X of anal tube (Fig. 14I-J) as long as wide; posterior margin (Fig. 14I) rounded; segment XI of anal tube almost reaching posterior margin of segment $X$; setose.

Female terminalia. Posterior margin of sternite VII (Fig. 15B) with median portion produced, setose. Gonoplac (Fig. 15C) sclerotized, sub-rectangular with apex truncate, setose. Anterior connective lamina of gonapophysis VIII (Fig. 15D) with two conspicuous apical teeth: innermost narrower and longer than outer one; with two small spines laterad of outer tooth. Posterior connective lamina of gonapophysis IX (Fig. 15E-F) distal part in lateral view (Fig. 15F) with longitudinal row of nine to 10 wide, triangular, inclined spines; middle portion with several pits (Fig. 15F); apex setose (Fig. 15F). Segment X of anal tube (Fig. 15G-H) longer than wide at widest portion; posterior margin (Fig. 15G) with apex rounded; setose.

\section{Remarks}

The new species resembles Fitchiella robertsoni (type species) and F. brachyrhina sp. nov., sharing the following characteristics: (1) pattern of coloration (Figs 11, 13); (2) brachypterous with reticulated venation and with stripes within cells (Figs 11B, E, 13B, E); (3) overall shape of snout (Figs 11C, F, 13C, $\mathrm{F})$, with anteroventrally produced clypeus, concavity on anterior margin of frons, and knobbed apex (Figs 11C, 13C, E); and (4) pattern of distribution of abdominal sensory pits (Fig. 26E-F). However, the new species can be distinguished from these two similar species by the following combination of characteristics: (1) snout (Fig. 13C, F) intermediate in length between the two previously described species, with apex less rounded and swollen than in F. robertsoni; and (2) lateral lobe of pronotum with four sensory pits (Fig. 13C, F). Other species in Fitchiella, such as F. rufipes Lawson, 1933 and F. grandis Lawson, 1933, among other, are easily distinguished from these species, F. robertsoni and F. brachyrhina sp. nov., by: (1) overall shape of snout, which is straight in some species, without concavity on anterior margin of frons and flattened laterally; (2) different pattern of coloration; (3) forewings without reticulated venation; (4) dorsoventrally expanded legs, more or less foliaceous in some species; and (5) different pattern of distribution of abdominal sensory pits (based on photographs of F. rufipes). More studies are necessary to better define Fitchiella.

Genus Nenema Emeljanov, 1996

Nenema virgata (Doering, 1941)

Figs $16-17,26 \mathrm{G}$

Aphelonema virgata Doering, 1941: 206, pl. XIII: fig. 4, pl. XIV: figs 16, 21, pl. XV: figs 11, 22.

Aphelonema (Nenema) virgata - Emeljanov 1996: 834 (proposed new subgenus of Aphelonema). Nenema virgata - Gnezdilov 2013: 212.

\section{Diagnosis}

Body mainly black and pale-yellow, with central plate of frons white and sublateral carinae black, forewing dark brown to black with oblique white stripe over claval suture, abdomen almost black, with broad pale-yellow median longitudinal stripe dorsally and narrower discontinuous white to paleyellow longitudinal stripes laterally, legs reddish brown (Fig. 16); clypeus swollen (Fig. 16A, C), with weak carina incomplete ventrally (Fig. 16A); abdominal tergites (Figs 16C, 26G) with one sensory pit followed by single isolated ventral sensory pit (tergite IV and $\mathrm{V}$ ) or isolated pair of diagonally aligned ventral sensory pits (tergites VI to VII). 


\section{Material examined}

MEXICO • 1 q; “COAH” [Coahuila de Zaragoza], Cuahtemoc rd., $\mathrm{Km} 7.4 ; 25.27970^{\circ} \mathrm{N}, 100.98747^{\circ} \mathrm{W}$; 2120 m a.s.l.; Oct. 2005; C. Dietrich leg.; vacuum sample; INHS • 1 क; same collection data as for preceding; DNA voucher ENT4919; DZRJ.

\section{Description}

Body Length. Females $=3.3$ to $3.5 \mathrm{~mm}$.

Coloration. Body mainly black and pale-yellow (Fig. 16A-C). Central plate of frons (Fig. 16A) white, sublateral carinae black and side of frons pale-yellow in frontal view. Clypeus mainly black, with dorsal portion pale-yellow (Fig. 16A). Vertex (Fig. 16B) white to pale-yellow with two pairs of brown maculae; pronotum and mesonotum (Fig. 16B) with pale-yellow continuous median longitudinal broad stripe. Gena (Fig. 16C) pale-yellow; with oblique black stripe starting at ventral margin of eyes, reaching clypeus and drop-like black macula near anteroventral margin of eye. Lateral lobe of pronotum (Fig. 16C) with anterior portion black and posterior portion pale-yellow continuous to forewing stripe. Forewing (Fig. 16B-C) dark brown to black, with oblique white stripe over claval suture. Abdomen (Fig. 16B-C) dark brown, almost black, with broad pale-yellow median longitudinal stripe dorsally and narrower discontinuous white to pale-yellow longitudinal stripes laterally. Legs (Fig. 16A, C) reddish brown.

HeAd AND thorax. Vertex (Fig. 16B) hexagonal, as long as half its width, as long as pronotum; posterior margin slightly elevated. Frons (Fig. 16A) with weak median carina and pair of sublateral carinae; sublateral carinae reaching clypeus ventrally (Fig. 16A); central plate (Fig. 16A) longer than wide at widest portion, not visible in dorsal view (Fig. 16B), not extending anteriorly beyond sublateral carinae in lateral view (Fig. 16C); sides of frons partially visible in frontal view (Fig. 16A), not fused above clypeus, with two rows of sensory pits on each side in lateral view (Fig. 16C): anterior row with eight sensory pits, two ventral ones slightly displaced; posterior row with four sensory pits, ventral one slightly isolated. Clypeus (Fig. 16C) swollen, with weak carina incomplete ventrally. Ocelli absent. Eye oblong. Antenna short, with several small circular structures visible on pedicel. Pronotum (Fig. 16B) semicircular, shorter than half its width, without median carina; median portion of disc without sensory pits and with posterior portion slightly elevated; lateral portion of disc with 15 to 17 sensory pits; lateral lobe of pronotum (Fig. 16C) with one sensory pit. Mesonotum (Fig. 16B) without median carina and
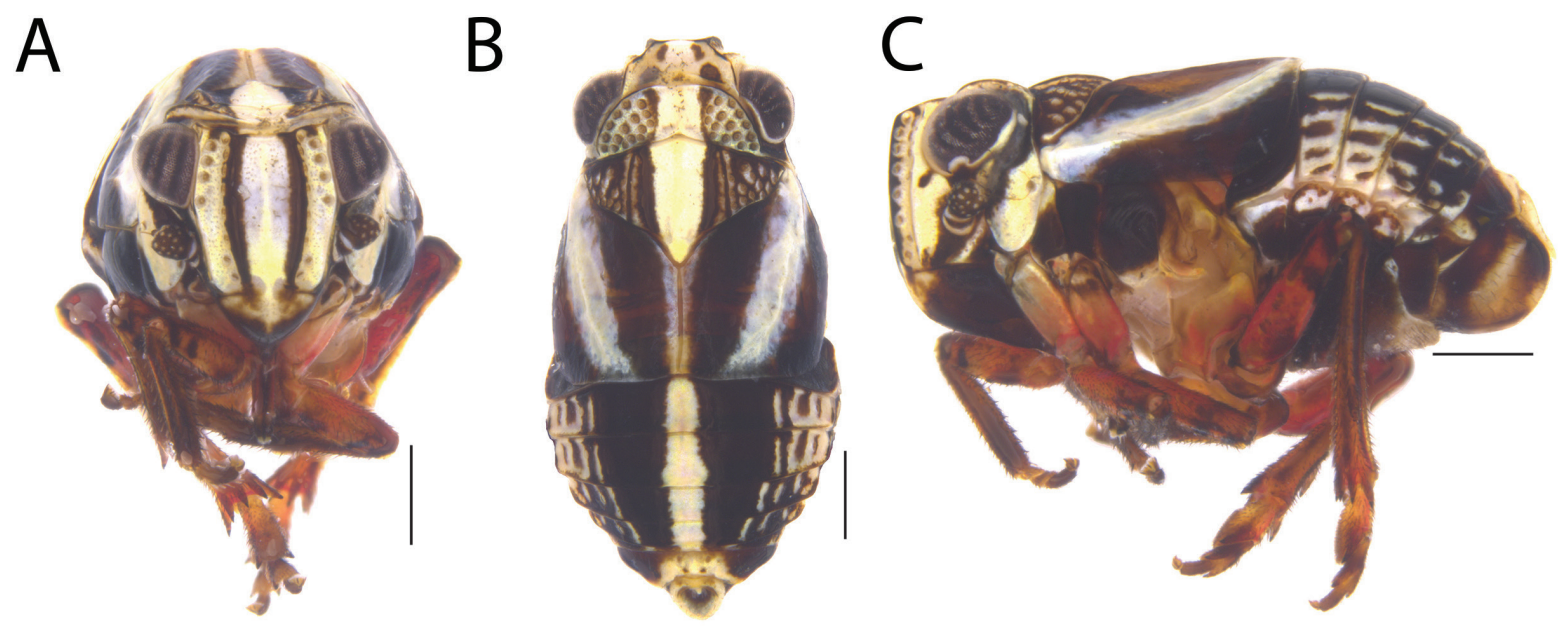

Fig. 16. Habitus of Nenema virgata (Doering, 1941), q (INHS). A. Frontal view. B. Dorsal view. C. Lateral view. Scale bar $=0.5 \mathrm{~mm}$. 
with pair of lateral carinae; region between lateral carinae depressed, without sensory pits; region laterad of lateral carina with 14 sensory pits. Brachypterous, with reduced venation. Legs simple, with carinae and setae; tibia III with single median spine.

AbDomen. Terga without longitudinal carinae. Tergite III (Figs 16C, 26G) without sensory pits. Tergites IV and V (Figs 16C, 26G) with one sensory pit followed by single isolated ventral one. Tergites VI and VII (Figs 16C, 26G) with one sensory pit followed by isolated ventral pair aligned diagonally. Tergite VIII with one sensory pit.

Female terminalia. Posterior margin of sternite VII (Fig. 17B) with sub-rectangular median projection; lateral portions concave; setose. Gonoplac (Fig. 17C) sclerotized, sub-rectangular with apex convex; setose. Anterior connective lamina of gonapophysis VIII (Fig. 17D) with three apical teeth: all subequal, two outermost closer to each other than to inner one. Posterior connective lamina of gonapophysis IX (Fig. 17E-F) distal part in lateral view (Fig. 17F) with longitudinal row of six wide triangular spines;

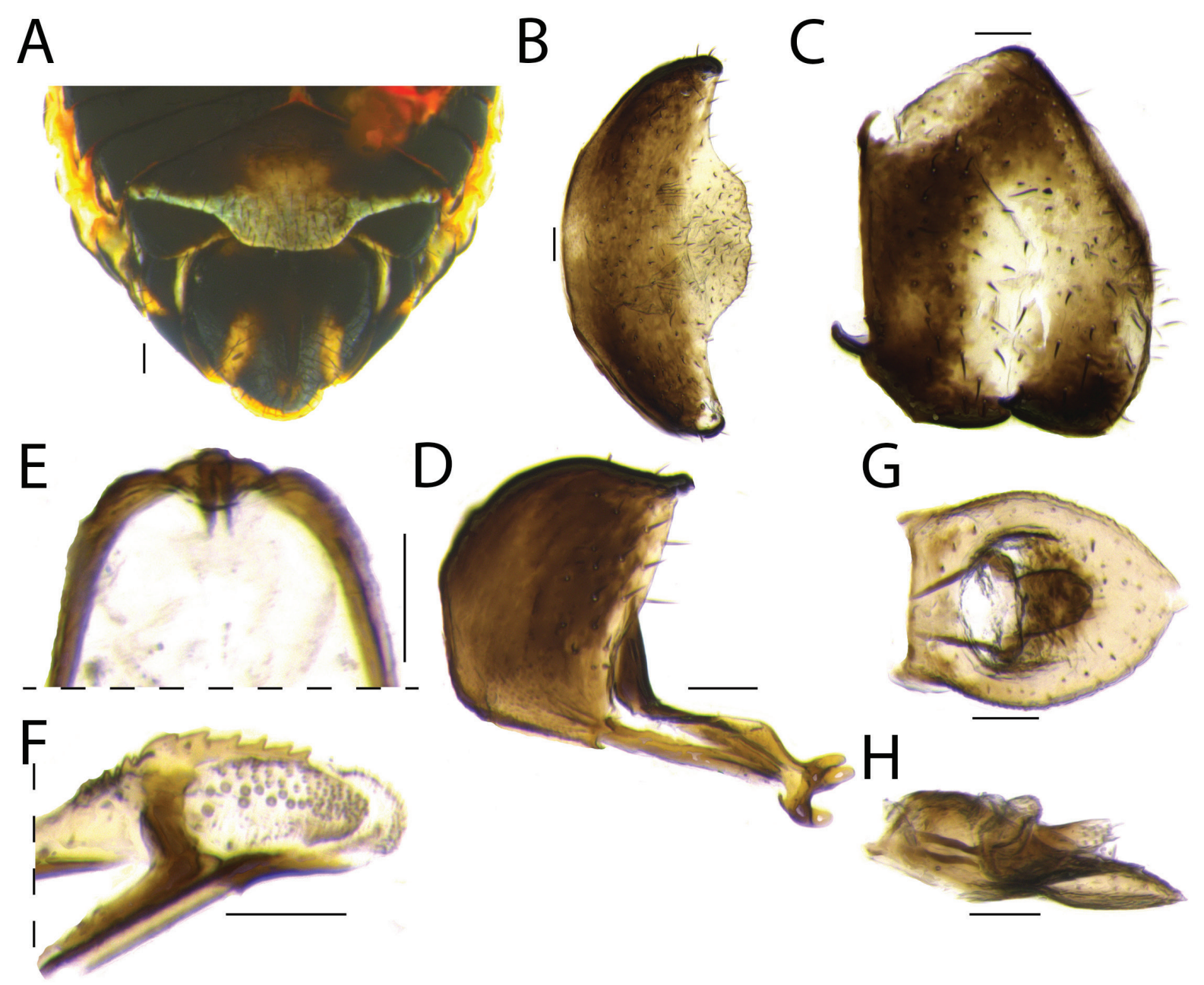

Fig. 17. Female terminalia of Nenema virgata (Doering, 1941) (INHS). A. External female terminalia, ventral view. B. Sternite VII, ventral view. C. Gonoplac, lateral view. D. Anterior connective lamina of gonapophysis VIII, ventral view. E-F. Posterior connective lamina of gonapophysis IX. E. Connective part in dorsal view. F. Distal part in lateral view. G-H. Anal tube. G. Dorsal view. H. Lateral view. Scale bars $=0.1 \mathrm{~mm}$. 
spines extending anteriorly to stem (Fig. 17F); middle portion with several pits (Fig. 17F); apex setose (Fig. 17F). Segment X of anal tube (Fig. 17G-H) longer than wide at widest portion; caudal margin (Fig. 17G) pointed with apex rounded; setose.

\section{Remarks}

This species was originally placed in Aphelonema and later transferred to Nenema by Emeljanov (1996). This species has all the diagnostic combination of characteristics of this genus (see Discussion), so we are following Emeljanov's allocation. The original description and illustrations of the dorsal view of the body and lateral view of the head by Doering (1941) suffice to identify this species. Unfortunately, we could not redescribe male terminalia of this species due to lack of male specimens. The original description does not include information about abdominal sensory pits or female terminalia. As indicated by Doering (1941), this species is similar to Nenema bivittata (Ball, 1902), Nenema confragosa (Doering, 1941) and Nenema convergens (Bunn, 1930) and can be distinguished from these species by the pattern of coloration (Doering 1941).

Genus Protrocha Emeljanov, 1996

Protrocha nesolitaria (Caldwell, 1945)

Figs $18-20,26 \mathrm{H}$

Aphelonema nesolitaria Caldwell 1945: 96, pl. I: figs 12, 13.

Aphelonema (Protrocha) nesolitaria - Emeljanov 1996: 834 (proposed new subgenus of Aphelonema). Protrocha nesolitaria - Gnezdilov 2013: 212.

\section{Diagnosis}

Body mainly light yellowish-brown, with broad continuous pale-yellow longitudinal stripe crossing vertex, pronotum and mesonotum; abdomen with one median and two pairs of lateral black longitudinal stripes (Fig. 18); frons with median carina (Fig. 18A, D), sublateral carinae ventrally curved (Fig. 18A, D), central plate round, slightly extending anteriorly beyond sublateral carinae in lateral view (Fig. 18C, F); sides of frons with two rows of sensory pits on each side (Fig. 18C); abdominal tergites (Figs 18C, F, $26 \mathrm{H}$ ) with row of sensory pits followed by isolated ventral pair (tergite IV) or one isolated row of three sensory pits almost aligned vertically (tergites V to VII), tergite VIII with more than one sensory pit.

\section{Material examined}

MEXICO • 1 đ̧; "DUR" [Durango], W of Durango, route 40, Km 31; $23.94487^{\circ} \mathrm{N}, 104.85435^{\circ} \mathrm{W}$; 2500 m a.s.1.; Oct. 2005; C. Dietrich leg.; vacuum sample; DNA voucher ENT4914; INHS • 1 क; same collection data as for preceding; INHS.

\section{Description}

Body Length. Male $=2.6 \mathrm{~mm}$; female $=3.0 \mathrm{~mm}$.

Coloration. Body mainly light yellowish-brown (Fig. 18A-F). Vertex, pronotum and mesonotum (Fig. 18B, E) with broad continuous pale-yellow longitudinal stripe (faint on vertex). Gena (Fig. 18C, F) with two black maculae, one in front of antenna and another under eye. Clypeus (Fig. 18F) with black maculae laterally in females. Forewings hyaline (Fig. 18B-C, E-F). Metathorax with wide black macula (Fig. 18B-C, E-F). Abdomen (Fig. 18B, E) with one median and two pairs of lateral black longitudinal stripes; lateral margin of tergites with thin white longitudinal stripe. 
HEAD AND THORAX. Vertex (Fig. 18B, E) hexagonal, almost as long as half its width, as long as pronotum; posterior margin slightly elevated. Frons (Fig. 18A, D) with median carina and pair of sublateral carinae; sublateral carinae convergent and almost fused to each other ventrally (Fig. 18A, D); central plate (Fig. 18A, D) almost as long as wide at widest portion, not visible in dorsal view (Fig. 18B, E), slightly extending anteriorly beyond sublateral carinae in lateral view (Fig. 18C, F); sides of frons partially visible in frontal view (Fig. 18A), almost fused above clypeus, with two rows of sensory pits on each side in lateral view (Fig. 18C, F): anterior row with eight sensory pits, five dorsal ones grouped together, followed by sixth isolated one aligned with antenna and pair of ventral ones isolated next to clypeus; posterior row with four sensory pits. Clypeus (Fig. 18C, F) not swollen, with median carina, with protuberance in lateral view. Ocelli absent. Eye oblong. Antenna short, with several small circular structures visible on pedicel. Pronotum (Fig. 18B, E) semicircular, shorter than half of its width, with median carina; median portion of disc without sensory pits; lateral portion of disc with 13 to 15 sensory pits; lateral lobe (Fig. 18C, F) with four sensory pits arranged in group. Mesonotum (Fig. 18B, E) with median carina and pair of lateral carinae; region between lateral carinae depressed, without sensory pits; region laterad of lateral carinae with 10 to 11 sensory pits. Brachypterous, with reduced venation. Legs simple, with carinae and setae; tibia III with single median spine.
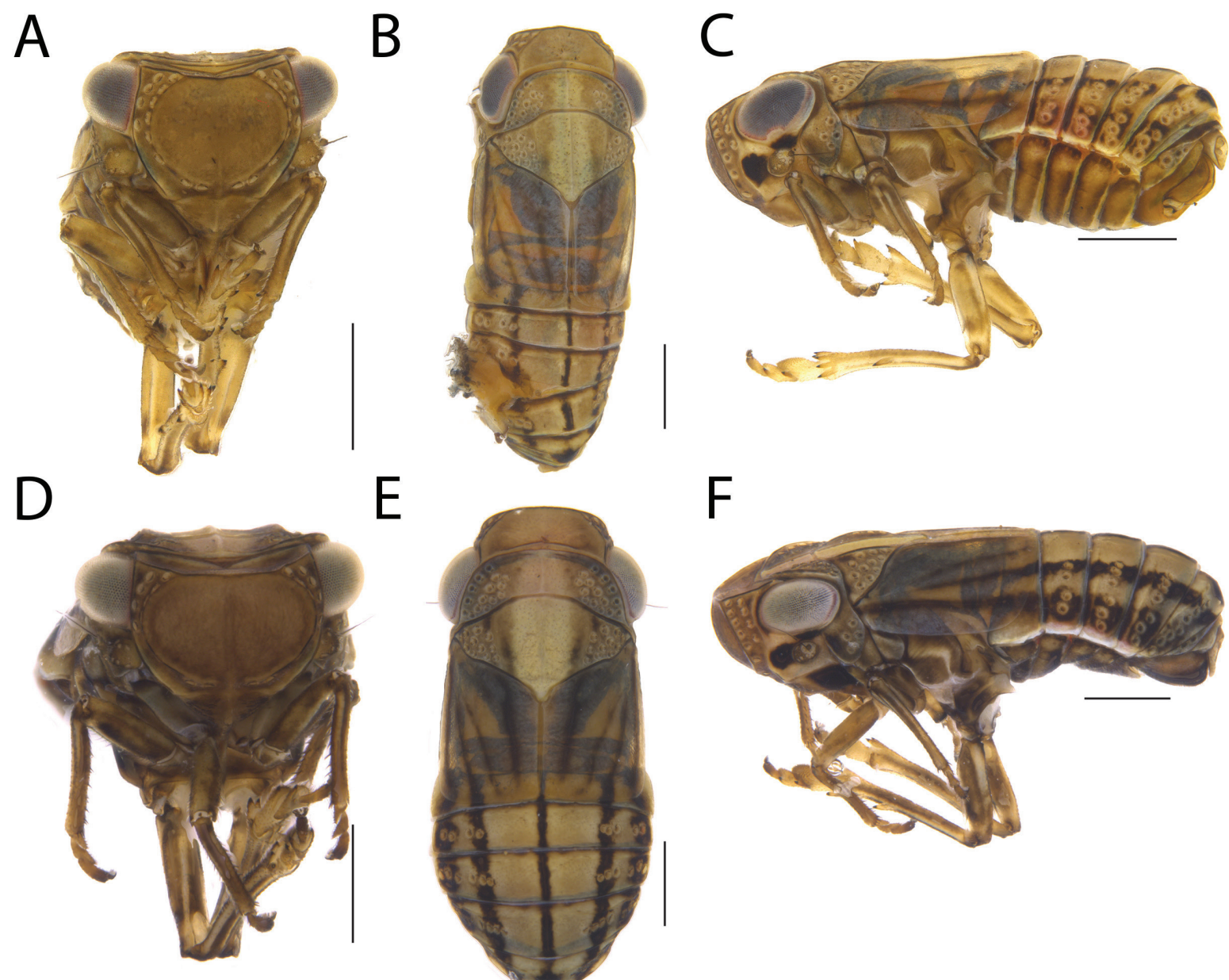

F
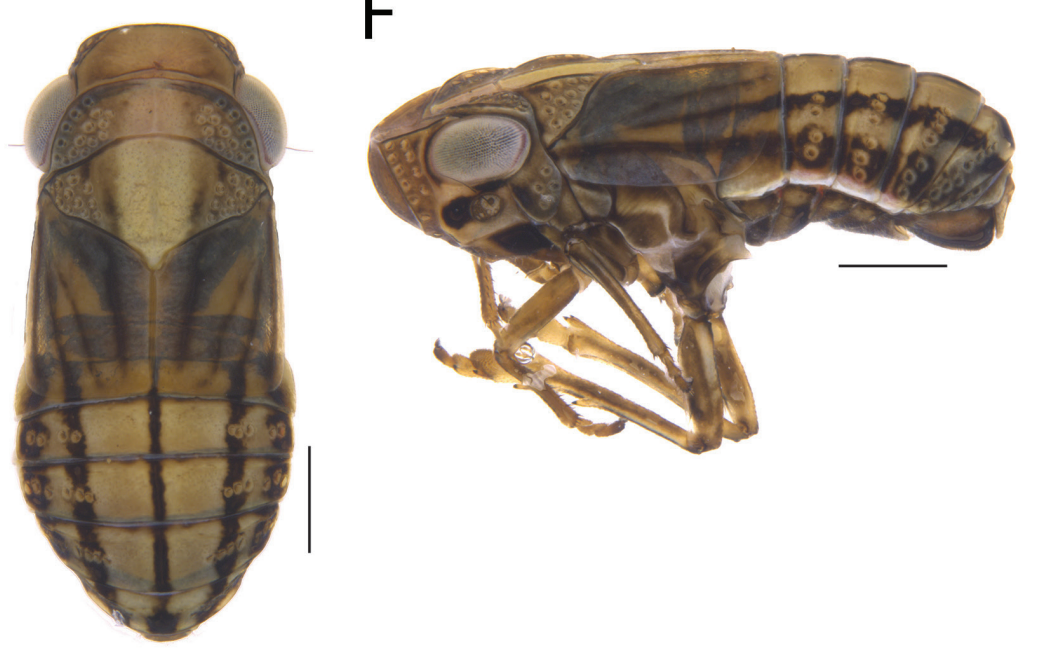

Fig. 18. Habitus of Protrocha nesolitaria (Caldwell, 1945). A-C. $\widehat{O}$ (INHS). A. Frontal view. B. Dorsal view. C. Lateral view. D-F. क (INHS). D. Frontal view. E. Dorsal view. F. Lateral view. Scale bars = $0.5 \mathrm{~mm}$. 
ABDomen. Terga with longitudinal carina. Tergite III (Figs 18C, F, 26H) without sensory pits. Tergite IV (Figs 18C, F, 26H) with one row of two sensory pits followed by isolated pair aligned vertically. Tergites V to VII (Figs 18C, F, 26H) with one row of two to four sensory pits followed by isolated row of three to four sensory pits aligned almost vertically. Tergite VIII (Fig. 26H) with three sensory pits.

Male terminalia. Pygofer (Fig. 19A) narrow, with anterior margin deeply concave; posterior margin dorsal third with convexity, middle third slightly convex, ventral third with convexity. Connective (Fig. 19B) inverted Y-shaped, with support bridge with dorsal flap. Style (Fig. 19C-D) hook-like; anterior portion pointed; caudal portion strongly curved anterodorsally, converging towards the other in dorsal view (Fig. 19C); dorsal margin (Fig. 19D) almost straight to caudal portion; ventral margin (Fig. 19D) with straight angle between anterior third and middle third, remainder rounded; median portion (Fig. 19D) as long as high, setose; apex serrated (Fig. 19D). Phallobase (Fig. 19E-H) sclerotized, symmetrical, with two defined lobes; apex with pair of lobes truncated in dorsal view (Fig. 19E-F)
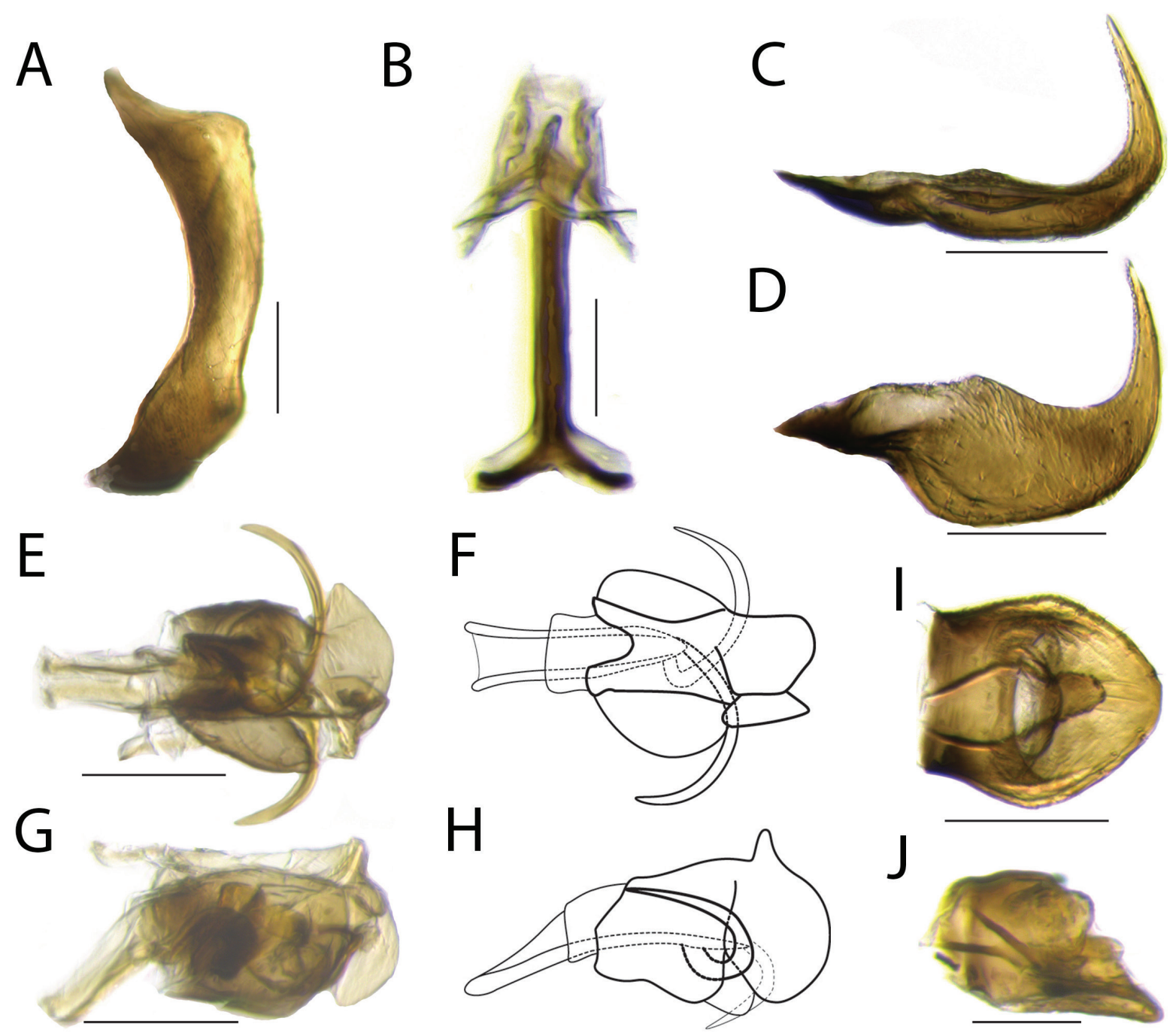

Fig. 19. Male terminalia structures of Protrocha nesolitaria (Caldwell, 1945) (INHS). A. Pygofer, lateral view. B. Connective, anterior view. C-D. Style. C. Dorsal view. D. Lateral view. E-H. Phallus. E-F. Dorsal view. G-H. Lateral view. I-J. Anal tube. I. Dorsal view. J. Lateral view. Scale bars = $0.1 \mathrm{~mm}$. 
and rounded in lateral view (Fig. 19G-H); sides expanded and rounded (Fig. 19E-F); with pointed dorsal process near apex in lateral view (Fig. 19G-H), surrounding apical half of aedeagus. Aedeagus (Fig. 19E-F) with apex narrow and open dorsally, with pair of aedeagal hooks, each curved laterally and crossing the other in dorsal view (Fig. 19E-F); one aedeagal hook curved anterodorsally and another curved anteroventrally in lateral view (Fig. 19G-H). Suspensorium V-shaped. Segment X of anal tube (Fig. 19I-J) as long as wide; posterior margin (Fig. 19I) rounded; setose.

Female terminalia. Posterior margin of sternite VII (Fig. 20B) with median portion roundly produced; setose. Gonoplac (Fig. 20C) sclerotized, sub-triangular, setose. Anterior connective lamina of gonapophysis VIII (Fig. 20D) with three large apical teeth: innermost larger than outer ones; and smaller teeth between and laterad of larger ones. Posterior connective lamina of gonapophysis IX (Fig. 20E-F) distal part with longitudinal row of eight long, narrow, triangular oblique spines in lateral view; middle portion with several pits (Fig. 20F); apex setose (Fig. 20F); region between distal parts with patch of small setae (Fig. 20E). Segment X of anal tube (Fig. 20G-H) as long as wide at widest portion; posterior margin (Fig. 20G) with apex rounded; setose.

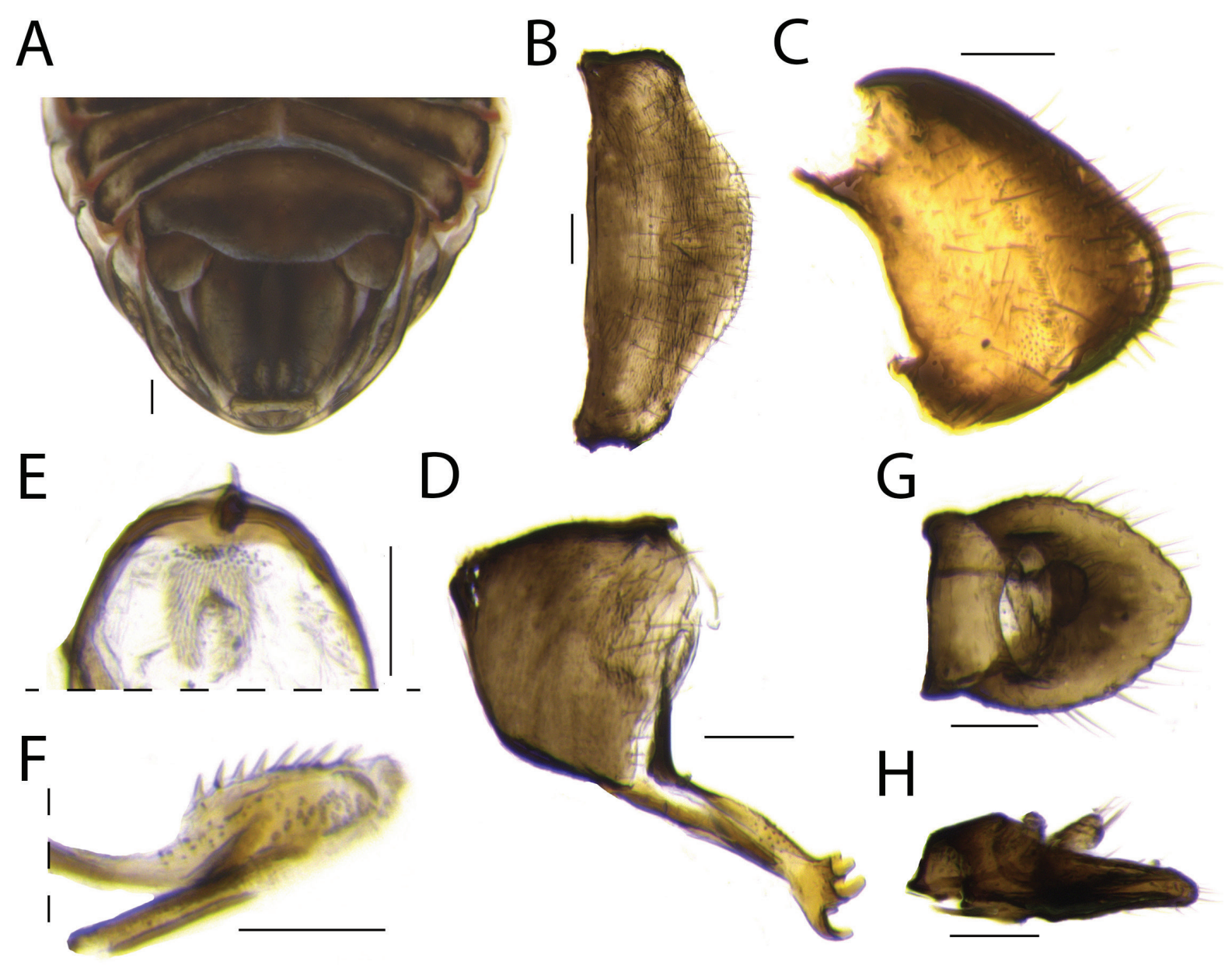

Fig. 20. Female terminalia of Protrocha nesolitaria (Caldwell, 1945), $q$ (INHS). A. External female terminalia, ventral view. B. Sternite VII, ventral view. C. Gonoplac, lateral view. D. Anterior connective lamina of gonapophysis VIII, ventral view. E-F. Posterior connective lamina of gonapophysis IX. E. Connective part in dorsal view. F. Distal part in lateral view. G-H. Anal tube. G. Dorsal view. H. Lateral view. Scale bars $=0.1 \mathrm{~mm}$. 


\section{Remarks}

This species was originally placed in Aphelonema and was later transferred to Protrocha by Emeljanov (1996). However, this species has only part of the diagnostic combination of generic characteristics (see Discussion), sharing other characteristics with Aphelonema, such as (1) sides of frons in upper half with two parallel rows of sensory pits (Fig. 18C, F); and (2) abdomen with sensory pits aligned in one row (Fig. 18C, F, 26H). Additionally, the male terminalia (Fig. 19) of this species are similar to those observed in other species of Aphelonema (as A. brevata, see Fig. 2) and when compared with the type species of Protrocha, the central plate of frons and the distribution of sensory pits on sides of frons are different. We chose to follow Emeljanov's allocation of this species in Protrocha because we couldn't check the holotype of this species. Specimens at hand were identified based on the original description and illustrations of Caldwell (1945) mainly because of: (1) the shape of vertex, central plate of frons and pronotum; (2) the lateral lobe of pronotum with four grouped sensory pits (Fig. 18C, F); and (3) the coloration with five black stripes on abdomen (Fig. 18B, E). Unfortunately, we were unable to study the holotype (not found at NMNH). The holotype is a female and the original description does not include information about abdominal sensory pits. The only information on the female terminalia given by Caldwell (1945) is "Last ventral segment of female with a broad caudal flap gently notched in the center." However, our female (which was dissected) does not have the mentioned median notch of sternite VII.

\section{Protrocha nigrilutea sp. nov. urn:lsid:zoobank.org:act:82B4DCB5-D192-4D93-86E0-55B01D97892C}

Figs 21-23, 26I

\section{Diagnosis}

Body mainly black with vertex, pronotum and mesonotum light yellowish-brown with white median longitudinal stripe continuing over abdomen; forewing black with clavus hyaline yellow and with broad white stripe along claval suture (Fig. 21); frons with median carina (Fig. 21A, D), sublateral carinae ventrally horizontally straight (Fig. 21A, D), central plate oblong, not extending anteriorly beyond sublateral carinae in lateral view (Fig. 21C, F); sides of frons with several sensory pits not arranged in rows (Fig. 21C, F) and pair of isolated sensory pits placed under horizontal portion of sublateral carinae, just above clypeus, on each side (Fig. 21A, D); abdominal tergites (Figs 21C, F, 26I) with row (tergite IV) or group of sensory pits followed by isolated ventral pair (tergite IV) or group of three to four sensory pits (tergites V to VII).

\section{Etymology}

The specific name 'nigrilutea' ('nigri', Latin = 'black'; 'lutea', Latin = 'yellow') refers to the coloration of this species.

\section{Material examined}

Holotype

MEXICO • ô; "MICH" [Michoacán], Morelia-Guadalajara, route 15, Km 313; $19.98883^{\circ} \mathrm{N}$, $101.79947^{\circ}$ W; 1900 m a.s.l.; Oct. 2005; R. Rakitov leg.; sweep; DNA voucher ENT4921; INHS.

\section{Paratypes}

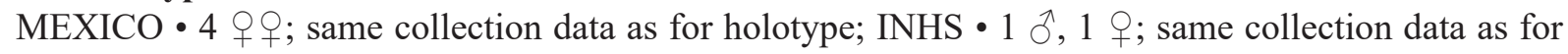
holotype; DZRJ.

\section{Description}

Body LenGth. Males $=2.5$ to $2.8 \mathrm{~mm}$; females $=3.4$ to $3.8 \mathrm{~mm}$. 
Coloration. Males and females with same coloration (Fig. 21A-F). Vertex, pronotum and mesonotum light yellowish-brown with broad median longitudinal white stripe (Fig. 21B, E). Lateral lobe of pronotum (Fig. 21C, F) dorsally black and ventrally white. Frons pale (Fig. 21A, D); sides of frons, gena and clypeus black (Fig. 21C, F). Gena (Fig. 21C, F) with white macula along clypeus margin. Forewings (Fig. 21B-C, E-F) black, clavus hyaline yellow, with broad white stripe along claval suture. Legs (Fig. 21B-C, E-F) black with pale maculae on femora; tarsi brown. Abdomen (Fig. 21B-C, E-F) black with broad white longitudinal median stripe, with white longitudinal continuous stripe along lateral margins of tergites in lateral view (Fig. 21C, F), with some red maculae in between abdominal segments (Fig. 21F).

HEAD AND thORAX. Vertex (Fig. 21B, E) hexagonal, as long as half its width, as long as pronotum length; posterior margin slightly elevated. Frons (Fig. 21A, D) with median carina and pair of sublateral carinae; sublateral carinae convergent, almost fused to each other, ventrally horizontally straight (Fig. 21A, D); central plate (Fig. 21A, D) oblong, as long as wide at widest portion, not visible in dorsal view (Fig. 21B, E), not extending anteriorly beyond sublateral carinae in lateral view (Fig. 21C, F); sides of frons partially visible in frontal view, almost fused above clypeus (Fig. 21A, D), in lateral view with 21 sensory pits not arranged in rows and pair of isolated sensory pits placed under horizontal portion of sublateral carinae,
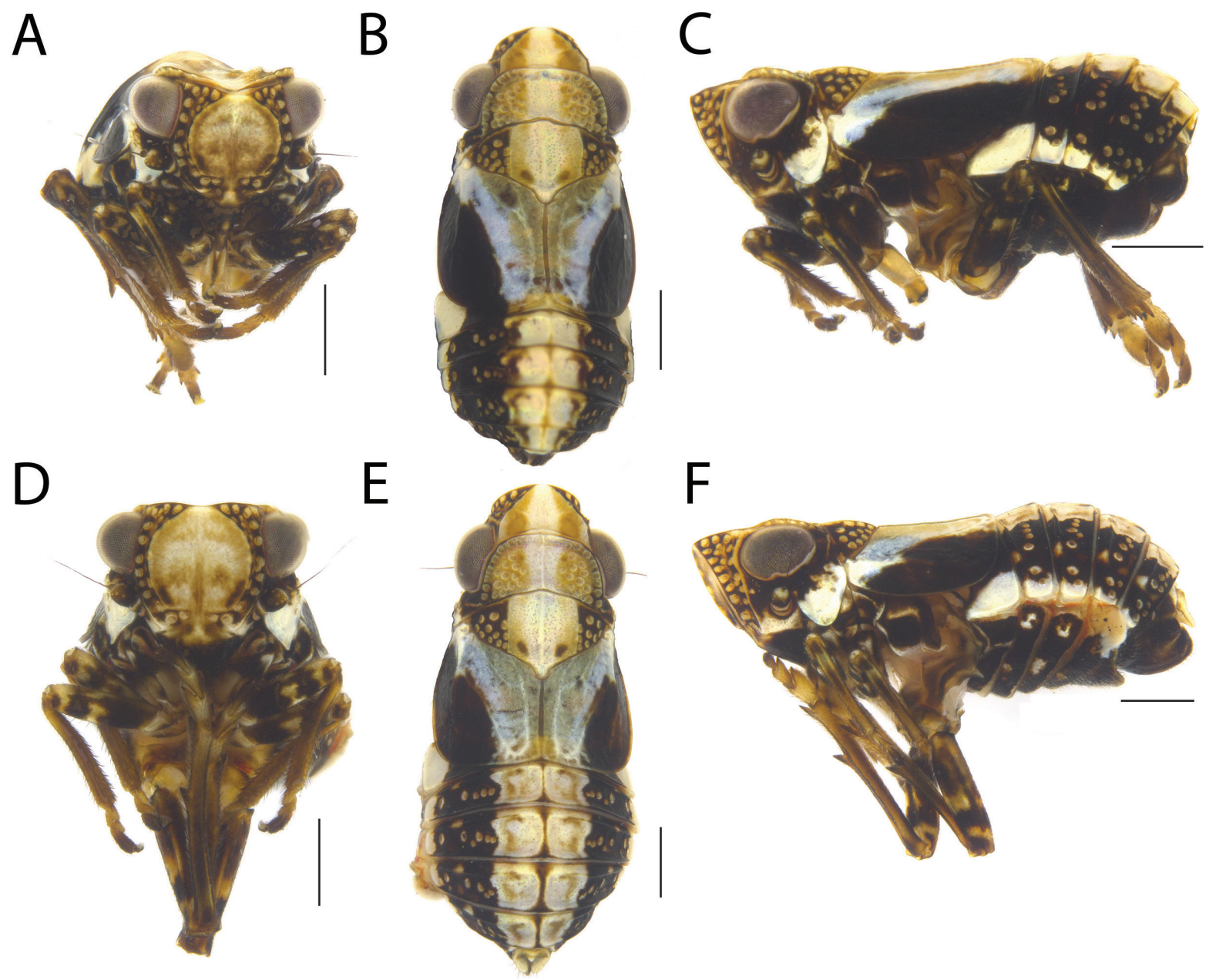

Fig. 21. Habitus of Protrocha nigrilutea sp. nov. A-C. Holotype, § (INHS). A. Frontal view. B. Dorsal view. C. Lateral view. D-F. Paratype, $q$ (INHS). D. Frontal view. E. Dorsal view. F. Lateral view. Scale bars $=0.5 \mathrm{~mm}$. 
just above clypeus, on each side. Clypeus (Fig. 21C, F) not swollen, without carinae. Ocelli absent. Eye oblong. Antenna short, with several small circular structures visible on pedicel. Pronotum (Fig. 21B, E) semicircular, as long as half its width; with median carina; median portion of disc depressed, without sensory pits; lateral portion of disc with 21 to 22 sensory pits on each side; lateral lobe of pronotum (Fig. 21C, F) with four sensory pits arranged in group. Mesonotum (Fig. 21B, E) with median carina and pair of lateral carinae; region between lateral carinae depressed, without sensory pits; region outerad of lateral carina with nine to 11 sensory pits. Brachypterous, with reduced venation. Legs simple, with carinae and setae; tibia III with single median spine.

ABDomEn. Terga with longitudinal carina. Tergite III (Figs 21C, F, 26I) without sensory pits. Tergite IV (Figs 21C, F, 26I) with one row of three to four (four in holotype) sensory pits, with penultimate one displaced, followed by isolated ventral pair aligned diagonally (Figs 21C, F, 26I). Tergite V (Figs 21C, F, 26I) with one row of four to five (five in holotype) sensory pits, with penultimate one displaced, followed by isolated ventral pair aligned diagonally or group of three sensory pits (Figs 21C, F, 26I).
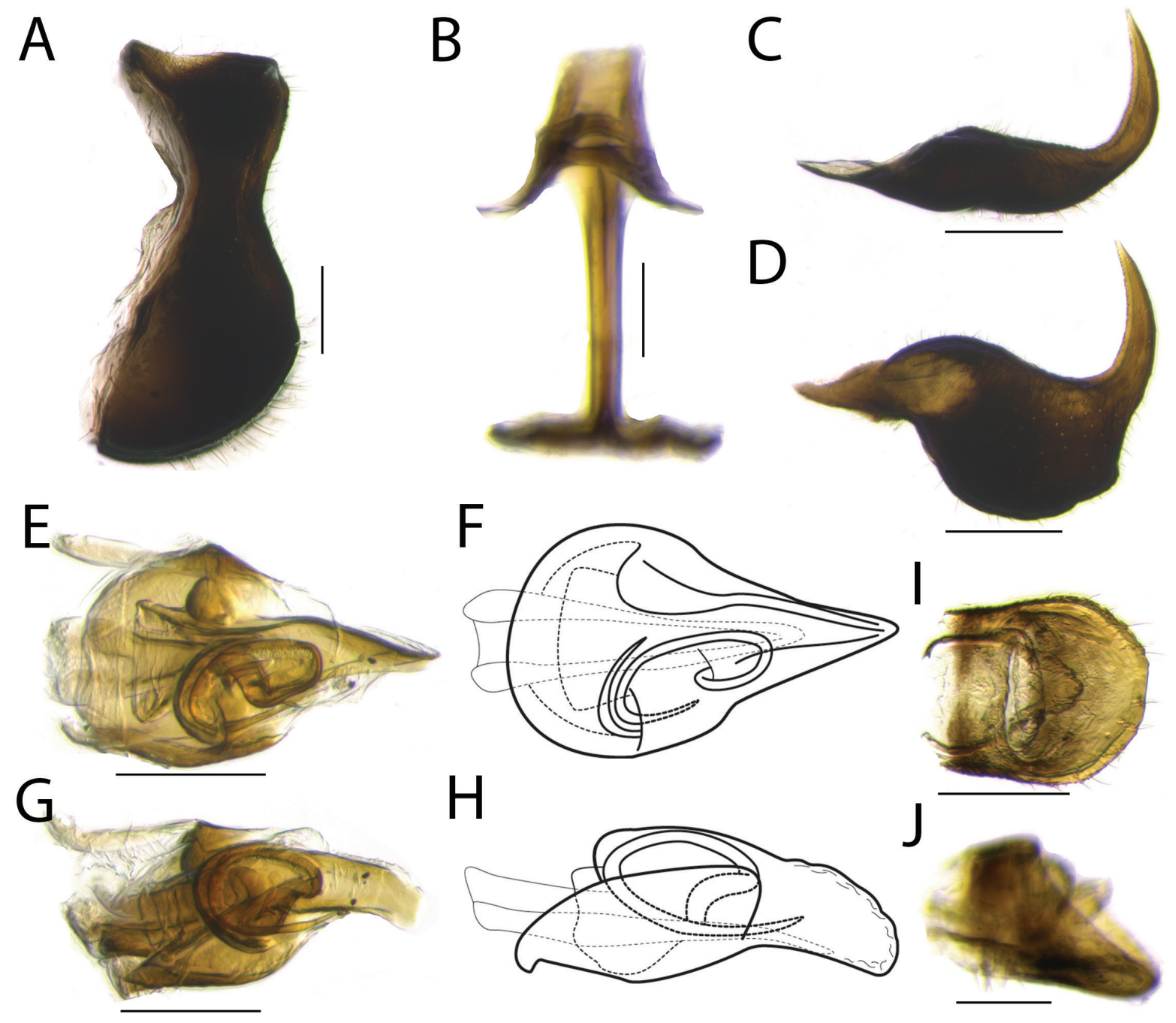

Fig. 22. Male terminalia of Protrocha nigrilutea sp. nov., holotype (INHS). A. Pygofer, lateral view. B. Connective, anterior view. C-D. Style. C. Dorsal view. D. Lateral view. E-H. Phallus. E-F. Dorsal view. G-H. Lateral view. I-J. Anal tube. I. Dorsal view. J. Lateral view. Scale bars $=0.1 \mathrm{~mm}$. 
Tergite VI (Figs 21C, F, 26I) with group of five to six (six in holotype) sensory pits followed by isolated ventral group of three sensory pits. Tergite VII (Figs 21C, F, 26I) with group of five to six (six in holotype) sensory pits followed by isolated ventral group of three to four (four in holotype) sensory pits. Tergite VIII (Figs 21C, F, 26I) with one sensory pit.

Male terminalia. Pygofer (Fig. 22A) wide, with anterior margin deeply concave; posterior margin with concavity at middle third; ventral portion broad; setose. Connective (Fig. 22B) inverted Y-shaped, with support bridge with dorsal flap. Style (Fig. 22C-D) hook-like; anterior portion pointed; caudal portion strongly curved anterodorsally, converging towards the other in dorsal view (Fig. 22C); dorsal margin (Fig. 22D) sinuous; ventral margin (Fig. 22D) with straight angle between anterior and middle third, after that almost rounded, with round projection in middle of middle third; middle portion (Fig. 22D) as long as wide, setose; apex serrated (Fig. 22D). Phallobase (Fig. 22E-H) sclerotized, symmetrical, with middle portion rounded and narrowing to apex in dorsal view, drop-shaped; apex pointed in dorsal view (Fig. 22E-F), irregularly rounded in lateral view (Fig. 22G-H), surrounding aedeagus almost
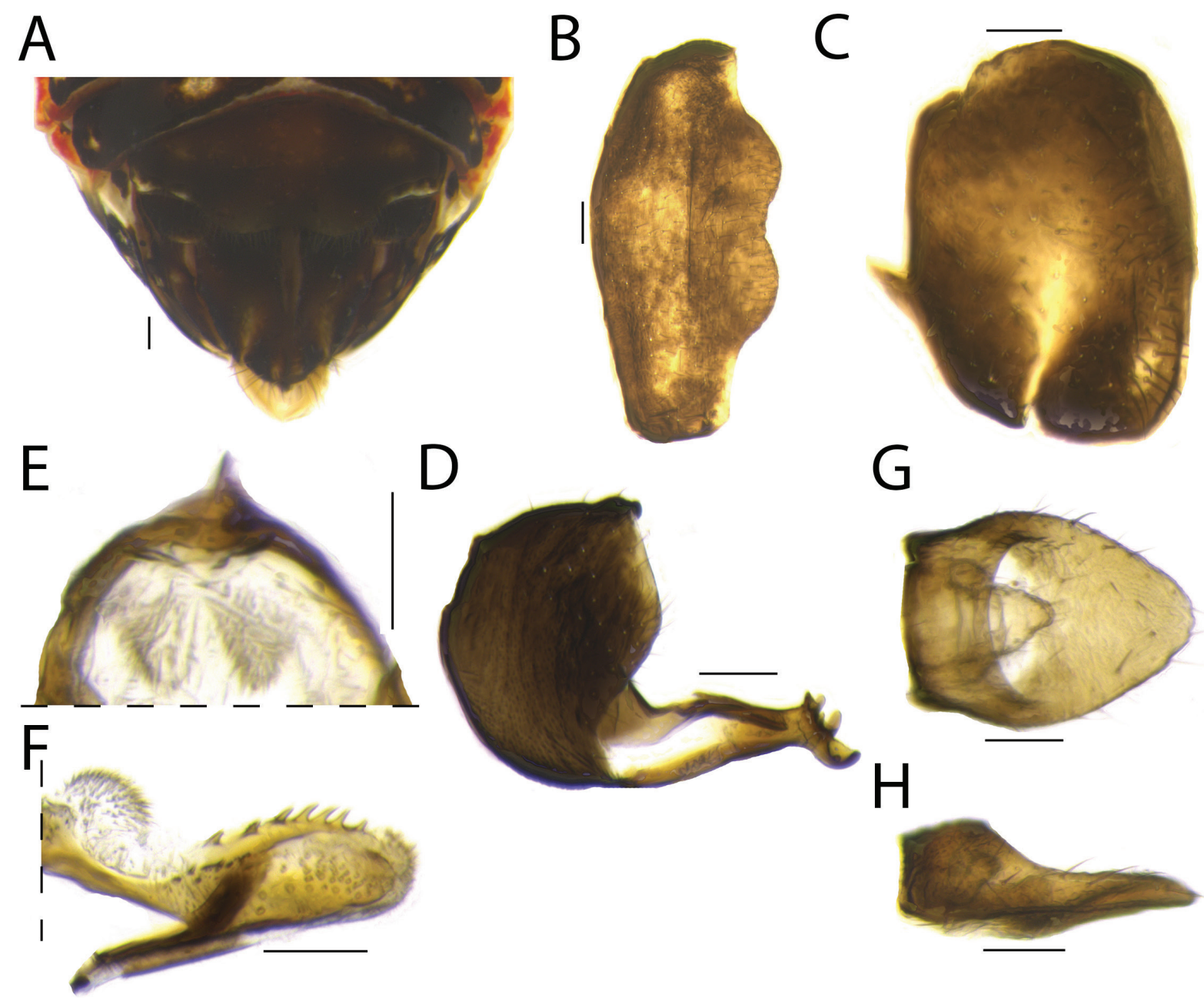
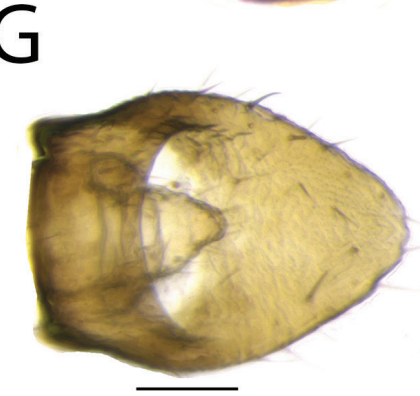

$\mathrm{H}$

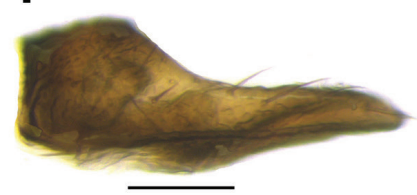

Fig. 23. Female terminalia of Protrocha nigrilutea sp. nov., + , paratype (INHS). A. External female terminalia, ventral view. B. Sternite VII, ventral view. C. Gonoplac, lateral view. D. Anterior connective lamina of gonapophysis VIII, ventral view. E-F. Posterior connective lamina of gonapophysis IX. E. Connective part in dorsal view. F. Distal part in lateral view. G-H. Anal tube. G. Dorsal view. H. Lateral view. Scale bars $=0.1 \mathrm{~mm}$. 
completely. Aedeagus (Fig. 22E-F) with apex narrowing and open dorsally; with pair of hooks on same side of phallus; in dorsal view (Fig. 22E-F), one hook strongly spiraled with apex curved posteriorly, other basally directed anteriorly but curved posteriorly; aedeagal hook spiraled dorsally in lateral view (Fig. 22G-H). Suspensorium V-shaped. Segment X of anal tube (Fig. 22I-J) as long as wide at widest portion; posterior margin (Fig. 22I) rounded; setose.

Female terminalia. Posterior margin of sternite VII (Fig. 23B) with median portion produced and with median concavity; lateral portion slightly concave; setose. Gonoplac (Fig. 23C) sclerotized, subrectangular with apex truncate, setose. Anterior connective lamina of gonapophysis VIII (Fig. 23D) with six apical teeth: three long, rounded and curved teeth, innermost larger than outer ones, with three small, rounded, straight teeth between them and outerad of them. Posterior connective lamina of gonapophysis IX (Fig. 23E-F) distal part in lateral view (Fig. 23F) with longitudinal row of six to eight wide spines; middle portion with several pits (Fig. 23F); apex setose (Fig. 23F); region between distal parts with two patches of small setae (Fig. 23E). Segment X of anal tube (Fig. 23G-H) longer than wide; caudal margin (Fig. 23G) slightly pointed; with setae.

\section{Remarks}

Although this new species has two to three isolated sensory pits on the abdominal tergites IV and V, and three or four sensory pits on tergite VII (Figs 21C, F, 26I) (see Discussion), we chose to allocate this species in Protrocha based on comparisons with photographs of the holotype of P. orbiculata (Ball, 1935) (type species of the genus), with which the new species shares the overall shape of body and distribution of sensory pits on the frons and abdomen (except for the tergites IV and V). The new species was compared to species of Aphelonema described and illustrated in the works of Doering (1941) and Caldwell (1945) and we conclude it is a new species. This species can be distinguished from the type species of the genus, P. orbiculata, by the following combination of characteristics: (1) pronotum shape semicircular in P. orbiculata and sub-rectangular in P. nigrilutea (Fig. 21B, E); (2) sublateral carinae straight ventrally in $P$. nigrilutea (Fig. 21A, D); (3) all abdominal tergites with three isolated sensory pits in $P$. orbiculata but varying from two to three on tergites IV and V and three to four on tergites VI and VII in P. nigrilutea (Fig. 21C, F, 26I).

Protrocha punctatosa sp. nov.

urn:1sid:zoobank.org:act:32899C75-BD40-461E-B89E-094CF2FF8E52

Figs 24-25, 26J

\section{Diagnosis}

Body mainly brown with broad pale-yellow median stripe crossing vertex, pronotum and mesonotum (Fig. 24); frons with median carina (Fig. 24A), sublateral carinae ventrally curved (Fig. 24A), central plate of frons oblong (Fig. 24A), not extending anteriorly beyond sublateral carinae in lateral view (Fig. 24C); sides of frons with two well-defined rows of sensory pits and some sensory pits between rows on each side (Fig. 24C); abdominal tergites (Figs 24C, 26J) with row (tergite IV) or group of sensory pits followed by three to four sensory pits almost aligned vertically (tergites V to VII).

\section{Etymology}

The specific name 'punctatosa' ('punctat-', Latin = 'punctured'; '-osa', Latin = 'full of') refers to several sensory pits covering some structures of the body of this species.

\section{Material examined}

Holotype

MEXICO • ○’; "COAH” [Coahuila de Zaragoza], Cuahtemoc rd., Km 7.4; $25.27970^{\circ}$ N, $100.98747^{\circ}$ W; 2120 m a.s.l.; Oct. 2005; C. Dietrich leg.; vacuum sample; DNA voucher ENT4916; INHS. 


\section{Description}

Body LeNGTH. Male $=2.3 \mathrm{~mm}$.

COLORATION. Body mainly brown with broad pale-yellow median stripe crossing vertex, pronotum and mesonotum (Fig. 24A-C). Clypeus with median longitudinal pale-yellow stripe (Fig. 24B). Sensory pits on body lighter than background color (Fig. 24A-C). Forewings hyaline brown (Fig. 24B-C). Legs (Fig. 24A, C) pale-yellow with brown maculae on femora and longitudinal stripes on tibiae.

Head AND thorax. Vertex (Fig. 24B) hexagonal, as long as half its width, as long as pronotum; posterior margin slightly elevated. Frons (Fig. 24A) with median carina and pair of sublateral carinae; sublateral carinae convergent and almost fused ventrally (Fig. 24A); central plate (Fig. 24A) oblong, as long as wide at widest portion, not visible in dorsal view (Fig. 24B), not extending anteriorly beyond sublateral carinae in lateral view (Fig. 24C); sides of frons partially visible in frontal view, almost fused above clypeus (Fig. 24A) in lateral view, with two well-defined rows of sensory pits and some sensory pits between rows on each side: anterior row with 10 sensory pits, seven dorsal ones grouped, followed by eighth isolated one aligned to antenna and isolated ventral pair, with three to four sensory pits between anterior and posterior row; posterior row with six to seven sensory pits. Clypeus (Fig. 24A, C) not swollen and without carina. Ocelli absent. Eye oblong. Antenna short, with several small circular structures visible on pedicel. Pronotum (Fig. 24B) semicircular, as long as half its width; posterior margin concave; with median carina; median portion of disc depressed, without sensory pits; lateral portion of disc with 20 to 22 sensory pits on each side; lateral lobe of pronotum (Fig. 24C) with four sensory pits arranged in group. Mesonotum (Fig. 24B) with median carina and pair of lateral carinae; region between lateral carinae depressed and without sensory pits; region laterad of lateral carina with 11 sensory pits. Brachypterous, with reduced venation. Legs simple, with carinae and setose; tibia III with single median spine.

AbDomen. Terga with longitudinal carina. Tergite III (Figs 24C, 26J) without sensory pits. Tergite IV (Figs 24C, 26J) with one row of four sensory pits followed by one isolated ventral row of three pits. Tergites V to VI (Figs 24C, 26J) with one anterior row of five sensory pits and posterior single displaced one, followed by isolated ventral row of three pits. Tergite VII (Figs 24C, 26J) with one anterior row of five sensory pits and posterior row of two pits, followed by one isolated ventral group of four pits. Tergite VIII with one sensory pit.
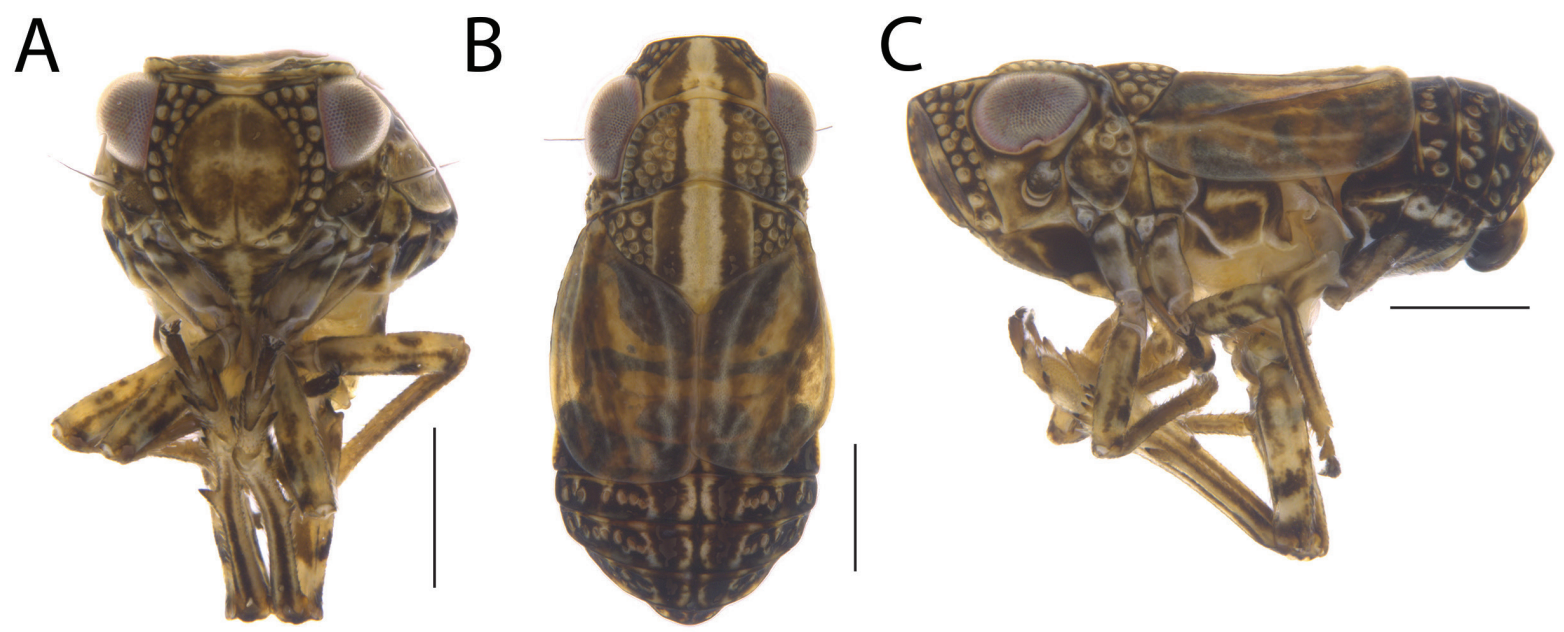

Fig. 24. Habitus of Protrocha punctatosa sp. nov. A-C. Holotype, ô (INHS). A. Frontal view. B. Dorsal view. C. Lateral view. Scale bars $=0.5 \mathrm{~mm}$. 
Male terminalia. Pygofer (Fig. 25A) with anterior margin deeply concave; posterior margin with dorsal third almost straight and with slight concavity at middle third. Connective (Fig. 25B) inverted Y-shaped, with support bridge with dorsal flap. Styles (Fig. 25C-D) hook-like; anterior portion pointed; posterior portion curved anterodorsally, converging towards the other in dorsal view (Fig. 25C); dorsal margin (Fig. 25D) mostly straight before curvature with three small spines near apex; ventral margin (Fig. 25D) with straight angle between anterior and middle third, after that mostly rounded; middle portion longer than high, setose; apex serrated. Phallobase (Fig. 25E-H) sclerotized, asymmetrical, with one side more extended anteriorly and more elevated than other side (Fig. 25E-F); apex rounded in lateral view (Fig. 25G-H), surrounding apical half of aedeagus. Aedeagus (Fig. 25E-F) with apex narrow and open dorsally; with single aedeagal hook curved anteriorly to right side in dorsal view (Fig. 25E-F) and curved anteroventrally in lateral view (Fig. 25G-H). Suspensorium V-shaped. Segment X of anal tube (Fig. 25I and 25J) longer than wide; posterior margin (Fig. 25I) pointed with apex rounded; setose.

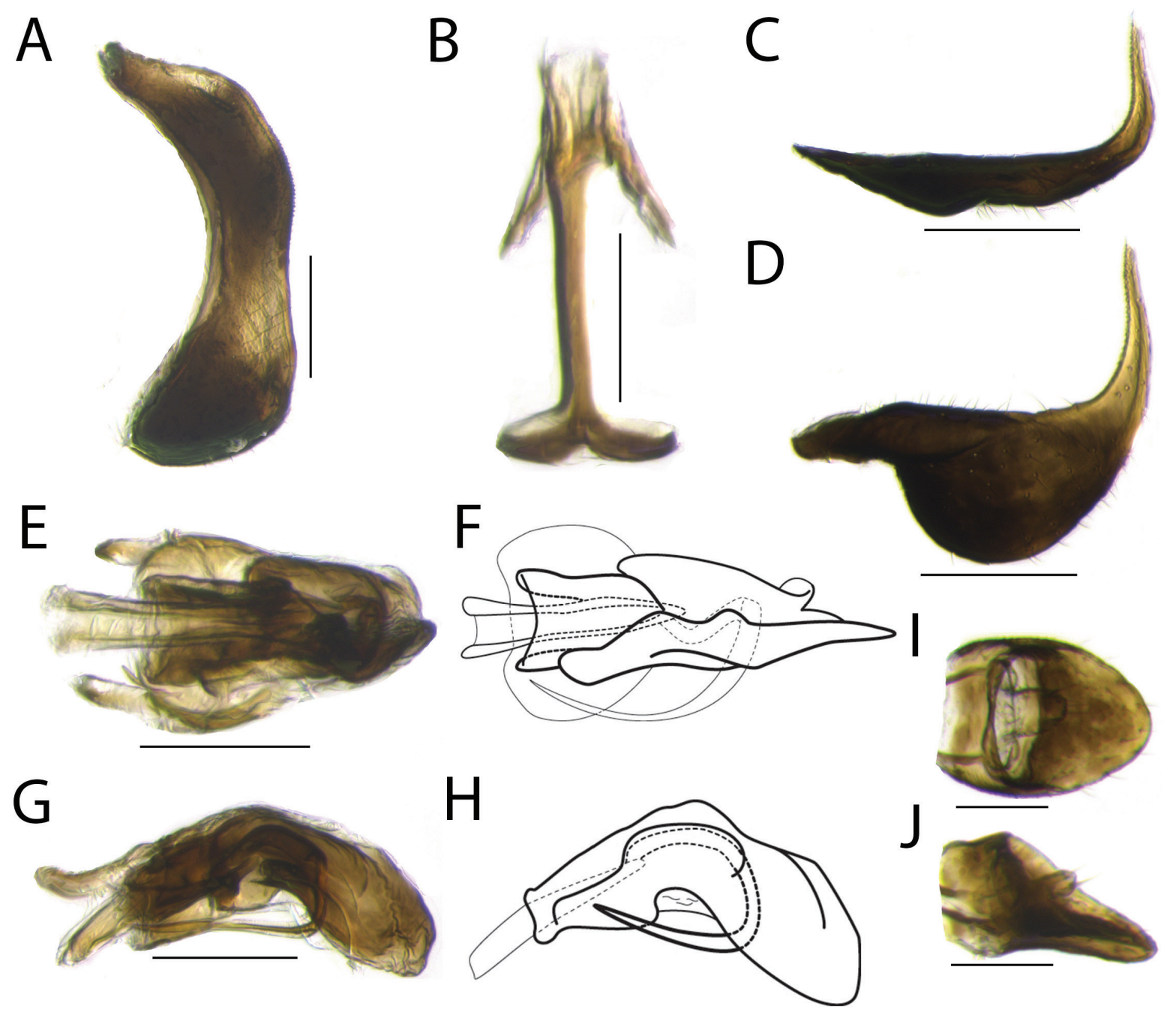

Fig. 25. Male terminalia of Protrocha punctatosa sp. nov., holotype (INHS). A. Pygofer, lateral view. B. Connective, anterior view. C-D. Style. C. Dorsal view. D. Lateral view. E-H. Phallus. E-F. Dorsal view. G-H. Lateral view. I-J. Anal tube. I. Dorsal view. J. Lateral view. Scale bars $=0.1 \mathrm{~mm}$. 
A

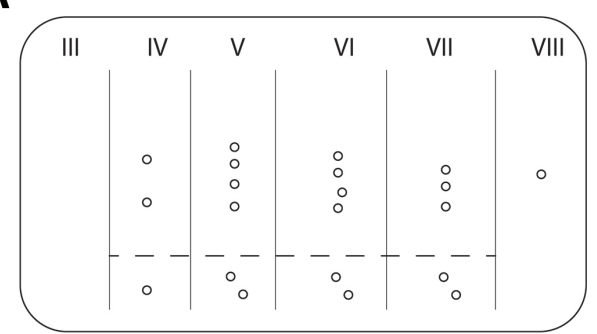

C

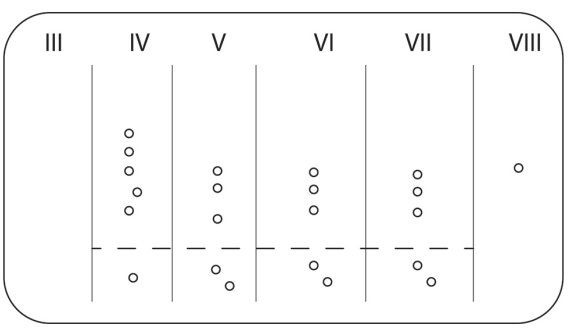

E

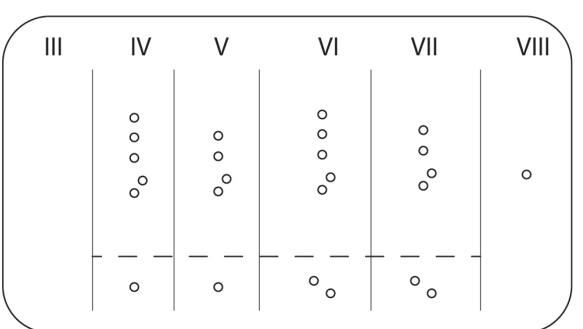

G

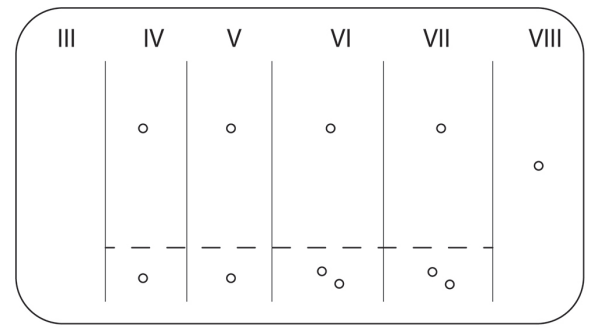

I

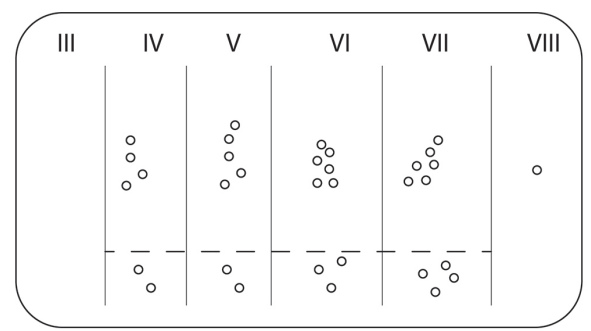

B

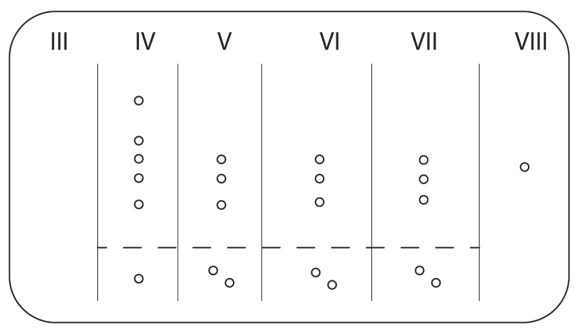

D

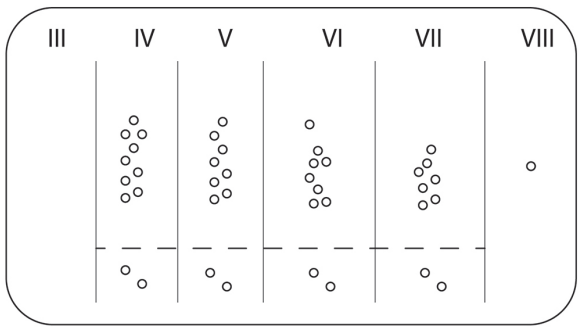

F

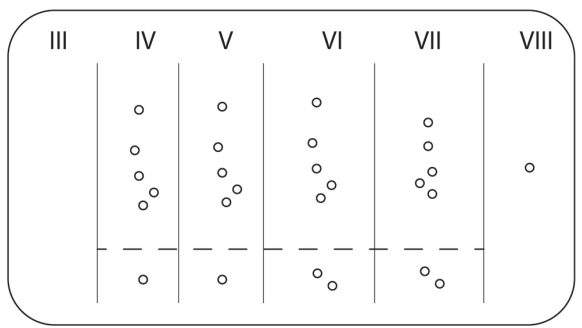

$\mathrm{H}$

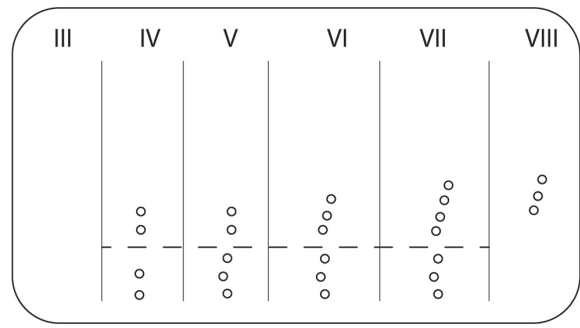

J

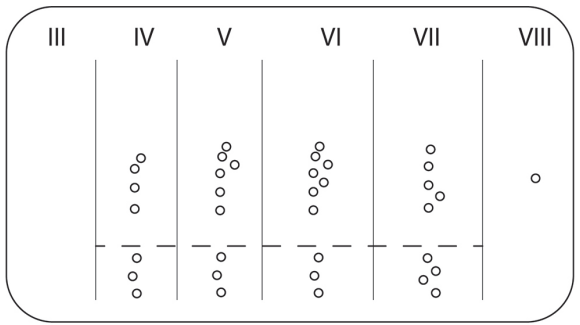

Fig. 26. Scheme of lateral abdominal sensory pit arrangement of Caliscelidae. Roman numerals refers to abdominal tergite number and sensory pits below the dashed line are the isolated ones. A. Aphelonema brevata Caldwell, 1945. B. Bruchomorpha decorata Metcalf, 1923. C. Bruchomorpha mormo Kirkaldy, 1907. D. Bruchomorpha pseudodorsata sp. nov. E. Fitchiella brachyrhina sp. nov. F. Fitchiella zahniseri sp. nov. G. Nenema virgata (Doering, 1941). H. Protrocha nesolitaria (Caldwell, 1945). I. Protrocha nigrilutea sp. nov. J. Protrocha punctatosa sp. nov. 


\section{Remarks}

The new species presents all of the diagnostic characteristics of Protrocha mentioned by Emeljanov (1996; see Discussion) and is therefore placed in this genus. The new species was compared to species of Aphelonema described and illustrated in the works of Doering (1941) and Caldwell (1945) and it can be distinguished from them by the following combination of characteristics: (1) all abdominal tergites (except VIII) with a group of three isolated sensory pits (Figs 24C, 26J); (2) pattern of coloration (Fig. 24A-C); and (3) overall shape of male terminalia (Fig. 25A-J). Additionally, this species was compared to photographs of the holotype of the type species of the genus, Protrocha orbiculata (Ball, 1935), and it is similar in overall body shape and distribution of sensory pits on the frons and abdomen.

\section{Discussion}

Our ongoing studies of the Neotropical fauna of Caliscelidae have revealed several new genera and species (unpublished), mainly in South America, showing that the diversity of this family is very underestimated in the New World. Despite this uncovered diversity, more revisionary studies are also necessary to better delimit the genera of American Peltonotellini, including the study of holotypes of several type species, to describe the pattern of sensory pits, male and female terminalia, and to propose new diagnostic characters for those genera. The characters cited above are important for the taxonomy of tribe and they are not mentioned in original descriptions of most described genera and species of the New World.

Based on the key to subgenera of Aphelonema by Emeljanov (1996) and our study of peltonotelline caliscelids, the distribution pattern of sensory pits on the head, thorax and abdomen seems to be a good character to define some genera. However, although numbers of sensory pits on pronotum and abdomen usually vary within a given genus, their numbers on sides of frons and lateral lobe of pronotum seem to be stable. Nevertheless, some genera seem to have a wider range of variation in these numbers, e.g., Protrocha, where the number of sensory pits on the sides of frons or isolated on abdominal tergites varies between species studied.

The present study highlights that more research is needed to better define some of the genera which were previously treated as subgenera of Aphelonema. However, that does not seem the case in Nenema. According to Emeljanov (1996), Nenema can be distinguished by the following combination of characteristics: (1) the frons with sublateral carinae gently convex laterad and central plate of frons elongate dolioform (= barrel-shaped) (Fig. 16A); (2) the lateral lobe of pronotum with only one sensory pit (Fig. 16C); and (3) the last sensory pit of anterior row of each side of frons not displaced (Fig. 16C). Based on the species studied herein, N. virgata, as well as other personal observations, Nenema seems to be a well-defined genus among those previously treated as subgenera of Aphelonema. On the other hand, according to Emeljanov (1996), Protrocha can be distinguished by the following combination of characteristics: (1) the frons with sublateral carinae almost fused ventrally and each side of frons with three rows of sensory pits (Fig. 21A, D, the latter also shared with Peltonotellus); (2) the lateral lobe of pronotum with no fewer than two, but usually with three or more sensory pits (Fig. 21C, F, also shared with Aphelonema and Peltonotellus); and (3) the abdomen with sensory pits aligned in more than one row or with at least one single displaced sensory pit and three isolated ventral sensory pits (Fig. 21C, F). However, most of these characteristics are shared with one or more other genera, and some species allocated in Protrocha do not have all the above cited diagnostic characteristics, e.g., P. nesolitaria, which shares more similarities with the species of Aphelonema, and one of the new species described herein (P. nigrilutea sp. nov.), which has a variable number of isolated sensory pits on some abdominal tergites. Thus, more studies are necessary to better define the genus Aphelonema and some of those genera previously treated as subgenera of Aphelonema. 
Finally, other genera with difficult taxonomy are Bruchomorpha and Fitchiella which share very similar male terminalia, expecially in the overall shape of styles and phallobase. Some diagnostic characteristics, such as the shape of the clypeus, seem to vary among species within Bruchomorpha. For example, some species of Bruchomorpha, including the type species, B. oculata, and B. extensa Ball, 1935 , have the dorsal portion of the clypeus produced anteriorly into a snout, which is also shared by all species of Fitchiella. Other species of Bruchomorpha, such as B. decorata and B. mormo, have the clypeus swollen, but not produced anteriorly into a snout. Another characteristic that varies considerably within the studied species of Bruchomorpha is the distribution pattern of abdominal sensory pits; some species have a single row of sensory pits while others have a group of sensory pits per tergite, and some species also have a variable number of isolated sensory pits. This kind of variation is uncommon within peltonotellini genera. A diagnostic characteristic for Fitchiella by Lawson (1933) is the flattened foreand middle tibiae. However, the type species, F. robertsoni, does not have expanded legs, although other species, such as F. rufipes, do.

\section{Acknowledgements}

Panama specimens were collected by J. Zahniser (USDA) who was funded by a project coordinated by S. McKamey (USDA). Several photographs of caliscelid holotypes housed at NMNH were provided by J. Zahniser and D. Garcia (USDA). This study was financed by a M.Sc. fellowship to ASF from Coordenação de Aperfeiçoamento de Pessoal de Nível Superior (CAPES, Finance Code 001). DMT is a research productivity fellow from Conselho Nacional de Desenvolvimento Científico e Tecnológico (CNPq, Process 313677/2017-4) and a Cientista do Nosso Estado fellow from Fundação Carlos Chagas Filho de Amparo à Pesquisa do Estado do Rio de Janeiro (FAPERJ Process E-26/202.672/2019).

\section{References}

Ball E.D. 1935. Some new Issidae, with notes on others (Homoptera-Fulgoridae). Bulletin of the Brooklyn Entomological Society 30: 37-41.

Available from https://www.biodiversitylibrary.org/page/50578338 [accessed 3 Oct. 2019].

Bartlett C.R., O'Brien L.B. \& Wilson S.W. 2014. A review of the planthoppers (Hemiptera: Fulgoroidea) of the United States. Memoirs of the American Entomological Society 50: 1-287.

Bourgoin T. 1993. Female genitalia in Hemiptera Fulgoromorpha, morphological and phylogenetic data. Annales de la Société entomologique de France 29: 225-244.

Bourgoin T. 2019. FLOW (Fulgoromorpha Lists on the Web): a world knowledge base dedicated to Fulgoromorpha. Ver. 8, updated. Available from http://hemiptera-databases.org/flow/ [accessed 25 Apr. 2019].

Caldwell J.S. 1945. Notes on Issidae from Mexico. Annals of the Entomological Society of America 38: 89-120. https://doi.org/10.1093/aesa/38.1.89

Doering K.C. 1939. A contribution to the taxonomy of the subfamily Issinae in America north of Mexico (Fulgoridae, Homoptera). The University of Kansas Science Bulletin 26: 83-167. Available from https://www.biodiversitylibrary.org/page/10705393 [accessed 3 Oct. 2019].

Doering K.C. 1941. A contribution to the taxonomy of the subfamily Issinae in America north of Mexico (Fulgoridae, Homoptera). The University of Kansas Science Bulletin 27: 185-233. Available from https://www.biodiversitylibrary.org/page/4393771 [accessed 3 Oct. 2019].

Dozier H.L. 1928. The Fulgoridae or planthoppers of Mississippi, including those of possible occurrence. Technical Bulletin of the Mississippi Agricultural Experiment Station 14: 1-152. Available from https://cpb-us-w2.wpmucdn.com/sites.udel.edu/dist/a/9656/files/2018/09/Dozier-1928a.pdf [accessed 3 Oct. 2019]. 
Emeljanov A.F. 1996. A new genus Chirodisca gen. n. and new subgenera of the genus Aphelonema Uhl. (Homoptera, Fulgoroidea, Issidae). Entomologicheskoe obozrenie 75: 834-835. [English translation published in Entomological Review 76: 993-994.]

Emeljanov A.F. 1999. Notes on delimitation of families of the Issidae group with description of a new species of Caliscelidae belonging to a new genus and tribe (Homoptera, Fulgoroidea). Zoosystematica Rossica 8: 61-72.

Emeljanov A.F. 2013. New genera and species of the tribe Augilini (Homoptera, Caliscelidae). Caucasian Entomological Bulletin 9 (2): 217-221. https://doi.org/10.23885/1814-3326-2013-9-2-217-221 [In Russian.]

Emeljanov A.F. 2015. A subgeneric subdivision of the genus Caliscelis Lap. with description of new species (Homoptera, Caliscelidae). Entomologicheskoe Obozreine 94: 684-697. [English translation published in Entomological Review 95: 918-930.] https://doi.org/10.1134/S001387381507009X

Fennah R.G. 1954. The higher classification of the family Issidae (Homoptera: Fulgoroidea) with descriptions of new species. Transactions of the Royal Entomological Society of London 105: 455-474. https://doi.org/10.1111/j.1365-2311.1954.tb00772.x

Gnezdilov V.M. 2003. Review of the family Issidae (Homoptera, Cicadina) of the European fauna, with notes on the structure of ovipositor in planthoppers. Chteniya pamyati N.A. Kholodkovskogo (Meetings in memory of N.A. Cholodkovsky), St. Petersburg, 56 (1): 1-145. [In Russian with English summary.]

Gnezdilov V.M. 2008a. To the taxonomy of higher Fulgoroidea. Bulletin of Insectology 61: 119-120.

Available from http://www.bulletinofinsectology.org/pdfarticles/vol61-2008-119-120gnezdilov.pdf [accessed 18 Oct. 2019].

Gnezdilov V.M. 2008b. On the taxonomy of the tribe Adenissini Dlabola (Hemiptera: Fulgoromorpha: Caliscelidae: Ommatidiotinae), with the description of a new genus and a new species from Vietnam. Acta entomologica Slovenica 16 (1): 11-18.

Gnezdilov V.M. 2011. New and little known planthoppers of the subfamily Ommatidiotinae (Homoptera, Fulgoroidea, Caliscelidae) from Madagascar and South Asia. Entomologicheskoe obozrenie 90 (2): 329-334. [English translation published in Entomological Review 91 (6): 750-754.] https://doi.org/10.1134/S001387381106008X

Gnezdilov V.M. 2013. A modern classification of the family Caliscelidae Amyot et Serville (Homoptera, Fulgoroidea). Zoologichesky Zhurnal 92: 1309-1311. [English translation published in Entomological Review 94 (2): 211-214.] https://doi.org/10.1134/S0013873814020092

Gnezdilov V.M. 2014. First record of the genus Issopulex (Hemiptera: Fulgoroidea: Caliscelidae) from Madagascar. Zoosystematica Rossica 23: 234-237. https://doi.org/10.31610/zsr/2014.23.2.234

Gnezdilov V.M. 2015a. A new genus and new species of the family Caliscelidae (Hemiptera: Auchenorrhyncha: Fulgoroidea) from Thailand with notes on evolution of the family. Proceedings of the Zoological Institute RAS 319 (1): 120-125.

Gnezdilov V.M. 2015b. Review of the genus Bolbonaso Emeljanov with checklist and key to Indian Caliscelidae (Hemiptera, Fulgoroidea). Journal of Natural History 50 (13-14): 847-863. https://doi.org/10.1080/00222933.2015.1103908

Gnezdilov V.M. 2015c. Madagascan Caliscelidae (Hemiptera, Fulgoroidea): current knowledge and description of a new genus and species. African Invertebrates 56: 739-746.

https://doi.org/10.5733/afin.056.0316 
Gnezdilov V.M. 2017. First record of the genus Raunolina (Hemiptera: Fulgoroidea: Caliscelidae) from tropical Africa with description of two new species from Sudan and Saudi Arabia. Acta Entomologica Musei Nationalis Pragae 57 (1): 11-22. https://doi.org/10.1515/aemnp-2017-0054

Gnezdilov V.M. 2019. A new species of the myrmecomorphic genus Formiscurra (Fulgoroidea: Caliscelidae) from Ethiopia. Acta Entomologica Musei Nationalis Pragae 59 (1): 17-22. https://doi.org/10.2478/aemnp-2019-0002

Gnezdilov V.M. \& Bourgoin T. 2009. First record of the family Caliscelidae (Hemiptera, Fulgoroidea) from Madagascar, with description of new taxa from the Afrotropical Region and biogeographical notes. Zootaxa 2020: 1-36. https://doi.org/10.11646/zootaxa.2020.1.1

Gnezdilov V.M. \& Wilson M.R. 2006. Systematic notes on tribes in the family Caliscelidae (Hemiptera: Fulgoroidea) with the description of new taxa from Palaeartic and Oriental Regions. Zootaxa 1359: $1-30$.

Gnezdilov V.M. \& Wilson M.R. 2011. Order Hemiptera, family Caliscelidae. Arthropod Fauna of the UAE 4: $114-122$.

Kirkaldy G.W. 1907. Leafhoppers. Hemiptera Homoptera. Hawaiian Sugar Planters' Association Experiment Station, Division of Entomology, Bulletin 4: 60-67.

Lawson P.B. 1933. The genus Fitchiella (Homoptera, Fulgoridae). Bulletin of the Brooklyn Entomological Society 28 (5): 194-198.

Available from https://www.biodiversitylibrary.org/page/16173237 [accessed 3 Oct. 2019].

Melichar L. 1906. Monographie der Issiden. Abhandlungen der Kaiserlich-Königlichen ZoologischBotanischen Gesellschaft in Wien 3 (4) 1-327.

Metcalf Z.P. 1923. A key to the Fulgoridae of Eastern North America with descriptions of new species. Journal of the Elisha Mitchell Scientific Society 28 (3-4): 139-208. Available from https://www.biodiversitylibrary.org/page/12208134 [accessed 3 Oct. 2019].

Metcalf Z.P. 1958. General Catalogue of the Homoptera, Fascicle IV, Fulgoroidea, Part 15, Issidae. North Carolina State College, Raleigh.

Available from https://www.biodiversitylibrary.org/page/54648931 [accessed 3 Oct. 2019].

Meng R., Gnezdilov V.M. \& Wang Y. 2015. Two new species of the genus Peltonotellus Puton (Hemiptera: Fulgoromorpha: Caliscelidae) from northwestern China with a world checklist. Zootaxa 4052 (4): 465-477. https://doi.org/10.11646/zootaxa.4052.4.4

O’Brien L.B. 2002. The wild wonderful world of Fulgoromorpha. Denisia 4 (176): 83-102.

O’Brien L.B. \& Wilson S.W. 1985. Planthopper systematics and external morphology. In: Nault L.R. \& Rodriquez J.G. (eds) The Leafhoppers and Planthoppers: 61-102. Wiley-Interscience, New York.

Song N. \& Liang A.P. 2013. A preliminary molecular phylogeny of planthoppers (Hemiptera: Fulgoroidea) based on nuclear and mitochondrial DNA sequences. PLoS ONE 8 (3): 1-11 (e58400).

https://doi.org/10.1371/journal.pone.0058400

Tishechkin D.Y. 1998. Acoustic signals of Issidae (Homoptera, Cicadinea, Fulgoroidea) compared with signals of some other Fulgoroidea with notes on the taxonomic status of the subfamily Caliscelinae. Entomological Review 78 (7): 884-892. [Original published in Russian on Zoologichesky Zhurnal 77 (11): 1257-1265.]

Tishechkin D.Y. 2003. Vibrational communication in Cercopoidea and Fulgoroidea (Homoptera: Cicadina) with notes on classification of higher taxa. Russian Entomological Journal 12 (2): 129-181. Available from http://zmmu.msu.ru/files/images/spec/Russ\%20Ent\%20J/ent12_2\%20127_181\%20 Tishechkin.pdf [accessed 18 Oct. 2019]. 
Urban J.M. \& Cryan J.R. 2007. Evolution of the planthoppers (Insecta: Hemiptera: Fulgoroidea). Molecular Phylogenetics and Evolution 42 (2): 556-572. https://doi.org/10.1016/j.ympev.2006.08.009

Wang M.L., Zhang Y.L. \& Bourgoin T. 2016. Planthopper family Issidae (Insecta: Hemiptera: Fulgoromorpha): linking molecular phylogeny with classification. Molecular Phylogenetics and Evolution 105: 224-234. https://doi.org/10.1016/j.ympev.2016.08.012

Yeh W.B., Yang C.T. \& Hui C.F. 1998. Phylogenetic relationships of the Tropiduchidae-group(Homoptera: Fulgoroidea) of planthoppers inferred through nucleotide sequences. Zoological Studies 37 (1): 45-55. Available from http://zoolstud.sinica.edu.tw/Journals/37.1/45.pdf [accessed 18 Oct. 2019].

Yeh W.B., Yang C.T. \& Hui C.F. 2005. A molecular phylogeny of planthoppers (Hemiptera: Fulgoroidea) inferred from mitochondrial 16S rDNA sequences. Zoological Studies 44 (4): 519-535. Available from http://zoolstud.sinica.edu.tw/Journals/44.4/519.pdf [accessed 18 Oct. 2019].

Manuscript received: 18 October 2019

Manuscript accepted: 27 July 2020

Published on: 25 September 2020

Topic editor: Nesrine Akkari

Desk editor: Radka Rosenbaumová

Printed versions of all papers are also deposited in the libraries of the institutes that are members of the EJT consortium: Muséum national d'histoire naturelle, Paris, France; Meise Botanic Garden, Belgium; Royal Museum for Central Africa, Tervuren, Belgium; Royal Belgian Institute of Natural Sciences, Brussels, Belgium; Natural History Museum of Denmark, Copenhagen, Denmark; Naturalis Biodiversity Center, Leiden, the Netherlands; Museo Nacional de Ciencias Naturales-CSIC, Madrid, Spain; Real Jardín Botánico de Madrid CSIC, Spain; Zoological Research Museum Alexander Koenig, Bonn, Germany; National Museum, Prague, Czech Republic. 